\title{
CHILDHOOD EPIDEMICS AND THE DEMOGRAPHIC LANDSCAPE OF THE ÅLAND ARCHIPELAGO
}

A Dissertation
presented to
the Faculty of the Graduate School
at the University of Missouri-Columbia
In Partial Fulfillment
of the Requirements for the Degree
Doctor of Philosophy
by
ERIN LEE MILLER
Dr. Lisa Sattenspiel, Dissertation Supervisor
MAY 2018


The undersigned, appointed by the dean of the Graduate School,

have examined the dissertation entitled

CHILDHOOD EPIDEMICS AND THE DEMOGRAPHIC

LANDSCAPE OF THE ÅLAND ARCHIPELAGO

presented by Erin Lee Miller,

a candidate for the degree of

Doctor of Philosophy,

and hereby certify that, in their opinion, it is worthy of acceptance.

Professor Lisa Sattenspiel

Professor Todd VanPool

Professor Mary Shenk

Professor Enid Schatz

Associate Dean James Mielke, University of Kansas 


\section{ACKNOWLEDGEMENTS}

This research was made possible by the aid and support of many friends, family, and colleagues over the years.

I would first like to express my deepest appreciation to my committee chair Professor Lisa Sattenspiel. Without her guidance and support over the years, this dissertation would not have been possible. As a mentor, Dr. Sattenspiel has always had an open door and willingness to provide support for whatever path her students chose. I also owe thanks to my Dissertation Committee members, Professor Todd VanPool, Professor Mary Shenk, and Professor Enid Schatz, for their insight, guidance, and time through the research and writing process. The dedication of these professors has enriched my life professionally and inspired me personally.

I owe special thanks to Associate Dean James Mielke (who also served on my Dissertation Committee) for providing archival records from Åland, Finland for the purposes of this research. I am grateful to Dr. Mielke and Dr. Kari Pitkänen (University of Jyväskylä, Finland) for working with me to better understand the archival records and the history of the Åland Islands. Dr. Pitkänen is owed additional thanks for providing translation references and assistance in the early stages of this project. In addition, I would like to thank Associate Professor Corey Sparks (University of Texas at San Antonio) for his instruction in adapting demographic methods for historical populations and encouragement during the dissertation process.

I am also deeply grateful for the family and friends who provided the motivation and support needed to make it through graduate school. I would like to thank my parents; whose love and support are always with me. They provided financial, mental, and moral support through this long, and sometimes difficult, journey. Thank you to my sister, and 
best friend, who is always there for me no matter how far apart we are. To Kate Trusler, my inspiration fairy, who took time out of her days to provide encouragement and laughter with a few simple texts. Finally, to other family, friends, and colleagues who provided advice and support during this process, thank you. 


\section{TABLE OF CONTENTS}

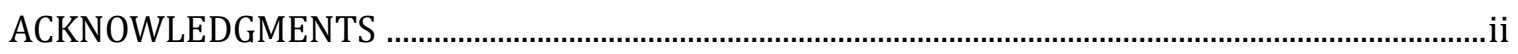

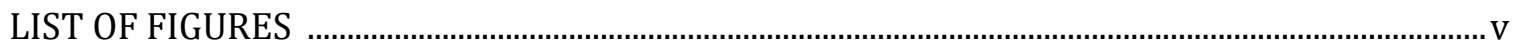

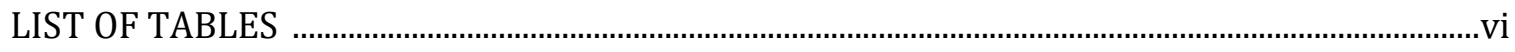

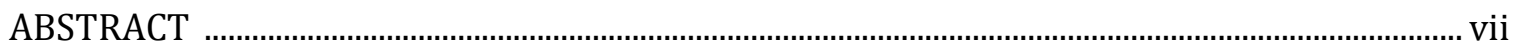

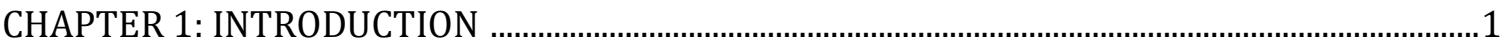

CHAPTER 2: USING AN ANTHROPOLOGICAL FRAMEWORK TO EXPLORE HISTORICAL

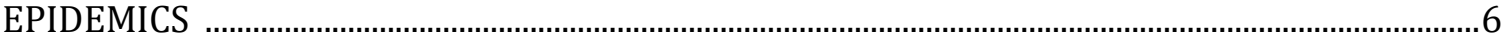

Sociocultural Approaches to Health and Disease .......................................................................

Critical Medical Anthropology and the Social Determinants of Health ............................... 9

Syndemic Theory ................................................................................................................ 11

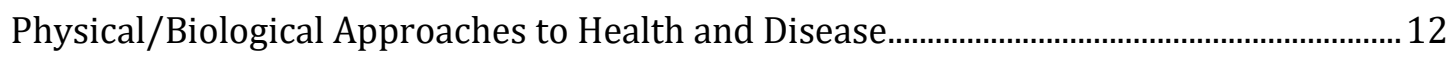

Transition Theory: Perspectives from Demography and Epidemiology ............................ 14

Demographic transition theory .................................................................................. 14

Epidemiological transition theory ………………........................................................ 17

CHAPTER 3: THE ÅLAND ARCHIPELAGO ……................................................................................... 22

Åland Households and Communities: An Overview …………………................................... 26

Pre-20th Century Åland, Finland: Demography, Mortality, and Epidemiology ....................29

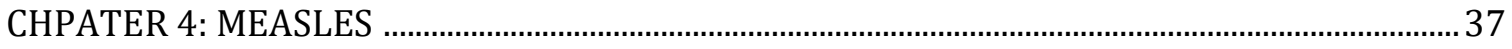

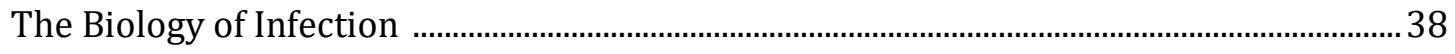

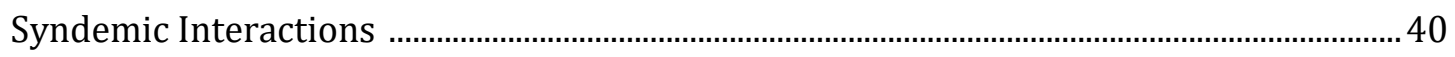

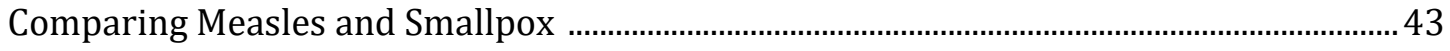

Measles Epidemiology: Quantitative Studies .......................................................................... 46

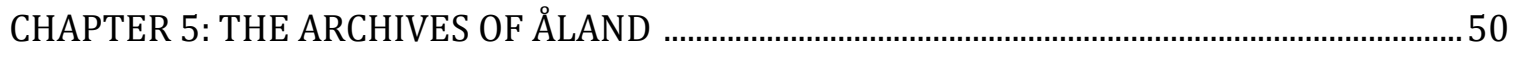

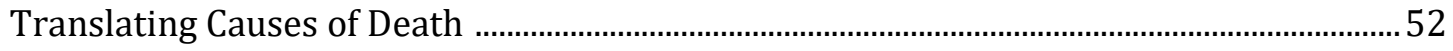

Understanding Archival Data in Demographic Research ........................................................55 
CHAPTER 6: METHODS

Graphic Analyses: Identifying Epidemics and Non-epidemics .58

Age-specific Death Rates: Bridging Gaps in Data .59

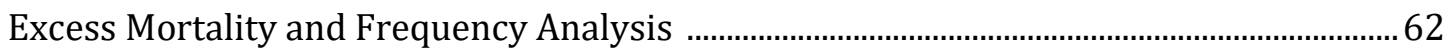

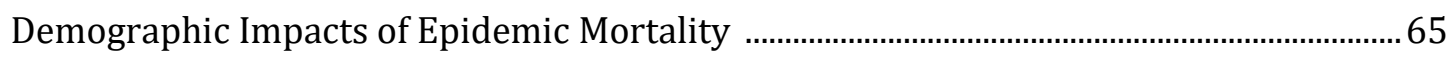

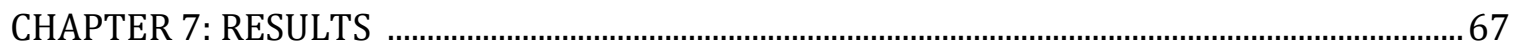

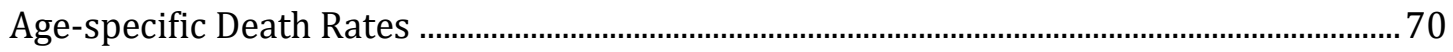

Excess Mortality and Frequency Analysis .......................................................................... 73

Long-term Demographic Consequences of Epidemic Mortality ............................................ 83

CHAPTER 8: DISCUSSION AND CONCLUSIONS ……................................................................. 93

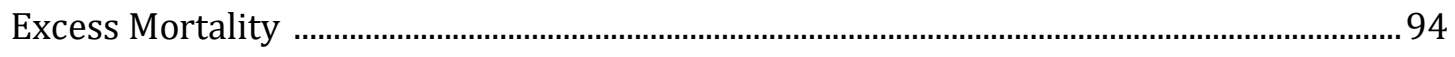

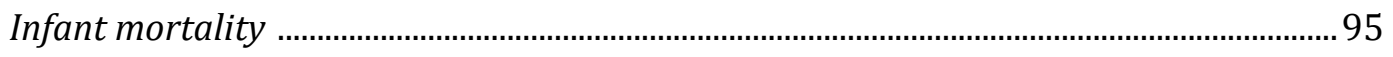

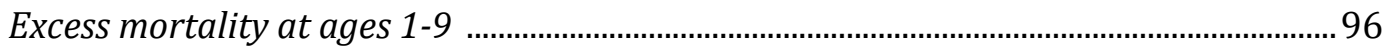

Excess mortality for individuals 50 years and older ..........................................................97

Demographic Impacts of Epidemic Mortality ........................................................................ 99

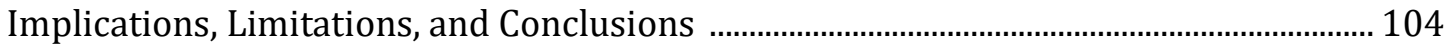

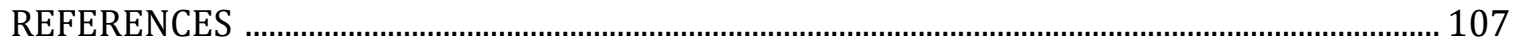

APPENDIX A: Cause of Death (COD) Translations: Some Examples .......................................... 124

APPENDIX B: Age-specific Death Rates by Study Period Only ................................................... 125

APPENDIX C: Infant Mortality Rate Confidence Intervals ......................................................... 128

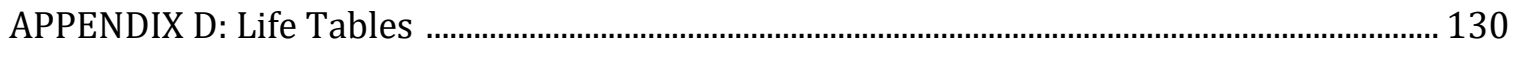

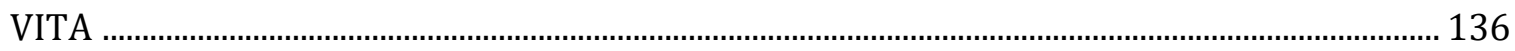




\section{LIST OF FIGURES}

Figure

3.1 Map showing position of Åland, Finland in northern Europe .23

3.2 Map of the Åland Islands parishes .25

4.1 Disease stages: Comparisons of measles and smallpox 45

5.1 Sample of data from the Finström parish death register .51

7.1 Graphic analysis of measles and smallpox deaths in Åland, Finland 1780-1850 .68

7.2 Infant mortality rates for Åland, Sweden, and Finland 70

7.3 Age-specific death rates in Åland, Finland by study period .72

7.4 Proportionate mortality ratio by cause of death category .77

7.5 Population pyramid comparing 1816-17 baseline with measles epidemic .84

7.6 Population pyramid comparing 1816-17 baseline with smallpox epidemic .85

7.7 Expected age at death 1815-1830 .87

7.8 Crude death rates and generalized fertility rates $1815-1830$ .88

7.9 Male excess mortality for selected age groups 90 


\section{LIST OF TABLES}

Table

Page

5.1 Examples of abbreviations in the recorded causes of death for Brändö Parish

5.2 Cause of death categories and descriptions

6.1 5-year age-specific census population estimates from the Åland Islands

6.2 Number of deaths by cause of death category 64

7.1 Excess mortality ratios for the Åland archipelago 74

7.2 Chi-square analysis of categories of death 76

7.3 Sample translations for Other/unknown category 79

7.4 Identifiable causes of death in Other category for ages 1-4 80

7.5 Identifiable causes of death in Other category for ages 5-9 81

7.6 Identifiable causes of death in Other category for individuals aged 50+

7.7 Average life expectancy at selected ages .86

7.8 Excess male mortality by age group and study period 90 


\title{
CHILDHOOD EPIDEMICS AND THE CHANGING DEMOGRAPHIC LANDSCAPE OF THE ÅLAND ARCHIPELAGO
}

Erin Lee Miller

\author{
Dr. Lisa Sattenspiel, Dissertation Supervisor
}

\begin{abstract}
Historically, the introduction of childhood diseases such as measles or smallpox resulted in the infection of nearly every susceptible individual in a community. While smallpox has long been considered the deadlier of the two childhood diseases, research has shown that the immune response to measles infection results in immune suppression that can last for weeks or even months. Higher mortality during measles epidemics has typically been associated with completely susceptible populations; however, in Åland, Finland-a population that experienced regular epidemics of both childhood diseases-mortality from all causes during the 1820-21 measles epidemic was 25\% higher than that experienced during the 1823-24 smallpox epidemic. Excess mortality surrounding measles epidemics suggests that this disease may have larger impacts on the demographic history of populations than previously thought.

This study uses archival records to investigate syndemic interactions between measles and other diseases during a $19^{\text {th }}$ century measles epidemic in the Åland Islands, Finland. Comparisons to smallpox and a non-epidemic period indicated greater than expected mortality for individuals aged 5 to 9 years and over 50 years; though neither epidemic had long-term demographic consequences. These results are consistent with deaths from secondary infections due to measles-induced immune suppression, but not conclusive. The unknown impact of measles exposure on adults with antibodies, and the variety of other diseases and symptom descriptions, indicates that the possibility of cooccurring epidemics cannot be ruled out.
\end{abstract}




\section{CHAPTER 1: INTRODUCTION}

Throughout history, infectious disease has shaped populations and societies and spurred research from multiple fields to uncover the underlying causes and factors that influence the spread of disease within and between populations. While initial studies were more concerned with understanding the biology of infection, each study of health or disease has provided another aspect of the epidemic puzzle, highlighting the complex interactions that contribute to the spread and impact of infectious diseases. Anthropologists and other social scientists have been increasingly called upon to explain social and cultural processes

which contribute to the distribution, spread, or overall impact of a disease-an approach to epidemiology with human behavior as a central theme that stands at the intersection of many disciplines, including, for example, biology, ecology, demography, geography, and politics (Janes et al., 1986).

Infectious disease research from the fields of epidemiology, anthropology and other disciplines, both current and historically situated, informed efforts that led to the eradication of smallpox and the reduction in prevalence and successful management of numerous other infectious diseases, including measles. Prior to vaccination, measles was estimated to cause over 2 million deaths across the globe, primarily in children under 5 years of age (WHO, 2018). Yet, measles vaccination campaigns have not had the same success as was seen with smallpox, due, in part, to social and cultural factors such as religious objections to vaccination or a fear of the vaccine itself.

The global incidence of measles fell by 78\% between 2000 and 2008 (WHO, 2011), but in the first half of 2011, the United States reported the largest number of measles cases in more than a decade; $45 \%$ of these cases occurred in adults aged 20 years or older (CDC, 2011). With the introduction of vaccination, measles has predominantly been a health 
concern for developing countries in Africa and Southeast Asia, but gaps in vaccination have resulted in measles reemerging as a major issue in industrialized nations. In addition, recent measles outbreaks have revealed infection even in individuals who were vaccine compliant. A greater understanding of measles epidemics is becoming increasingly important in the context of reemerging infectious diseases.

Measles is well known through historical records and data from England and Wales, as well as Fiji and other islands in the Pacific (Cliff and Haggett, 1985; Cliff et al., 1993, 2009; Creighton, 1965; Panum, 1939). While measles has largely been considered a major childhood disease with numerous epidemiological studies surrounding it, the perception of measles as a, generally, low mortality disease persists in Western nations and has left a gap in the foundational measles literature that informs current epidemiological studies as well as prevention and management strategies. Historic accounts of measles epidemics, as well as more recent research, suggests that biological interactions between the measles virus and its human host restrict immune responses in the host for a short time, resulting in increased mortality that is not attributed to the epidemic (Aaby et al., 1984b, 1993; Mina et al., 2015; Oldstone, 2010). This understanding of how measles affects the immune system has raised the possibility that excess mortality during measles outbreaks is a syndemic interaction; an interaction between measles infection and other factors in the host or environment which results in an increasingly negative outcome-increased mortality (Singer and Clair, 2003).

The goal of this research is to add new insight into the mortality and demographic impact of a historical measles epidemic, which will contribute to an overall better understanding of the underlying mechanisms that influence the distribution and severity of mortality during a measles epidemic. The research presented here is a quantitative epidemiological and demographic study of a historical measles epidemic that is focused on 
mortality that occurred during a measles epidemic but that was due to diseases other than measles. This study will also show how measles mortality patterns compare to those resulting from smallpox, a similar childhood disease with high mortality, and how high mortality during each epidemic impacted the population of the isolated archipelago of Åland, Finland during the $19^{\text {th }}$ century.

Historical studies can provide greater insight into mechanisms that generate disease distributions or patterns of infection, and they can be used to analyze seasonal or geographic patterns of disease spread. Studies of recent measles epidemics are complicated by partial vaccination and the course of the real-time epidemics proceed at a pace that prohibits in-depth study in real-time. That is, collecting detailed information on affected communities, local lifeways, and cultural traditions and understanding how these elements interact with social structures and environmental conditions can take years. Historical approaches to epidemiology can provide a baseline of information that can be used as a foundation to inform studies of epidemics occurring in real-time or the recent past. Such studies may also consider interactions between diseases or other ecological or cultural interactions (Simonsen et al., 2011). A historical focus allows researchers to access large quantities of multi-faceted data and conduct in-depth investigations on the short- and longterm consequences of an epidemic. An anthropological approach to epidemiology is of great value because it provides understanding of how human behaviors influence disease dynamics by incorporating historical context and social interactions within and between populations for a more comprehensive understanding of complex interactions that influence epidemic trajectories (Herring and Swedlund, 2010).

The research presented here uses archival records to compare two 2-year periods during the early 19 th century in which the islands of Åland, Finland experienced childhood epidemics of measles and smallpox. The Åland archipelago contains small, isolated, 
agricultural societies with limited access to health care, which can serve as a reasonable model for similar societies that are still common today, notably in areas of where measles remains a common childhood disease (e.g. sub-Saharan Africa). In addition, the focus on early $19^{\text {th }}$ century epidemics places this study prior to the second epidemiological transition; the period in which changes in society, technology, and the economy led to the decline of infectious disease as a primary source of death (Omran, 1971; Zuckerman et al., 2014). The selection of a pre-transition and pre-vaccination epidemic provides the opportunity to create a baseline for understanding mortality surrounding a measles epidemic that can be used to evaluate the impact of both cause-specific and overall mortality during a measles epidemic in both historic and current contexts.

This dissertation is organized into eight chapters, including this one, and four appendices. Chapters 2 through 4 contain background and discussions of existing literature relevant to the project. Chapter 2 is an overview of the theoretical framework of the research and includes discussions of how anthropology can combine demography, epidemiology, and syndemic theory to better understand historical epidemics. This chapter will provide an understanding of how the research presented here fits into and contributes to the overall body of existing epidemiological literature. Chapter 3 presents an overview of the communities of Åland and the archival records that make this research possible. The richness of the archival records has provided data for numerous demographic studies which will also be outlined in Chapter 3 to provide a demographic foundation for the population of Åland, Finland. Chapter 4 discusses the current biological and epidemiological understanding of measles, using studies of both current and historical epidemics. This information is presented with comparisons to smallpox to provide a foundation for understanding the implications of the comparisons between measles and smallpox that are the foundation of this research. Chapter 5 discusses the archival materials used in this 
study. This chapter presents the history of the region that led to the creation of these materials in addition to the availability, completeness, and potential drawbacks of using historical records. The cause of death field in the parish burial records is in the original 19th century Swedish, so this chapter also discusses methods of translation and the challenges involved in using historical diagnoses of disease. Chapter 6 is a detailed presentation of the methods used in this research and includes the approaches to data as well as epidemiological and demographic analyses used in this research. The results of these analyses are presented in Chapter 7 with detailed explanations of why certain approaches were taken and how the results of these analyses are situated in the current literature. Chapter 8 is a summary of the major findings of the research presented here and includes a discussion of the broader implications and potential avenues for future research. The appendices contain samples of cause of death translations, age-specific death rates, infant mortality rates and confidence intervals for both Åland and Sweden, as well as abridged life tables pertaining to this study. 


\section{CHAPTER 2: USING AN ANTHROPOLOGICAL FRAMEWORK TO EXPLORE HISTORICAL EPIDEMICS}

Anthropological approaches to the study of infectious disease are uniquely situated in a holistic framework that combines biology, behavior, and ecology and can be adapted to myriad environments, societies, and cultures (McElroy and Townsend, 2015). The term epidemic is widely used, but it does not capture the individual experiences that vary within and between communities and cultures across time and space. As a multi-faceted field, anthropology encompasses varied and overlapping approaches to health and disease in current populations and throughout human history to better understand how the underlying demography, cultural, and social factors of a community or region contribute to health-related processes (Herring and Sattenspiel, 2007; Inhorn and Brown, 1990).

Medical anthropology is an approach to studies of illness, health, and human disease from the broader perspective of anthropology. While the impact of social phenomena was recognized as early as the $19^{\text {th }}$ century (Scotch, 1963), the field of medical anthropology did not emerge until the mid-20 $0^{\text {th }}$ century. Early definitions focused on behavioral responses to illness and disease and largely began with classically trained anthropologists acting as cultural interpreters between medical professionals and traditional societies (Fabrega, 1971; Manderson, 1998). In its infancy, scholars acknowledged contributions to medical anthropology literature from the fields of physical/biological anthropology, but prioritized cultural approaches (Janes et al., 1986; Young, 1982). However, Colson and Selby (1974) suggested that medical anthropology could draw upon all aspects of anthropology and even pull from other disciplines as well. Over time, this relatively young field developed multiple approaches combining anthropological subfields and related disciplines to better understand aspects of human health and disease including illness and healing, social 
institutions, culture, and health inequalities (Inhorn, 2010; Inhorn and Brown, 1990;

McElroy and Townsend, 2015; Wiley and Allen, 2009).

The research presented takes cues from both social and biological approaches to medical anthropology, discussed later in this chapter, to incorporate biological and demographic information within a social, cultural, and historical context to study mortality resulting from epidemics of childhood disease. The specific details of how each aspect of this study fits within the theoretical framework of medical anthropology will be discussed as they appear in subsequent chapters. This chapter will provide a broad overview of the primary theoretical approaches that shape the research presented in this study, and it includes explanations of how this research builds upon, and contributes to, the field of medical anthropology and studies of health and human disease.

\section{Sociocultural Approaches to Health and Disease}

Sociocultural approaches to medical anthropology have largely focused on topics such as local social and cultural determinants of disease, ethnomedical systems of diagnosis and treatment, alternative health systems such as Ayurveda or Chinese medicine, and ethical issues arising from power differentials that increase the risk of poor health (Inhorn and Brown, 1990; Wiley and Allen, 2009). Cultural systems create ways of thinking about health and illness that become embedded in a society. Western medicine, or biomedicine, developed from the $18^{\text {th }}$ century European approach to science with a mechanistic view of disease centered on the individual; an approach which reflects the values of societies in which it was developed (Wiley and Allen, 2009). In other cultures, disease may be understood as the result of an imbalance (e.g. emotional or energy) or related to beliefs about the body in which certain circumstances (e.g. childbirth or the dead) create pollution or contagion (Erickson, 2008). Still other cultures might conceptualize disease as a personal 
attack caused by an outside force such as witchcraft or sorcery or consider a supernatural event triggered by gods, demons, spirits or ghosts (Erickson, 2008). Some localized societies may have distinctive illnesses referred to as culture-bound syndromes, which are aberrant behaviors or clusters of symptoms that only occur in relation to a specific culture and are defined within that culture as an illness (Wiley and Allen, 2009). These examples demonstrate why a cultural understanding of the causes of disease better inform anthropologists regarding the experiences of an individual and the community and how societies informed by these cultural perceptions will impacted by, and react to, major health events such as epidemics.

Early cultural approaches in medical anthropology combined psychiatry and epidemiology in non-Western societies, circumstances in which anthropologists would be viewed as having expertise (Janes et al., 1986). As the field of medical anthropology has developed it has included a wide range of studies ranging from chronic non-infectious diseases such as heart disease or substance abuse to infectious disease epidemiology. In the 1970s, studies turned to the impacts of political, economic, social, and cultural factors which provide the foundation for power differentials and the role of socioeconomic status in shaping health disparities, disease outcomes, and access to medical care (Joralemon, 2010; Wiley and Allen, 2009).

Critical medical anthropology grew out of medical anthropology studies in the 1970s focused on the links between macro-level social and economic processes, social and cultural determinants of disease, and disparities in disease and illness within and between populations. The foundation of critical medical anthropology is the understanding that inequalities in wealth and status may, either purposely or unconsciously, marginalize entire communities or even whole populations subjecting them to increased risk of disease or death (Joralemon, 2010; Wiley and Allen, 2009). This approach emphasizes the importance 
of studies focused on macrolevel institutional forces such as political or economic policies or social stratification by race, economic status, or gender-factors which are institutionally embedded in a society-and how these factors increase the risk of disease or access to health care (Farmer, 1996; Manderson, 1998; Trostle and Sommerfeld, 1996). This avenue of research on social, political, economic determinants of health has resulted in two major cultural approaches to studies of health and disease: social determinants of health and syndemics.

\section{Critical Medical Anthropology and the Social Determinants of Health}

Under the umbrella of critical medical anthropology, studies of the social determinants of health focus on systematic inequalities linked to disparities in health outcomes and rooted in the distribution of social, economic, and political resources (Marmot, 2005; Marmot and Bell, 2016; Raphael, 2006). This approach is based in applied anthropology where the goal is advocacy for long-term measures necessary to influence the distribution of social and economic resources and, consequently, to reduce the risk of disease and death from poor health (Bambra et al., 2010; Marmot, 2005; Marmot and Allen, 2014; Marmot et al., 2008; Raphael, 2006). Several studies have identified key factors in health disparities such as shelter, education, environmental stability and sanitation as well as access to resources such as food, clean water, and health care services (Bambra et al., 2010; Marmot et al., 2008; Marmot, 2003; Raphael, 2006).

In the United States, health disparities are largely viewed as differences in access to care or quality of care for minorities or marginalized groups, with a larger focus on health education and individual health-related behaviors (Marmot and Allen, 2014). This research has illustrated that the focus on individual behaviors can only be understood within the larger social environmental contexts that shape behaviors and choices (Denton and Walters, 
1999; Marmot and Allen, 2014). According to Marmot and Bell (2014), the impact of inequalities in the social or economic aspects of a community or population are evidenced by the magnitude of the health disparities experienced by the people.

Unlike the United States, European nations have a long history of research into institutional mechanisms that create health inequalities and frequently employ this research in the implementation of public health policy (Marmot and Allen, 2014; Raphael, 2006). Out of this research has come a fundamental understanding that underlies much of the current research on social determinants of health: every society, rich or poor, has a gradient of health that lies on a sliding socioeconomic scale (Blane, 1995; Marmot and Allen, 2014; Marmot et al., 2008; Marmot, 2003). Simply put, in any society, individuals of lower social status have lower life expectancy, higher risk of disease, and worse health outcomes compared to those of higher status-a gradient of health based upon an individual's socioeconomic position within that society (see, for example, Blane, 1995; Braveman and Tarimo, 2002; Commission on Social Determinants of Health, 2008; Denton and Walters, 1999; Marmot and Allen, 2014; Marmot et al., 2008; Marmot, 2003).

The research presented here will not explicitly consider social determinants of health, though an understanding of these concepts provided the foundation on which the comparisons of this study were designed. For example, the location of this study is restricted to the archipelago of the Åland Islands, Finland as the social structures and economic factors on mainland Finland may be very different. In addition, the childhood epidemics being compared in this study were chosen for their proximity in time to remove the effects of social or political changes on epidemic mortality. While these communities have some degree of social and economic stratification, there is no evidence of access to medical care or institutions and no advanced education outside of that received by the clergy. An understanding of how social determinants of health in small, historical societies 
can influence epidemic outcomes informed the research design used here so that this study could generate valid comparisons of epidemic mortality.

Syndemic Theory

Syndemic studies are primarily concerned with social conditions and cultural practices that interact with human illness and disease in a specific environment to increase the burden of disease in a population (Singer and Claire 2003). Much like the gradient of health understood through the study of social determinants of health, syndemics applies a similar framework to evaluate the gradient of disease burdens within and between populations in relation to social structures and cultural factors as well as biology and environment. This approach to human health and disease moves away from the identification of diseases as discrete units toward a biocultural approach which focuses on the understanding of disease outcomes and severity in relationship to other factors. The interaction of multiple illnesses or pathogens is the most basic approach to this framework; however, the idea is to move beyond pathogens to understand how other factors such as environment, social stigma, political policies, and poverty combine to produce the context within which health issues are situated (Singer and Clair, 2003). Syndemics specifically refers to how the study of these interactions, directly or indirectly, creates an additive or compounding effect that results in new or worse health outcomes than would be expected with a single, isolated condition (Singer, 2009).

Introduced in the 1990s, the syndemic concept was first presented as a cumulative effect of the social environment (lack of housing and poverty) and social stigma on the relationship between substance abuse, violence, and AIDS (The Lancet, 2017). This research has been expanded upon in further publications demonstrating the interconnected relationship between increased disease burdens of individuals with HIV/AIDS and drug use, 
intimate partner violence, and mental health (see, for example, Halkitis et al., 2012;

Illangasekare et al., 2013; Meyer et al., 2011; Mustanski et al., 2007; Parsons et al., 2012). A special issue of the Annals of Anthropological Practice, published in 2012, included research on topics such as the impact of social and cultural integration and childhood malnutrition, adult obesity, and diabetes in indigenous communities (Everett and Wieland, 2012) and the interaction between tuberculosis and helminths (Littleton et al., 2012). In 2017, The Lancet launched a new series tying syndemics to social determinants of health through the understanding that syndemic approaches to human health research can be instrumental in addressing issues of health inequalities and reducing disease burdens across the globe (The Lancet, 2017).

As an emerging field that emphasizes the use of social context in studies of disease, syndemics provides an ideal framework for determining whether the mortality surrounding measles epidemics is a result of interactions between measles and other cultural or environmental components. Specifically, this study provides an opportunity to look at the impact of co-occurring infections during a measles epidemic and how potential interactions between measles and other health conditions change the dynamics of epidemic mortality. This is an ideal opportunity to combine qualitative social science with archival research and syndemic theory to understand the impact of childhood disease mortality in small, isolated communities with little access to health care, societies which are still common today.

\section{Physical/Biological Approaches to Health and Disease}

In anthropology, physical or biological approaches to health and disease focus on the impacts of evolutionary or ecological factors on disease processes using a biomedical or biocultural framework (Inhorn and Brown, 1990). Biomedicine arose out of the $19^{\text {th }}$ and $20^{\text {th }}$ century "germ" theory of disease, the view of a pathogenic cause of disease, to create a 
new understanding that all illnesses and disease have a unique biological cause mediated by the host-pathogen environment (Wiley and Allen, 2009). It was not until the mid-20th century that studies of human health and disease began to take off in the fields of biological anthropology and archaeology; research which used biomedicine as a foundation to create a new biocultural approach to understanding human health (Zuckerman and Martin, 2017).

Disease-related studies from the combined fields of biological anthropology and archaeology, referred to as bioarchaeology, are largely concerned with understanding the origins of diseases, the prevalence of different types of diseases at specific times and places, and how diseases spread throughout human history. For example, research from this field has played a large role in understanding the origins of syphilis (e.g., Crosby, 1969; Harper et al., 2011; Livingstone, 1991; Powell and Cook, 2005) and the global distribution of tuberculosis (e.g., Arriaza et al., 1995; Donoghue et al., 2004; Klaus et al., 2010; Salo et al., 1994). Other research has considered the history of human behavior and the zoonotic transfer of diseases from animals to humans as well as the coevolution of humans and pathogens (e.g., Sattenspiel, 2015; Van Blerkom, 2003; Wolfe et al., 2005)

Ecological and evolutionary approaches observe how human hosts interact (socially and culturally) with their environment and consider how that interaction affects disease spread and distribution. For example, some studies evaluate how humans interact with water sources and alter water landscapes and the impact of these activities on the prevalence and distribution of schistosomiasis infections (Dalton and Pole, 1978; Farooq and Mallah, 1966; Hibbs et al., 2011; Yi-Xin and Manderson, 2005). However, Zuckerman and Martin (2017) argue that it was Livingstone's foundational work on human environments, insect vectors, and ecological changes over time that laid the groundwork for the development of the biocultural approach. For example, malaria research considered how forest clearing and crop cultivation, among other factors, were pivotal in the 
development of sickle cell trait which reduces the impact of malaria on human populations (Livingstone, 1958; Wiesenfeld, 1967). More recent research builds upon the work above to create a biocultural approach to human health and disease research that combines all aspects of the social and cultural environment with biological and ecological factors, past and present (see, for example, McElroy and Townsend, 2015; Zuckerman and Martin, 2017).

\section{Transition Theory: Perspectives from Demography and Epidemiology}

Transition theory provides a framework for understanding long-term trends in health and demography, and the factors that contribute to those trends. Transition theories describe changes in the characteristics of a population over time-models for understanding how populations change. There are two primary approaches to transition theory: demographic and epidemiological. Demographic transition theory uses observations of demographic trends, primarily fertility and mortality, to create generalizations for understanding population. Epidemiological transition theory provides a similar framework but focuses on the mortality component of the demographic transition by addressing the determinants and consequences of changing patterns in primary causes of morbidity and mortality (Mackenbach, 1994; Zuckerman et al., 2014).

Demographic transition theory is a descriptive model that characterizes demographic transformations, couched largely in terms of overall decreases in fertility and mortality, in a framework meant to forecast demographic changes in population size and age or sex distribution at different points in history (Caldwell, 1976; Kirk, 1996; Teitelbaum, 1975). The earliest formulations of the demographic transition theory were developed to explain trends that occurred with the rise of industrialization, and the corresponding rise in urbanization, occurring in Europe and North America. The overall pattern was of high rates of fertility and mortality (often resulting in a population equilibrium) gradually 
transitioning to historically low rates of mortality and an eventual decline in fertility (Gage, 2005; Teitelbaum, 1975). As this theory has been evaluated and expanded, it has been suggested that the shift to industrialization was not the earliest demographic transition (Armelagos et al., 1996; Bocquet-Appel, 2002; 2011b).

Further studies have supported a pre-historic, Neolithic transition marked by increased population size that accompanied the shift away from hunting and gathering towards an agricultural-based mode of subsistence (Armelagos et al., 1996; Bocquet-Appel, $2002 ; 2011 b)$. Sometimes referred to as the agricultural demographic transition (BocquetAppel, 2011a), this time period was characterized by a marked increase in fertility without evidence of change in mortality (Bocquet-Appel, 2011b; Gage, 2005; Sattenspiel and Harpending, 1983). As agriculture expanded the carrying capacity of populations, the resulting population density may have led to reduced access to clean water, increased contamination of water or food sources, as well greater opportunity for infectious diseases to spread (Bocquet-Appel, 2011b); in short, increased fertility and population growth in the Neolithic may be linked to increased mortality leading up to the historical pre-transition era.

The classical approach marks the start of the first demographic transition as occurring during historical, pre-industrial Europe where the expectation is a population of slow growth or equilibrium in which both mortality and fertility are high and variable (Gage, 2005; Kirk, 1996). The original European and North American model describes preindustrial populations as having little or no population growth and periods of mortality punctuated by episodes of "crisis" mortality caused by epidemics, wars, natural disasters, or other catastrophes (Gage, 2005; Kirk, 1996). In the classical model, the first demographic transition describes the shift from pre-industrial to post-industrial as characterized by declines in the frequency and magnitude of mortality crises leading up to the twentieth 
century. Declines in fertility follow more slowly, but ultimately both mortality and fertility eventually reach historically low levels; a pattern which was observed in Western Europe in the $18^{\text {th }}$ century, expanded to much of Europe and the United States by the nineteenth century, and followed by other developed countries across Europe by the $20^{\text {th }}$ century (Mielke, 2016). The second demographic transition characterizes current trends in Western Europe and the United States in which populations are aging and persistently low fertility and mortality often result in population declines.

Attempts to fit the classical Europe and North American model to regions with distinctly different social and economic circumstances, such as Asia, Africa, or Latin America, exposed a flaw in these generalizations making the applicability of this model to all populations controversial (Teitelbaum, 1975; Watkins, 1987). Initially linked to economic development, i.e. urbanization and industrialization, more recent literature has challenged the idea that the mechanisms of the transition are purely economic (Shenk 2009). For example, in rural parts of France, fertility was observed to decline in concert with, or prior to, mortality (Teitelbaum, 1975). In these regions, the transition occurred before the spread of industrialization and the linkage to cultural and linguistic groupings indicates that economic factors were not the primary drivers of change (Teitelbaum, 1975). Over the course of the 19th century, populations in Bangalore, South India showed fertility declines prior to mortality declines (Shenk, 2009)—declines largely linked to economic changes that led to investments in the education of mothers and children followed by increased access to contraceptives and the cultural transmission of fertility control messaging (Shenk, 2009). This and other similar studies have shown that demographic transitions are complex shifts in behavior related to specific cultural, social, and economic circumstances present in a population or region. Understanding the causes of these shifts requires an in-depth look at these factors and how they have developed over time. 
Demographic transitions are a global phenomenon. Studies in countries outside of Western Europe and North American indicate, however, that different populations (even those in close geographic proximity) experienced different stages of the transitions at different speeds, with different timing (Gage, 2005; Kirk, 1996), and with very different internal and external drivers of change (Clarke and Low, 2001; Shenk, 2009).

Epidemiological transition theory arose out of demographic transition theory as a framework to examine trends in the relationship between the continually changing social and economic landscapes and the disease burden of human populations (Armelagos et al., 2005; Omran, 1971; Zuckerman et al., 2014). Epidemiological transition theory posits that, over time, the primary causes of morbidity and mortality shift from infectious disease to degenerative and man-made diseases (i.e. resulting from environmental threats such as pollution or behaviors such as smoking) in parallel to demographic transitions. Based upon the premise that mortality is a driving factor in population dynamics, Omran (1971) first proposed a model to describe both how causes of disease were changing over time and the consequences of these changes for mortality and population dynamics. In this model, he divided recent human history into three timespans: The Age of Pestilence and Famine, the Age of Receding Pandemics, and the Age of Degenerative and Man-Made Diseases.

Similar to the Paleolithic demographic transition above, it has been argued that the first epidemiological transition actually occurred during the shift to agriculture and that it led to substantial changes in disease ecology (Armelagos, 2013; Armelagos et al., 2005). The Neolithic transition gave rise to populations that were more geographically fixed, which provided increased opportunities and nutritional availability to maximize fertility. This situation led to greater population growth and density (Armelagos et al., 2005; BocquetAppel, 2011b). 
While access to nutrition increased during the Neolithic transition, agricultural subsistence made populations more susceptible to nutritional diseases such as anemia or scurvy, while food storage attracted pests and rodents and the domestication of animals created greater exposure to animals and resulted in increased opportunities for zoonotic pathogens to take hold and spread (e.g. tuberculosis). In addition, population density, without effective approaches to sanitation, led to water source contamination by human and animal waste, increasing the risk and prevalence of waterborne pathogens and persistent parasitic infection (Cockburn, 1971; Mielke, 2016). Infectious diseases became endemic as populations grew to sizes not observed in prehistory and spread through epidemics as trade routes and migration increased contact between new population centers. It has been argued that the rise of civilizations following the Neolithic transition eventually gave rise to the conditions prevalent in the time period Omran referred to as the Age of Pestilence and Famine (discussed above) (Armelagos et al., 2005).

The Age of Pestilence and Famine is characterized by high mortality from frequent crises caused by war, famine, and disease that arose sometime after the shift to agriculture and persisted until the historical pre-industrial period. The Age of Receding Pandemics corresponds to what could be called the $2^{\text {nd }}$ epidemiological transition and is characterized by decreases in mortality from infectious diseases associated with increased public health campaigns and improvements in sanitation that accompanied the Industrial Revolution (Armelagos et al., 2005; Cutler and Miller, 2005; Omran, 1971). During Omran's Age of Degenerative and Man-Made Diseases, the $3^{\text {rd }}$ epidemiological transition, the period of high infectious disease mortality ends, with the Spanish Flu of 1918-19 representing the last major pandemic crisis (Gage, 2005). Further research built upon this foundation to create an expanded framework that includes additional stages and time periods, and which also 
accounts for different patterns based on local cultures and timing of the transitions (Armelagos et al., 1996; Barrett et al., 1998; Harper and Armelagos, 2010).

In this expanded framework, it has been proposed that prehistoric human populations of hunter-gatherers, which encompasses much of human prehistory, can serve as a reference point, often referred to as the Paleolithic Baseline. In the Paleolithic era, human populations were too isolated and spread out to support major infectious disease pathogens from more recent human history (e.g. smallpox, measles, respiratory infections) (Barrett et al., 1998). However, there is evidence of long standing coevolutionary interactions between humans and parasitic infections. Nomadic behavior and migration may have exposed early populations to emerging pathogens as they encountered novel ecologies, parasites, and other pathogens. In addition, infections may have occurred through raw food consumption or other vectors such a ticks, mites, or mosquitos (Barrett et al., 1998; Cockburn, 1971).

As pandemics and crisis mortality recedes, fertility becomes the primary driver of population growth and as mortality reaches a stable low rate, life expectancy continues to rise (Omran, 1971). Studies from England, Wales, Chile, and Japan show that the greatest reductions in mortality were observed in infants, young children, and mothers (Mielke, 2016). Consequently, the age-distribution of mortality transferred toward the older segments of the population, increasing life expectancy, but also providing a larger portion of the population susceptible to chronic and degenerative diseases (Barrett et al., 1998; Mackenbach, 1994). This $2^{\text {nd }}$ epidemiological transition first occurred in Europe and North America in the mid- to late 19th century, and was later followed by Eastern Europe, Japan, and other developing countries where advances in medical technologies played a larger role in mortality reduction (Mackenbach, 1994). 
A further expansion of epidemiological transition theory adds a third transition which considers the changing landscape of disease in today's global populations, a situation in which chronic and degenerative diseases are still prominent but emerging and reemerging infectious diseases are becoming a concern (Harper and Armelagos, 2010; Zuckerman et al., 2014). Reemerging diseases are those that were previously under control but are reoccurring with increased frequency due to antibiotic resistance and gaps in vaccination (e.g. measles) (Barrett, 2017; Barrett et al., 1998). When a new disease emerges (e.g. HIV/AIDS) or a previously known disease begins occurring more frequently or spreading to new geographies (e.g. Ebola) it is referred to as an emerging disease (Barrett, 2017). Diseases have been emerging in human populations and shaping human societies through the course of human history; however, the $3^{\text {rd }}$ epidemiological transition considers how the emergence and reemergence of infectious disease has begun to alter distributions of mortality in the context of increasing globalization and modern social, political, and economic environments (Barrett, 2017).

This study combines insights from both biological and cultural theoretical perspectives of medical anthropology to address research questions related to mortality surrounding a measles epidemic and the impact that mortality has on the communities of Åland, Finland. The theoretical approaches described here are the foundation that informed the design, execution, and interpretation of this study. The research presented here focuses on childhood epidemics of measles and smallpox in an early $19^{\text {th }}$ century population on the archipelago of Åland, Finland. These communities are situated in the first stage of the demographic transition, during The Age of Pestilence and Famine, and prior to the $2^{\text {nd }}$ epidemiological transition. At this time mortality and fertility were both high and punctuated by frequent mortality crises caused by war, famine, and epidemics. 
By using a historical study site, this project creates a baseline that can be used to evaluate the impact of infectious disease following the $2^{\text {nd }}$ epidemiological transition. The epidemic periods under study occurred prior to the $2^{\text {nd }}$ epidemiological transition and the demographic shifts that accompany the industrial revolution. The research design chosen uses epidemics within the same population, close together in time, and prior to transitions that resulted in reduced fertility and mortality to remove confounding factors that could influence the magnitude of mortality during a measles epidemic such that the results will provide a baseline to better understand mortality surrounding measles. Understanding whether a syndemic process is creating excess mortality not attributed to measles during an epidemic may highlight a significant gap in the historical studies of measles epidemics and fundamentally shift the perspective of the impact of measles on a community. The study proposed here hopes to use this theoretical foundation to combine biological, social, and demographic information in a syndemic context in a way that adds new insight into the demography of Åland and the epidemiology of measles. 


\section{CHAPTER 3: THE ÅLAND ARCHIPELAGO}

Located in the Baltic Sea, the islands of Åland (Finnish: Ahvenanmaa) create an archipelago consisting of approximately 6,600 small islands and skerries off the southwest coast of Finland (Figure 3.1) (Mielke, 1980; Mielke et al., 1982). There were fewer islands when the archipelago was first inhabited approximately 5000 years ago, but archaeological evidence supports long-term occupation of the archipelago as sea levels dropped and the number and square mileage of islands continued to increase. In the first few centuries of the Common Era, the population of the Åland islands dwindled and the island communities were abandoned or devastated for unknown reasons; subsequently, the islands were not home to any substantial population for several centuries (Dreijer, 1968).

In a search for better economic opportunities, a wave of colonization in the 6th century landed populations of Scandinavian farmers from Denmark, Norway, and Sweden on the Åland islands. These new communities left behind archaeological and historical evidence of a population that was distinguished culturally and linguistically from the coastal and mainland communities of Finland at the time. The islands were densely populated due to the fact that the demand for animal oil (a primary source of which was seal oil from the Baltic region) made the harbors of the archipelago, which lay along Viking trade routes, an economic hub of the time. Christianity took hold in Åland near the beginning of the $9^{\text {th }}$ century with some of the first stone churches replacing wooden structures as early as the $12^{\text {th }}$ century (Dreijer, 1968).

Åland was part of the Kingdom of Sweden from the 11th century until the end of the War of 1808-09 when the archipelago became a province of the Grand Duchy of Finland (Mead and Jaatinen, 1975). The location of Åland, seated in the Baltic sea between eastern and western Europe, has resulted in the involvement of the archipelago in nearly every war 


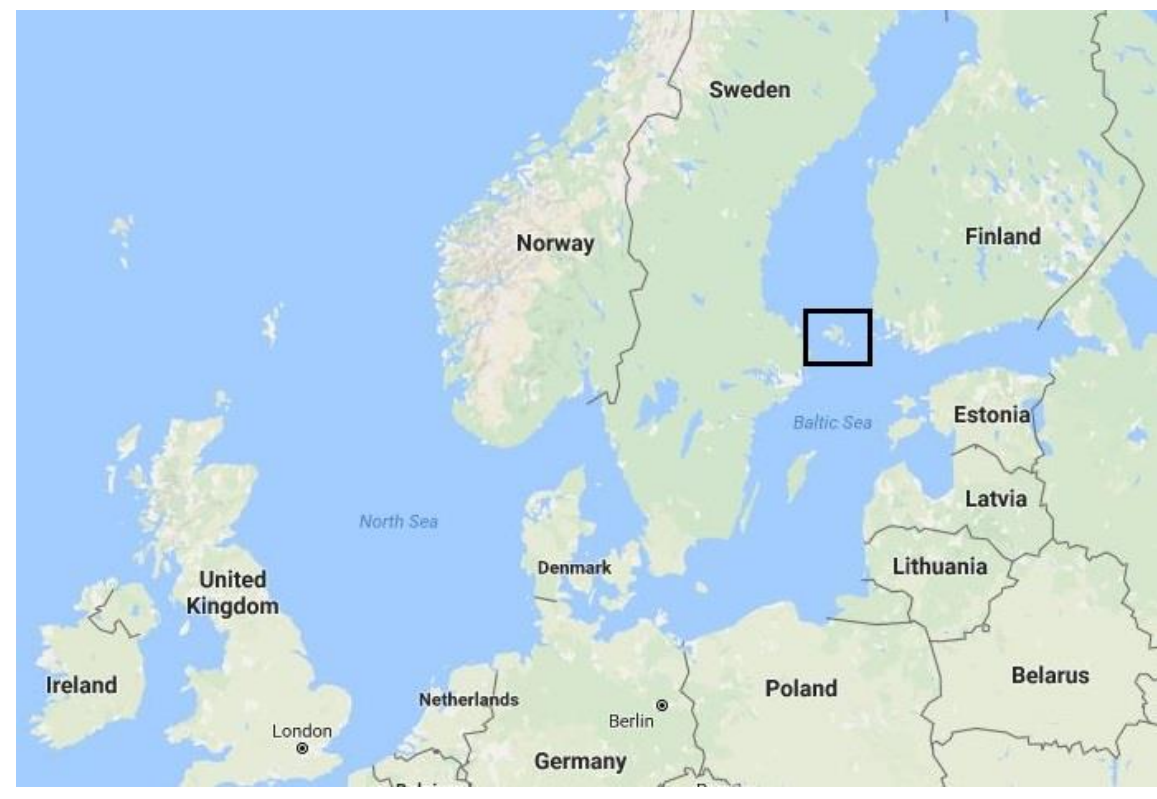

Figure 3.1. The location of Åland in northern Europe. The archipelago is situated in the Baltic Sea between Sweden and Finland. [Google Maps. 2017. View of Northwestern Europe including the Åland Islands].

concerning control of the Baltic Sea beginning in the 1700s. In 1714, during The Great Northern War between Sweden and Russia, Russian troops descended upon Åland, causing Ålanders to flee to Sweden (Mead and Jaatinen, 1975; Mielke et al., 1976). It was not until after the Peace Treaty of Nystad (Uusikaupunki) in 1721 that the people of Åland returned to the islands. As the war ended and the people returned, the population began to grow rapidly (Devor, 1979; Mead and Jaatinen, 1975; Mielke et al., 1976; Sonck, 1979).

The War of Finland (1808-1809), part of the Napoleonic Wars, again resulted in Russian occupation of the archipelago; however, most of the residents remained and there is no evidence of mass displacement (Devor, 1979). During this time, war-related deaths from violence were nearly unheard of in the islands, but more than 1400 Ålanders died as a result of scarce resources and subsequent starvation, infectious diseases, and other diseases of crowded conditions as a consequence of the Russian occupation of the islands (Mielke, 2003; Mielke et al., 1984; Mielke and Pitkänen, 1989). The Treaty of Fredrikshamn ended 
the Russian occupation in 1809 , but barriers to trade with both Sweden and Russia severely hampered the Åland economy (Devor, 1979; Mead and Jaatinen, 1975; Sonck, 1979).

When the War of Finland ended in 1809, Finland separated from Sweden and became an autonomous grand duchy in the Russian Empire (Devor 1979). Finland retained their own laws and continued using parish population registers as the basis of official population vital statistics for administrative purposes (Eriksson, 1980b; Mead and Jaatinen, 1975). As part of this process, the Åland islands were retained as part of the Grand Duchy of Finland and continued to keep their own population registers. However, the islands wouldn't be caught up in another major military campaign until the Åland War (1854-1855) when British and French naval expeditions sought to destroy Russian strongholds and block Russia's access to the Baltic Sea (Mead and Jaatinen, 1975).

Although fighting among European powers for control of the archipelago continued into the 20th century, peace eventually prevailed in the islands and Åland became an autonomous province of Finland in 1920, a status it retains to the present (Mead and Jaatinen, 1975; Mielke et al., 1976). As an autonomous province, the Åland people established their own governing bodies and retained Swedish as the official language of the archipelago (Mead and Jaatinen, 1975; Sonck, 1979). Despite this change, the island parishes continued to serve as administrative districts for the purposes of collecting and reporting vital registration data such as births, marriages, and deaths to the Finnish government.

It should be noted that there is debate over whether Åland was culturally more similar to Sweden or Finland prior to the mid-19th century (Sonck, 1979). In the first half of the $19^{\text {th }}$ century, the archipelago was divided into 15 parish communities of varying size and population density (Figure 3.2) and villages could be close together or on separate islands. The unique settlement history, and the fact that the archipelago's governing body 
eventually chose Swedish as the primary language, suggests a largely Swedish social and cultural influence on the population. Yet, the archipelago's geographic proximity and governmental ties to mainland Finland make it probable that there was some influence of Finnish society and culture in the make-up of the archipelago's communities. This unique combination emphasizes the need to consider the demographic trends of Åland separately from mainland Finland or Sweden, as the communities of Åland may be a social and cultural medley drawing on influences from both, creating an ultimately unique society. Detailed ethnographic information on the Åland Islanders is unavailable at the present time; however, some insights can be gained from other studies of the archipelago and nearby areas.

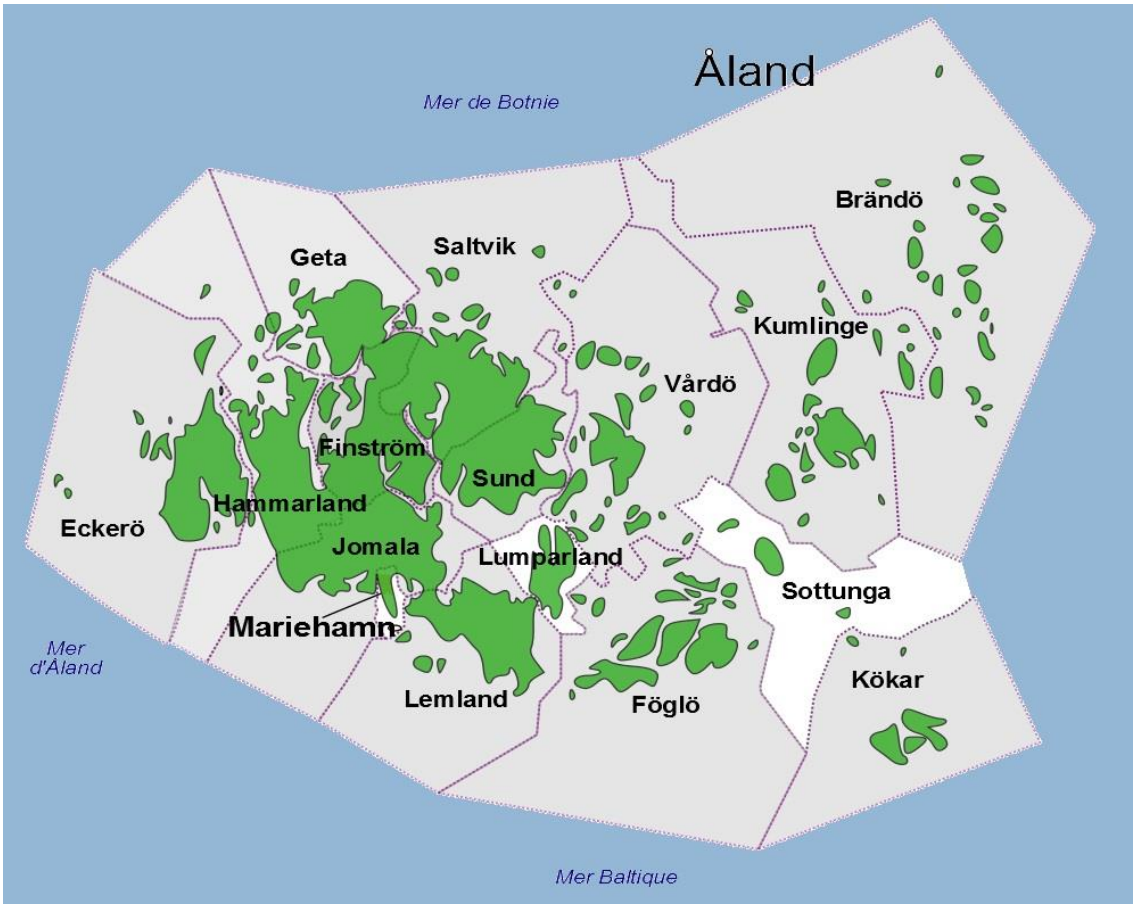

Figure 3.2. Åland, Finland. The islands comprising each parish are delineated by lines. The parishes with a grey shaded background recorded at least one measles death during the 1820-21 epidemic. [Adapted from Google Maps. 2017. Åland Islands, Finland]. 


\section{Åland Households and Communities: An Overview}

Prior to the $19^{\text {th }}$ century, most households were complex, extended-family homes comprised of family members and servants associated with a wealthy land-owning family (Devor, 1979). During this time, Swedish law prevented farmsteads from being divided to sell land in parcels or divide it among successors as an inheritance (Devor, 1979). In 1747, the first crofting law was passed, allowing non-crown lands to be subdivided into tenant farms, or crofts, in which land was rented to a farmer in return for part of the income produced by the crofter (Devor, 1979). Ten years later, this law was expanded to include crown-owned lands, but crofting as a general practice was not immediately adopted (Devor, 1979; Sonck, 1979). This shift to tenant farming began in the less isolated regions and did not move to the more isolated parishes until the late 1800s (Devor, 1979), resulting in greater stratification for some parishes in relation to others and over time (Sonck, 1979).

The new laws allowing crofting, as well as changes in other political and economic policies in the mid- to late $18^{\text {th }}$ century, triggered a change in household size and created multiple social classes by the 1800s (Devor, 1979; Mielke et al., 1982). Lower class individuals went from being members of these larger households to having their own single-family homes, with fewer children on average (and subsequently fewer caretakers) within the home, while upper class families continued to have the larger, extended-family household structures (Devor, 1979). During the first half of the 19th century, the people of Åland lived primarily in agricultural communities, and, with the exception of a few craftsmen, domestic servants, and fishermen, the majority of families made their living as landowners, tenant farmers, or landless farm hands. The average village was composed of local farms, each containing approximately 8 farms, though the number of villages within each parish depended upon the isolation of the parish and the usable land area (Devor, 1979). 
The view of early $19^{\text {th }}$ century Åland as a group of isolated communities has been reinforced through research conducted by various scholars starting in the 1960s and 1970s. The Seventh Sigrid Jusélius Foundation Symposium was held in Mariehamn, the capital of the Åland Islands, in 1978. A symposium volume published in 1980 featured studies focused on the population structure, history, and various genetic studies of the Åland communities (Eriksson, 1980c). The research presented built upon demographic and ethnographic studies and paved the way for further studies which demonstrated, among other things, the close kinship ties, high levels of endogamy, genetic isolation, and limited migration patterns in the Åland archipelago (Eriksson, 1980b; Eriksson et al., 1980; Mielke, 1980; Mielke et al., 1982; Mielke et al., 1987; Mielke et al., 1994; Mielke et al., 1976).

The settlement pattern in the archipelago leaned towards isolated farmsteads, fostering further isolation compared to communities with compact villages (Turpeinen and Kannisto, 1997). Studies of migration have indicated that geographic distance and population size had the greatest effect on migration in the islands with more migration from larger to smaller populations (Mielke et al., 1994). These studies highlighted that the archipelago's regions could be separated into groups defined by three levels of isolation among the communities: the mainland parishes, the peripheral islands, and the outer Islands. Outer parishes were far more isolated compared to the mainland parishes, though this isolation would begin to decrease in the late $19^{\text {th }}$ century with new technologies and methods of travel over time (Mielke, 1982; Mielke et al., 1976).

Marital migration is a demographic measure that evaluates how far individuals travel from their recorded home (birthplace and/or residence) to find a marriage partner. Studies of marital migration indicate high levels of endogamy in Åland's communities from 1750 through the mid-20th century; that is, Ålanders were more likely to marry community members from within their home parish (Mielke et al., 1976). Analyses have shown that 
endogamous marriage, averaged across the archipelago, was between $80 \%$ and $86 \%$ from the mid-18 ${ }^{\text {th }}$ through the $19^{\text {th }}$ century resulting in high estimates of local kinship (Eriksson et al., 1980; Mielke, 1980). Furthermore, it was concluded that outer parishes, which were furthest from the main island, were far more isolated, in terms of migration and marriage distance, than mainland parishes (Mielke et al., 1976). This may also be partly due to the fact that Ålanders needed a special dispensation to marry outside of their parish communities (Mielke et al., 1982, 1976).

In the mid-17th century, the population of Åland's Kökar parish, one of the outermost parishes, was drastically reduced by famine, war, and disease. The population became so small that consanguineous marriages, while frowned upon, were common enough that a rural dean was said to have sent a warning stating it was unwise to marry a close relative (Eriksson, 1980b). While the population recovered within a few decades, eliminating the need for such close marriages, this anecdote highlights how population size influences the ability to locate a "suitable" marriage partner and the level of isolation that must have occurred for Ålanders to bend the rules of local marriage practices.

In the early half of the $19^{\text {th }}$ century, Åland was not only isolated within its parishes, but was isolated from mainland Sweden and Finland as well (Eriksson, 1980a; Mielke, 1980). Mielke and colleagues (1976) concluded that, prior to the 1900s, immigration between mainland Sweden or Finland was rare and had little effect on the composition of Åland's population. This does not imply a complete lack of social or cultural interaction between mainland Sweden or Finland and the archipelago, but rather implies that relocation was not occurring in a way that would impact the demographic make-up of the communities. Though this isolation decreased over time as industry, transportation, and technology began to bridge the gaps between communities in the late 1800 s, the research presented here provides further support that the communities of Åland, and the 
epidemiological and demographic processes operating within these communities, were significantly influenced by the archipelago's history of isolation.

In an article on the history of the Åland people, Eriksson (1980b) stated that the communities of the archipelago exhibited a blending of ethnographic characteristics typical of societies on the boundary between different cultures. Based upon the research discussed here, it is necessary to consider that the ethnographic situation of these boundary communities, combined with the isolation of the $18^{\text {th }}$ and early $19^{\text {th }}$ century could potentially create mortality patterns that are not characteristic of most mainland communities in Finland. Subsequently, grouping Åland with other Finnish communities, as many studies have done, may obscure patterns of mortality which result from unique demographic and cultural aspects of the Åland communities.

\section{Pre-20th Century Åland, Finland: Demography, Mortality, and Epidemiology}

The abundance and quality of archival data in Finland has fostered numerous studies on the mortality of Finnish populations. These studies frequently include data from the Åland archipelago, but rarely consider the archipelago separately in analyses, discussion, and conclusions. Demographic and epidemiological background information for the Åland Islands comes from a limited number of studies. What follows is an overview of the early demographic research available on the population of the Åland archipelago. The remainder of the chapter focuses on situating the archipelago in terms of overall population processes (fertility, mortality, and population size) and detailed discussions of infant mortality and epidemiology research. Insights from larger studies of Finland will be included where they provide additional context for the demographic and epidemiological processes that are occurring in the archipelago. 
According to Turpeinen and Kannisto (1997), the earliest work on Finnish mortality was undertaken by Jutikkala in the 1930s, who used tax registers to estimate earlier populations and produce crude rates of birth and death in the 18th century. ${ }^{1}$ Strömmer (1969) compiled a comprehensive overview of the demographic transition in Finland which began near 1880; roughly the same time as industrialization came to the country (Turpeinen and Kannisto, 1997). This coincided with the second epidemiological transition in other parts of Europe (see Chapter 2), where declining trends in mortality were only interrupted by war and the 1918-19 Spanish Flu pandemic (Turpeinen and Kannisto, 1997)

One of the most comprehensive demographic studies of Finland is comprised of abridged life tables and analyses using vital records spanning from 1750 to 1995 (Kannisto et al., 1999; Turpeinen and Kannisto, 1997). These in-depth studies provide a history of demographic trends in Finland as well as a comparative basis to investigate and observe demographic trends over time; a resource that allows greater understanding of the population trends in Finland and how these trends fit into the overall pattern in Europe. However, these are aggregate analyses of the people of Finland and cannot answer questions regarding differences between regions or parishes within Finland. They also cannot explain why Åland so rarely fits the demographic trends observed for the majority of Finland. For example, The Great Famine (1866-68) is discussed as one of the most significant mortality crises in Finland during the early stages of the second epidemiological transition (Pitkänen, 1993; Pitkänen and Mielke, 1993; Turpeinen and Kannisto, 1997). However, there is no evidence in the historical record that Åland incurred a mortality crisis at this time.

\footnotetext{
${ }^{11}$ At the time of this study, Jutikkala's research from the 1930s was unavailable in English, and a secondary source that discusses this work could not be obtained.
} 
This research is primarily concerned with the demographic processes and composition in the Åland Islands during the first half of the $19^{\text {th }}$ century. At this time, the archipelago was still in the first stage of the demographic transition and experienced high mortality and fertility but overall slow population growth (Mielke et al., 1982; Mielke et al., 1987). During the 19th century, the population of the Åland Islands grew at an average rate of $0.5 \%$, similar to Sweden but much less than the $1.0 \%$ average of Finland (Mielke et al. 1987). While there was a general decline in crude death rates over the course of the $19^{\text {th }}$ century, epidemics and the 1808-09 War of Finland resulted in peaks of very high mortality (between 24 and 26 per 1,000 population) placing the archipelago in the first stage of Omran's (1971) epidemiological transition (Mielke, 2016). Mielke and colleagues (1987) concluded that the population decline, attributed to the crisis mortality of the 1808-09 War of Finland, and slow population recovery was likely due to subsequent declines in birth rates, higher than average mortality, and low infant survival.

Infant mortality has been a great concern to the Finnish people since the mid-18th century when observations of population data collected from parishes indicated high mortality in children under one year of age (Pitkänen, 1983). Still, the loss of children, and infants in particular, was often regarded as inevitable and part of the pattern of life (Moring, 1998; Pitkänen, 1983). Studies of 18th and 19th century mortality in Finland have suggested that the primary factors influencing childhood mortality include the nature of breastfeeding practices (Knodel, 1968; Moring, 1998; Pitkänen, 1983; Trapp et al., 1983; Turpeinen, 2000; Woods, 1997), inadequate sanitation affecting the quality of food and water, which subsequently increased the incidence of diarrheal disease (Mielke and Pitkänen, 1989; Trapp et al., 1983; Woods, 1997; Woods R, 1997), and the prevalence of other infectious diseases (Creighton, 1965; Trapp et al., 1983; Woods R, 1997). A wealth of articles discuss the history of infant mortality of Finland in general (see, for example, 
Moring, 1998; Pitkänen, 1983; Turpeinen, 1979a; Turpeinen, 1979b; 2000; Turpeinen and Pitkänen, 1979; Vuorinen, 1991); however, investigations into the differences and similarities between various deaneries and parishes are far less common.

Studies that have considered regional and other spatial differences suggest that many cultural, social, and environmental factors play a key role in infant mortality and may have resulted in considerable differences between the different administrative segments of Finland (Moring, 1998). While the absence of breastfeeding is often brought up as the key factor in 19th century infant mortality, this most likely does not apply to $19^{\text {th }}$ century Åland mothers as breastfeeding was commonly practiced. It is necessary to look for other factors that play a role in the high infant mortality observed in Åland communities. It has been noted that mothers in the Åland Islands worried their children were not well fed and often supplemented breastmilk with chewed up bits of food and a mixture of milk, water, and flour (called "välling"), a cultural feeding practice which may have contributed to infant mortality through contaminated utensils and greater risk of transmission of illness from caretaker to child (Moring 1998).

Citing cultural aspects such as diet, food preparation, vaccination, environment, and isolation as contributing factors in infant mortality, Moring's (1998) study compares the high mortality of Åland, specifically the parish of Kumlinge, to the nearby parish of Houtskär in the Aboland archipelago of Finland. Comparison of these two parishes identified greater infant mortality, and a slower decline in infant mortality, in the parish of Kumlinge despite more prosperous conditions when compared to the coastal parish of Houtskär. One factor may be the marked winter peaks in infant mortality that likely relate to cold and wet conditions in Kumlinge, in addition to indoor crowding. This peak in infant mortality may be explained by a highly seasonal pattern of births with peaks in March and April and again in 
September and October (Fellman and Eriksson, 2009), which may have increased the number of infants dying during the harsh winter months.

Turpeinen's (1979b) analysis of infant mortality provides a general view of the state of infant mortality in Finland between 1749 and 1865 with a focus on differences between deaneries and urban and rural areas, as well as mortality differences between legitimate and illegitimate infants (though this study was restricted to specific towns and did not include Åland). Maps and statistical tables of infant deaths, live births, and infant mortality rates for a sample of deaneries and towns across Finland depict a general trend of increased infant mortality in urban areas when compared to rural (Turpeinen, 1979b). Yet, Åland, a rural deanery without any major towns or cities at this time, had an infant mortality rate of 254 infant deaths per 1000 live births, higher than that of both the rural (196/1000) and urban (232/1000) parishes (Trapp et al., 1983; Turpeinen, 1979b).

Further comparisons of Åland's infant mortality rates to those of Sweden and Finland suggest living conditions in Åland were much harsher and resulted in much higher infant mortality, but lower childhood mortality, than most parishes in Finland (Mielke et al., 1987; Trapp et al., 1983). Trapp and colleagues (1983) list measles, smallpox, and typhoid as major contributors for post-neonatal infant mortality in the early $19^{\text {th }}$ century. Åland also had one of the highest recorded frequencies of twinning (over 20\%) (Eriksson et al., 1980; Mielke et al., 1976), which may have influenced infant mortality rates (Trapp et al., 1983). Epidemiological studies using archival data have been increasingly employed for the demographic analysis of mortality, and specifically, mortality related to epidemic processes. Islands have long been thought of as optimal field laboratories for understanding natural processes such as disease transmission because of their small community size and relative isolation (Cliff and Haggett, 1984; 1985). Yet, despite the isolation of the Åland archipelago, large quantities of high quality data, and numerous studies on the mortality of the Finnish 
people (see, for example, Doblhammer et al., 2013; Kannisto et al., 1999; Pitkänen, 1983;

1993; Pitkänen and Mielke, 1993; Strömmer, 1969; Turpeinen, 1973; 1978; 1979a; b; 2000; Turpeinen and Kannisto, 1997; Valkonen et al., 2008; etc...), epidemiological studies of 19th century Åland have been few.

One study by Huldén and colleagues (2005) investigated the role of climate on endemic malaria in Finland. Other studies have linked the effects of biological stress and social behavior during mortality crises (for example, the Great Famine or the War of 180809) to changes in patterns of mortality and disease spread (Mielke and Pitkänen, 1989; Pitkänen, 1993; Pitkänen and Mielke, 1993). In addition, Turpeinen and Kannisto’s (1997) study using abridged life tables also discusses mortality crises and provides timelines for key epidemics, while Turpeinen's (1973) study linked differences in regional mortality rates to outbreaks of infectious disease.

Torres and Núñez (2005) provide an overview of the temporal and spatial distribution of smallpox, malaria, and acute gastroenteritis over 100 years (1751-1850). This study was published as part of a larger mortality study which included a more detailed analysis comparing the two Finnish parishes of Rovaniemi (Lapland) and Saltvik (Åland) (Núñez and Garcia-Guixé, 2011). While the 2011 article provides a comparative analysis between the two parishes for diseases such as influenza, pneumonia, tuberculosis, and others, it is important to remember that the identification of many of these diseases, particularly influenza and pneumonia, is unreliable during this period of time (Pitkänen, personal communication). In addition, the English language version of this Spanish publication appears to be flawed, especially with respect to numeric values. Given these two primary concerns, at the present time this study, while potentially providing substantial contributions to the epidemic literature of Åland, specifically, and Finland in general, cannot 
be used as a foundational or comparative resource for the research reported in this dissertation.

The most detailed epidemiological studies using the Åland archives have focused on smallpox-one of the most visible diseases in the archipelago, in terms of mortality. Of primary importance is the foundational work of Mielke and colleagues (1984) on the frequency and magnitude of smallpox epidemics in Åland (discussed in Chapter 5), and indepth studies on the impact of smallpox vaccination in Finland (Pitkänen et al., 1989). Similar to Turpeinen and Kannisto's (1997) timeline of mortality crises, including epidemics, for Finland, Mielke and colleagues provide a timeline of identifiable epidemics from 1751-1890 for Åland, specifically and a detailed look at mortality surrounding smallpox epidemics in the region.

Mielke et al. (1984) concluded that widespread vaccination decreased the magnitude and frequency of smallpox epidemics in Åland caused by endemic smallpox in nearby mainland countries. While the influences of medical interventions are often debated in relation to the decline of infectious diseases at various times and in different places, this analysis clearly illustrates the effect of vaccination, particularly compulsory vaccination, in eliminating a major source of mortality. Vaccination had a clear effect on the size of the susceptible population, and thus the cycles of epidemics that moved through the populations (Mielke et al., 1984; Pitkänen et al., 1989). The periodicity of smallpox in the archipelago shifted from 7 years to 8 years after the introduction of the vaccine (Mielke et al., 1984). Studies show that vaccination clearly reduced the number of smallpox deaths; however, refusal to vaccinate and the short-term protection of early vaccinations (in which the protection waned in adulthood) resulted in a late $19^{\text {th }}$ century smallpox epidemic and prompted re-vaccination strategies mid-century (Mielke et al., 1984). The unexpected effect 
of reducing smallpox mortality, however, was a larger pool of Ålanders susceptible to other diseases.

19th century Åland, Finland is a unique set of communities isolated geographically on a cultural borderland between Sweden and Finland. Communities were stratified socially between land owning farmers and the crofters, craftsman, and fisherman who lived in the island villages. The archipelago experienced high mortality resulting from wars and epidemics, the most historically visible being smallpox. The introduction of smallpox vaccination, and subsequent reduction in smallpox deaths, provided an opportunity for other epidemics to take hold in the archipelago, including the 1820-21 measles epidemic. The next chapter provides a detailed discussion of the biology of measles in comparison to smallpox and the factors known to influence disease transmission and mortality. These two chapters together provide the biological and ecological, as well as the social and cultural, frameworks in which the epidemics in question are situated during this study. 


\section{CHAPTER 4: MEASLES}

Measles is a highly infectious human virus that, until the introduction of vaccination in the 1960s, infected nearly every individual in a population through cyclical epidemics. Prior to vaccination, it is estimated that $70-78 \%$ of children became infected by age 15 and that over $90 \%$ of a population became infected by the age of 20 (Benjamin and Gore, 1952; Heymann, 2008). This high rate of infection ensured that measles remained a disease of childhood, sweeping through communities and infecting nearly every susceptible individual.

The time between measles epidemics is known to be heavily dependent upon the timing of the reintroduction of disease, population size, and geographic isolation (Bartlett, 1957, 1960; Cliff et al., 1993). Larger, more densely populated areas experienced epidemics approximately every three years (Bartlett, 1957, 1960; Cliff et al., 1993). More isolated populations, such as the Faroe Islands communities, often saw gaps of more than 60 years between epidemics (Panum, 1939). Few populations, however isolated, remained unexposed for long and the wider the gap between epidemics, the greater the potential magnitude of the epidemic became. The mechanisms that drive differential effects of population size on the epidemic experience of a community are discussed later in the chapter.

Despite repeated epidemics and high rates of infection, measles mortality attributed to measles infection is generally low (around 3\%) and measles epidemics do not evoke the same fear when compared to a high mortality disease such as smallpox. Various studies (discussed below) support the hypothesis that measles infection may have a negative impact on the immune system's response to other infections. As a result of impaired immune function, it is hypothesized that measles epidemics may be accompanied by hidden 
mortality-mortality that occurs during a measles epidemic but is not attributed to measles infection.

This chapter provides a detailed background on the large body of literature addressing various aspects of measles infections and epidemics. Still, a large portion of these studies, many of which make up the foundational framework for understanding measles epidemics, consider only measles cases or measles-specific mortality and do not examine whether any other diseases are impacted by the presence of a measles epidemic. This research proposes to evaluate the potential for unexpected mortality separate from that caused directly by measles infection and addresses the potential for demographic impacts similar to that observed during crisis periods of high mortality.

To assess the impact of measles mortality on Åland communities, it is necessary, for comparison, to have both a baseline (a period of non-epidemics) and mortality data from another disease that caused epidemics in the same population. Smallpox (Variola major), was known to be present in the archipelago as repeated epidemics were recorded in mortality records both prior to and following the 1820-21 measles epidemic. As another historical disease of childhood, and one with visibly high mortality, smallpox epidemics provide an ideal comparison for the evaluation of mortality during measles epidemics. While this chapter focuses on measles, relevant comparisons to smallpox are made as needed to provide insight into the potential similarities and differences that should be expected during the course of an epidemic.

\section{The Biology of Infection}

Measles, or rubeola, virus is a member of the Paramyxoviridae family in the genus Morbillivirus (Heymann, 2008). There are no other known reservoirs for measles, so transmission of the virus occurs through direct contact among humans (Cliff et al., 1993; 
Heymann, 2008). The virus is spread through respiratory droplets and infection has four major symptomatic stages: exposure, incubation, prodrome, and the characteristic rash (Oldstone, 2010; Racaniello, 2011). After exposure, the incubation period, the period between infection and the first symptoms, can last up to 12 days (Oldstone, 2010) though some sources indicate much more variation with lengths as long as 18 days (Cliff and Haggett, 1985; Cliff et al., 1993; Heymann, 2008). A short period of non-specific symptoms, a prodromal stage, follows and includes generic symptoms such as fever and cough.

The characteristic measles rash appears 3 to 4 days after the onset of symptoms and can last for up to seven days, after which the individual recovers (Cliff et al., 1993; Heymann, 2008; Lloyd and Sattenspiel, 2009). The period of infectiousness begins just before the onset of the prodromal stage and lasts for approximately 4 days after the rash appears, but infectivity sharply decreases after the first day or two (Heymann, 2008; Oldstone, 2010). Consequently, transmission of the measles virus can occur while the infected individual is asymptomatic and unaware of any illness. While infection results in long-lasting immunity to future infection (Heymann, 2008; Oldstone, 2010), the time from initial infection to recovery can span nearly a month in the most drawn-out cases.

Case-fatality rates, a measure of the proportion of cases that result in death from a specific disease, can be as low as 3\%, though rates as high as $30 \%$ have been recorded in some regions, with more severe infections occurring in infants, malnourished children, and adults (Heymann, 2008). Historically, higher rates of mortality have been associated with virgin soil populations (Crosby, 1976; Jones, 2003) and in geographically isolated communities experiencing large gaps between epidemics, as seen in the Faroe Islands (Panum, 1939) and Fiji (Cliff and Haggett, 1985). In these situations, large segments of the population spanning most age groups are susceptible to measles infection. 
Higher case fatality rates have been linked to social and economic disruptions such as inadequate care for sick and vulnerable members of the population as well as poor access to food caused by widespread illness (Cliff and Haggett, 1985; Cliff et al., 2000; Crosby, 1976; Sattenspiel and Herring, 1998; Shanks et al., 2014). For example, Cliff and Haggett's 1985 study of the spatial diffusion of an 1875 measles epidemic in Fiji is thought to have caused the loss of $20 \%$ of the population. The authors cite the breakdown in food subsistence activities, hygiene, and general care as contributing to high levels of mortality. However, Panum (1939) attributed high mortality in the 1846 Faroe Islands epidemics to cultural dietary choices and living conditions, citing no breakdown of social or economic functions in the communities.

These and other studies indicate that measles may interact with other social and cultural factors to create mortality. Still, it has become clear in recent years that measles infection has an effect on mortality that exceeds the number of deaths attributed solely to the measles virus itself (Aaby and Garly et al., 2003b; Aaby and Samb et al., 1996; Oldstone, 2010; Preston and Haines, 1991). In addition to understanding how the cultural and social conditions interact to influence disease transmission, it is necessary to take into account how the biology of measles interacts with the host and the host's environment in order to create greater mortality surrounding measles epidemics.

\section{Syndemic Interactions}

According to Oldstone (2010), measles virus was the first infectious disease known to interfere with the immune response to infection. The immune system comprises organs, tissues, and specialized cells that work together to identify, disable, destroy, "remember", and prevent the intrusion of foreign substances (Netea et al., 2011). B and T lymphocytes (types of white blood cells) have several roles in the immune response; however, in the 
simplest terms, these cells are the memory and recognition portion of the immune system (Netea et al., 2011). When compromised by measles infection, the immune system's ability to recognize and fight other infections is reduced. Studies of measles induced immune suppression have noted that many of the characteristic symptoms are the result of the immune response to infection, and that a large proportion of measles deaths are the result of increase susceptibility to secondary infections (Griffin, 2010; Griffin et al., 1994).

Research has shown that measles infection depletes B and T lymphocytic cells, resulting in immune suppression that last for weeks or even a few months after infection (de Vries et al., 2012; Griffin, 2010; Mina et al., 2015; Perry and Halsey, 2004). A 2015 study by Mina and colleagues suggests that the recovery of normal levels of B and T lymphocytic cells that occurs as the individual recovers from infection does not restore immune memory. Instead, these new cells are primarily measles-specific B and T lymphocytes which, the authors suggest, could extend measles-induced immunosuppression for up to 3 years (Mina et al., 2015). While the full extent and impact of measles-induced immunosuppression during an epidemic is still being investigated, it is clear that infection by the measles virus and the resultant immunosuppression exposes the infected individual to an increased risk of secondary infections and complications.

This is the very definition of a syndemic interaction-measles virus interacts with the host's immune system to create an environment in which infection by measles and other pathogens result in a worse outcome than that caused by the measles infection alone. Creighton (1965) first noted an unusual trend in the London Bills of Mortality in the late 19th century when he observed increases in mortality from other causes of death during a measles epidemic. It was noted that deaths from infant diarrhea, wasting, as well as a category denoted "teeth" (which indicated deaths during the teething stage) increased in concert with increasing mortality during a measles epidemic (Creighton, 1965). Other 
authors have noted similar increases in mortality when one or more other causes of death occur at the same time as measles (Cliff and Haggett, 1985; Cliff et al., 1993; Preston and Haines, 1991). In more recent studies from Senegal and Bangladesh, statistical analysis has suggested that measles infection alone is not responsible for the excess mortality observed during measles epidemics (Aaby and Bhuiya et al, 2003a; Aaby and Samb et al., 1996). These studies suggest that greater than expected mortality during measles epidemics may be the result of syndemic interactions between measles and some other factor(s). Many studies since have been dedicated to understanding the factors involved in this interaction and how they combine to create excess mortality beyond that accounted for by measles deaths. However, the majority of studies were done during contemporary epidemics which have numerous confounding factors including partial measles vaccination of the communities, vaccinations for multiple diseases, modern medical treatment, etc.

In 1984, Aaby and colleagues associated with the Bandim Health Project in GuineaBissau published a study which examined the effects of overcrowding, vaccination, and nutrition on measles mortality during contemporary measles epidemics in the region. This study, followed by many others, concluded that measles mortality was higher in conditions where more intense exposure occurred at the household level (see, Aaby, Bukh, Lisse, and Smits, 1984a; see, Aaby, Bukh, Lisse, Smits, and Gomes et al., 1984c; Aaby, Bukh, Lisse, \& Smits, Wesley, and Kiepiela, 1985; Cisse et al., 1999; Garenne and Aaby, 1990). While most studies listed malnutrition as a risk factor during measles epidemics (e.g., Burström et al., 1999; Moss and Griffin, 2012; Perry and Halsey, 2004; Wolfson et al., 2009), other studies showed no correlation between general nutritional deficiencies and measles mortality (Aaby, 1988; Aaby, Bukh, Lisse, and Smits, 1983; Aaby, Bukh, Lisse, Smits, and Gomes et al., 1984c; Sinha, 1977). Overcrowding, however, correlated with earlier infection and increased virulence (Aaby, Andersen, and Knudsen, 1993a; Aaby, Bukh, Lisse, and Smits, 
1984b; Aaby, Bukh, Lisse, Smits, Wesley, and Kiepiela, 1985). The authors tied this result to the intensity of exposure to measles virus as the mortality among cases decreased in concert with the clustering of cases. In other words, when cases were not closely grouped together socially, case fatality rates fell (Aaby, Bukh, Lisse, and da Silva, 1988).

Intensity of exposure cannot account for all of the mortality surrounding measles epidemics, but studies surrounding vaccination shed light on another possible factor contributing to syndemic measles deaths. Immunization studies showed that the introduction of the measles, mumps, and rubella (MMR) vaccine resulted an overall greater reduction in childhood mortality after vaccination than could be explained by measles prevention (see, Aaby and Bhuiya et al., 2003a; Aaby, Bukh, Lisse, \& Smits, 1981; Aaby and Knudsen et al, 1993b; Aaby and Martins et al, 2010; Aaby and Samb et al, 1995; Peter, 1995). Repeated studies have found that children who had been infected with measles prior to vaccination were subject to higher mortality and that there was a significant reduction in overall mortality for children who were part of the vaccination program (see, for example, Aaby, Bukh, Lisse, and Smits, 1984a; Clemens et al., 1988; Fisker et al., 2015; Koenig et al., 1990; Kristensen et al., 2000; van Wijhe et al., 2016). These and similar studies began to point to the interaction between the measles virus and the human immune system as a syndemic link to increased mortality during measles epidemics.

\section{Comparing Measles and Smallpox}

A baseline period provides information on how mortality varies between a measles epidemic and non-epidemic period; however, it is also necessary to compare mortality between measles and a similar epidemic to identify mortality characteristics that are unique to the measles epidemic. Smallpox caused by Variola major, was known to be present in the archipelago in cyclical epidemics and was recorded both prior to and following the 1820-21 
measles epidemic. Contrary to measles, smallpox has a characteristically high mortality rate (30\% on average) which serves as a counterpoint in this study to the characteristically lower mortality of measles (3\% on average) (Heymann, 2008). It is also a highly infectious childhood disease which was accurately recognized during the time period of this study and rarely confused with measles.

Measles is primarily spread through respiratory droplets and can remain in the air for up to 2 hours (CDC, 2017). Smallpox can be spread through aerosol droplets (with prolonged exposure); however, it is most commonly spread through bodily fluids or direct contact with contaminated items (CDC, 2017). In this way, the infectivity of smallpox is, at least in part, due to the long duration of the infectious period and the multiple avenues for transmission. Figure 4.1 compares the disease progression of measles and smallpox.

Measles had less of a presence in the historical records of Åland during the $18^{\text {th }}$ and early $19^{\text {th }}$ centuries as waves of smallpox repeatedly reduced the susceptible population. The high mortality of smallpox removed large segments of the population that traditionally played host to measles, consequently, there were fewer measles infections and overall lower measles-attributed mortality. This situation resulted in fewer opportunities for measles to catch hold and, subsequently, measles epidemics were smaller epidemics in general. The occurrence of smallpox epidemics is one factor that contributes to the magnitude and impact of measles epidemics.

High epidemic mortality can create large ripple effects in the demography of a population (Mielke, 2003), changing the overall population size, population growth, fertility, and even the age or sex distribution of communities. While measles mortality may not be visible in the historic records, this does not mean that mortality during a measles epidemic cannot have a similar or greater demographic impact when compared to a high mortality 


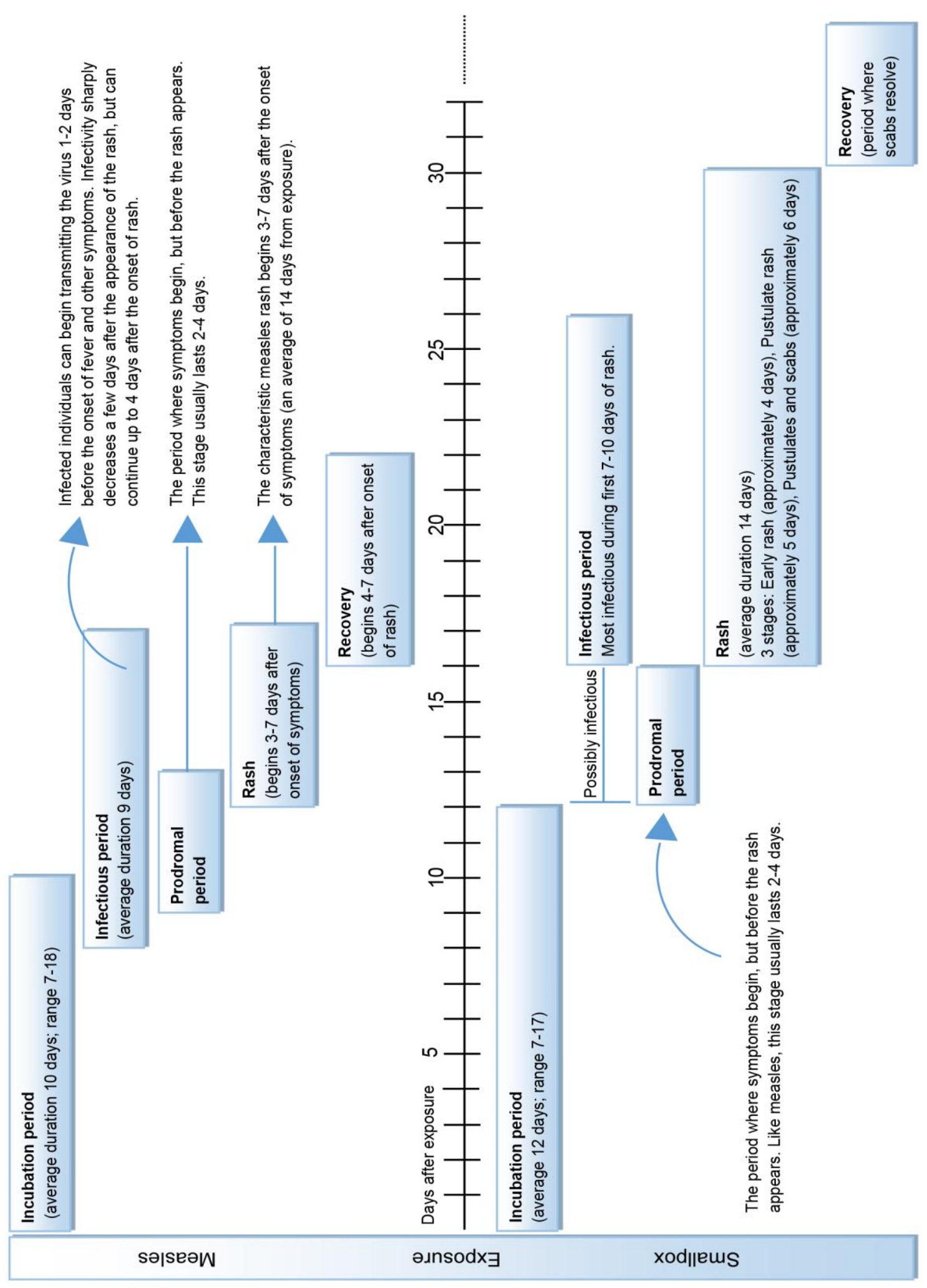

Figure 4.1. Comparison of the characteristic stages of measles and smallpox infection. This figure was compiled from information in the following sources; CDC (2017); Cliff et al. (1993); Heymann (2008); Oldstone (2010); Racaniello (2011); Sattenspiel (2009). 
epidemic such as smallpox. The importance of the comparison between smallpox and measles is to see if both time periods produce similar demographic changes regardless of whether the mortality is attributed to the epidemic specifically.

\section{Measles Epidemiology: Quantitative Studies}

Measles epidemics occur when the virus is introduced into a population that has enough individuals who are susceptible to the disease for infection to take hold and spread. Still, the appearance of measles did not always result in an epidemic and the frequency of the occurrence of epidemics and their severity varied widely across populations. Interest in the recurrence of measles epidemics, specifically explaining the factors that create or alter the magnitude and periodicity of measles, became the driving force for early mathematical models (Hamer, 1906; Soper, 1929; Wilson and Worcester, 1945) and were the beginning of a considerable body of research surrounding measles epidemics. This body of research built the groundwork for what is known about measles and other childhood epidemics and serves as the foundation for understanding measles epidemiology.

One early issue explored in quantitative studies of measles epidemiology was explanations for the effects of community size on the sustainability of the chain of infection. Bartlett $(1957 ; 1960)$ and Black (1966) demonstrated that a minimum number of individuals, a population threshold, is required to sustain endemic measles in a population. In very large communities (excess of 250,000 residents according to Bartlett (1957)), the number of births and the influx of migrants can continually provide enough individuals susceptible to measles that the virus becomes endemic to the community. This is known as a Type I population. Further studies expanded this concept to islands and more remote regions, noting that a slightly larger critical community size, 300,000, was necessary for sustained epidemic transmission of measles (Black, 1966; Cliff and Haggett, 1985). In 
smaller, isolated communities, measles is not endemic; that is to say infection cannot be continuously sustained by the population and fades out until it is reintroduced. Populations such as those in the Åland Islands experience infectious diseases like measles regularly because of frequent reintroductions, but with clearly defined breaks between epidemics (Type II populations). Extremely small or isolated populations such as the Faroe Islands or islands in the Pacific during the early $19^{\text {th }}$ century are Type III populations where epidemics such as measles occur irregularly with varying magnitudes (Cliff and Haggett, 1985).

The influence of population size and community isolation led to a large body of work on geographic studies of measles epidemics. Investigations focused on understanding how geography combines with cultural and social influences to impact the timing and spread of epidemics. In the early 1980s, spatial diffusion models were used to illustrate how the social linkage of communities influenced cycles and synchronicity of measles epidemics. Much of this work was completed by Cliff, Haggett, and colleagues and focused primarily on the island populations of Fiji and Iceland (Cliff and Haggett, 1980; 1984; 1985; 1993; Cliff et al., 1983a, 1983b). For example, Cliff and Haggett's (1980) investigation of patterns in Iceland revealed a link between changing seasonal patterns and increasing external transportation. Other spatial epidemiology studies have linked disease transmission to social and cultural travel patterns in conjunction with the overarching influence of geography (Cliff and Haggett, 1985; Cliff et al., 1993; Cliff et al., 2009; Herring and Sattenspiel, 2007; Sattenspiel and Powell, 1993). Additional modelers incorporated geographic space while adding in other factors that could influence the long-term cycles of epidemics, including stochasticity (randomness) (Murray and Cliff, 1977), realistic variation in seasonal contact rates (Fine and Clarkson, 1982), and even chaos theory (Olsen and Schaffer, 1990). 
As measles was, historically, a disease of childhood, age structure has long been included in measles models in recognition of the importance of school related transmission in childhood infectious disease (Bolker and Grenfell, 1993; Cisse et al., 1999; Ferguson et al., 1996; Keeling and Grenfell, 1997; 1998; Schenzle, 1984). School-related seasonality of measles transmission has been addressed with models that combine seasonality with variable contact rates in children of different ages. Examples include the use of seasonally varying contact rates between pre-school and primary-school-aged children (Bolker and Grenfell, 1993), the introduction of stochasticity (Grenfell, 1992), and the use of single year age classes through age five (Ferguson et al., 1996). Other research suggests that a normal distribution of values for both the incubation and infectious periods provide more realistic results (Keeling and Grenfell, 1997; 1998). In general, analyses of these models have demonstrated the importance of incorporating realistic biological complexity (age structure) and seasonal variability in studies of measles transmission.

Further attempts to more closely approximate realistic epidemics combined multiple approaches. For example, Ellner et al. (1998) used a realistic age structure coupled with a semi-mechanistic model, statistical time-series analysis, and a basic epidemiological model with seasonal forcing. Building on these concepts, Bjørnstad et al. (2002) further incorporated time-series data. This work linked endemicity to seasonal contact rates, variable birth rates, and patterns of fade-out through the interaction of population size and the reintroduction of infection (see Bjørnstad et al., 2002; Cauchemez and Ferguson, 2008; Finkenstadt and Grenfell, 2000; Grenfell et al., 2002). More recently, Bharti et al. (2011) used satellite imagery to track population density through the detection of nighttime lights and confirmed the long-held view that cultural factors, such as seasonal movement, increased the intensity and spread of measles. 
Mathematical models have been the foundation of much that is known about the spread of measles today, and as a similar childhood disease, much of this knowledge is applicable to smallpox. Both measles and smallpox are highly infectious diseases that generate epidemics as they are introduced into populations with sufficient size to foster transmission. The age-distribution of infection is related to the frequency of epidemics in the population, and the spread of infection is largely related to geography in conjunction with social and cultural patterns of travel. By examining historical epidemics, we can compare the outcomes of measles epidemics to that of smallpox epidemics-a disease with high mortality in which immunosuppression is not known to have occurred - to get a clearer view of the impact of measles virus infection on a susceptible community.

As the preceding discussions have illustrated, the circumstances surrounding measles mortality are often varied and complicated; arising from studies in different geographies and cultures or during different time-periods and local or global events. These studies provide insight into the underlying mechanisms which promote or inhibit disease transmission as well as the potential social, cultural, and biological interactions which contribute to mortality. This foundational knowledge was used to inform the design of the study presented here which aims to understand factors contributing to measles mortality and the impact of a measles epidemic on the island communities of Åland, Finland. 


\section{CHAPTER 5: THE ARCHIVES OF ÅLAND}

The data used to complete this research come from vital registers compiled by parish clergy members by order of the Swedish Ecclesiastical Laws of 1686 and aggregated for the needs of the Swedish, and later Finnish, governments as a national vital records system was established (Turpeinen and Kannisto, 1997). Three primary datasets were used in this research: 1) Åland, Finland parish records of burials, 2) the Population Change Tables for Åland, which contained yearly frequencies of births, marriages, and deaths, and 3) the Åland Population tables, which contain population estimates compiled every 5 years from the Parish Main Books. Many, but not all, of these records have been digitized and are available in the Digital Archives of the National Archives of Finland

(http://digi.narc.fi/digi/?lang=en US).

James Mielke and a group of colleagues worked to obtain and transcribe the original vital records for a series of analyses primarily published in the 1970s and 80s (e.g., Eriksson, 1980c; Mielke et al., 1987; Pitkänen, 1977; Pitkänen et al., 1989, see Chapter 3 for a full discussion). Mielke provided copies of the transcribed records for the purposes of this research; however, limited population data, difficulties translating causes of death, and other recording issues limit the use and reliability of these records to some extent.

The archives of the Åland Islands, as discussed in this study, are the vital records that resulted from the 16th century Protestant Reformation and the Ecclesiastical Law of 1686. During the Protestant Reformation, the established Christian following shifted to a Lutheran Christian following and the islands were subsequently divided up into fifteen rural parishes (Mielke et al., 1982) (later extended to include the urban parish of Mariehamn (Eriksson, 1980a)). The Lutheran Church subsequently implemented the Ecclesiastical Laws of 1686 (Mielke, 1980; Mielke et al., 1982). This law required all Lutheran ministers to keep 
detailed records of the inhabitants and activities of their parish and parishioners. These records included general information of interest to the parish such as births and baptisms, deaths and burials (Figure 3.3), marriages, migration in and out of the parish, and other religious milestones (Mielke, 1980; 2003; Mielke et al., 1982).

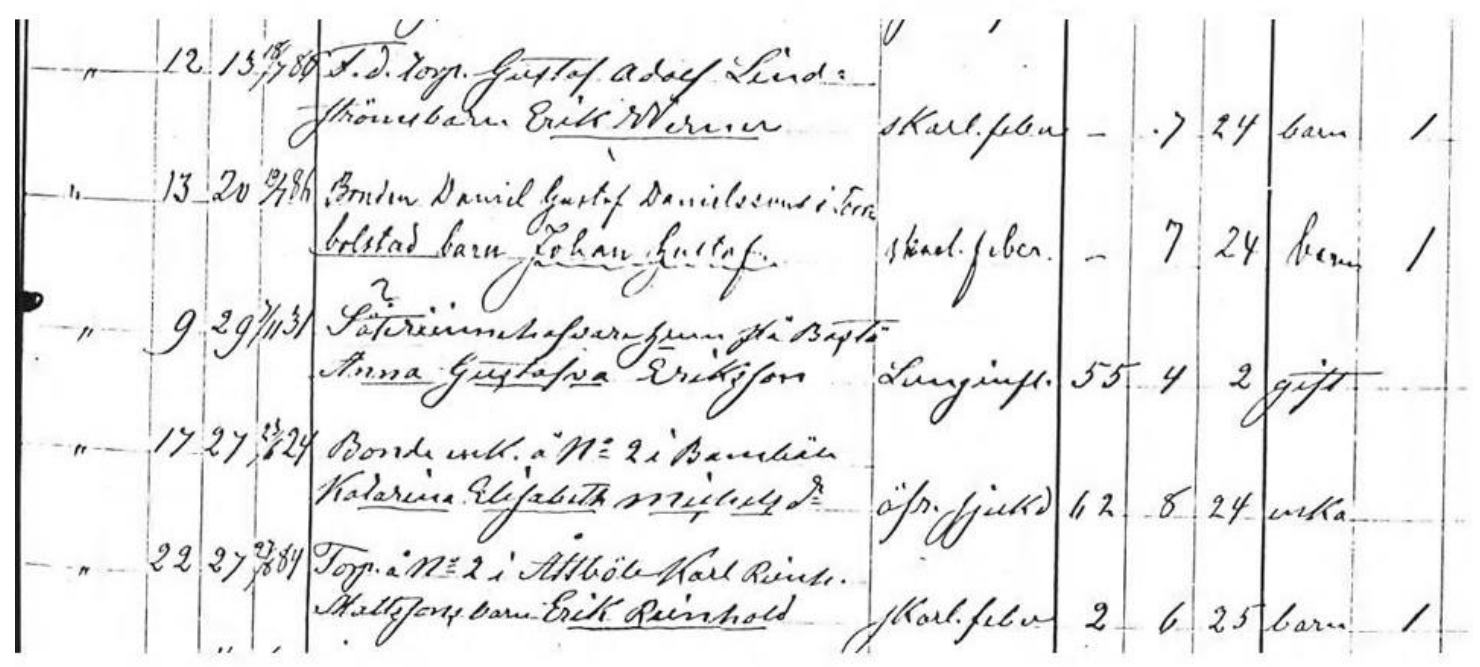

\section{Finström Death Record 1887}

Figure 5.1. Sample of data from the Finström parish death register.

Many records were lost after the Great Northern War (1700-1721) (Eriksson, 1980b; Pitkänen, 1977; Turpeinen and Kannisto, 1997); however, by the mid-18 ${ }^{\text {th }}$ century parish records were being kept consistently and systematically. In 1749, a new office for population statistics was founded, the Tabellverket in Stockholm, by the governing bodies of The Kingdom of Sweden with the purpose of collecting and aggregating parish records for administrative uses (Turpeinen and Kannisto, 1997). Archival loss and inconsistencies in recording practices (Strömmer, 1969; Turpeinen, 1973) are why much of historical demography research in the Åland Islands has focused on the period between 1750 and 1950. 


\section{Translating Causes of Death}

Assessing data quality is essential when performing historical demography studies. The primary concern relating to reliability of the Åland data is the recording and identification of the cause of death. Ministers of the parish, not doctors, were frequently responsible for identifying and recording illness and causes of death in the parish records of deaths and burials (Eriksson, 1980b; Mielke et al., 1984; Turpeinen, 1973). Unfortunately, the parish ministers were not trained physicians and often had a limited knowledge of medicine or health conditions (Turpeinen, 1973). To add further difficulty, the causes of death were recorded in a dialect of $19^{\text {th }}$ century Swedish, the script is difficult to read, and the language does not directly translate to modern Swedish. In addition, neither the names for causes of death nor spelling were standardized at the time (Pitkänen, personal communication) and abbreviations were common in the records; both spelling and abbreviations varied by priest and parish. There was a small problem with a specialized form used from 1749 to 1773 . This form combined measles and smallpox into one tabulation making it impossible to distinguish between the two (Mielke et al., 1984). Fortunately, the 19th century records separate the two diseases, removing this concern for the present study, and there would be no major changes in reporting of vital statistics until 1878 (Turpeinen and Kannisto, 1997).

Causes of death in the archival records may be questionable, especially in instances when overarching terms are used for a wide range of illnesses. Diseases such as smallpox and measles were very distinctive and produced an identifiable rash and course of illness (Cunha, 2004). Consequently, measles and smallpox were well known, and it is reasonable to conclude that each disease was recorded with an acceptable degree of accuracy throughout the 19th century (Mielke et al., 1984). Methods to address instances where measles and smallpox reports overlap, the cause of death is uncertain, or the cause of death 
listed conflates different diseases will be discussed in the next section and in the next chapter as each situation pertains to specific analyses.

Because both measles and smallpox are childhood diseases, it is important to note weaknesses in the accuracy and precision with which births and deaths were recorded, tabulated, and transferred to the population change tables. Primarily, the births and deaths of children under one year of age appear to be underreported with some frequency (Pitkänen, 1977; Turpeinen, 1979a; b; Turpeinen and Pitkänen, 1979). Still, analyses of these records showed no indications of systematic biases in the vital records used for this research (Mielke et al., 1982).

When translating the causes of death, it was necessary to start with the word or phrase that had a corresponding Swedish translation. For example, the word Ålderdom directly translates to old age in both modern and historical Swedish. From this point, it was possible to identify words which could not be associated with a direct translation but had similar structure and spelling (Table 5.1). For this example, the cause of death was always cross checked with the individual's age and status (e.g. a status of barn, or baby, with a cause of death recorded as Ålderdom would be assumed to be an error in recording or transcription of the records). In some parishes, there is no reference to the full word or phrase that corresponds to cause of death, so abbreviation trends were cross-referenced across parishes. Using this method, it was possible to recognize that the entries $A l b r$ from the Finström records and $O k b s j$ from the Saltvik records were references to old age and an unknown disease of childhood, respectively.

Because the language of the archival records does not directly translate to modern Swedish, translating each cause of death required a cross-reference of several translation resources. The Demographical Database for Southern Sweden (DDSS 2012) was the primary translation source used for this purpose. When a translation was unavailable, or listed 
multiple meanings, it was necessary to cross-reference several other Swedish translation sources to estimate a modern analog (see, for example, Family Search, 2012; Rudy's List, 2013; SFHS, 2013; SweGGate, 2013). Any causes of death that were blank or could not be assigned a reasonable translation were designated as unknown.

Table 5.1. Examples of abbreviations in the recorded cause of death for Brändö Parish Records.

\begin{tabular}{|c|c|}
\hline Approximate translation & Recorded cause of death \\
\hline \multirow{4}{*}{ Old age } & Ålderdom \\
\hline & Ålderd \\
\hline & Ålder \\
\hline & Åld \\
\hline \multirow{2}{*}{ Infirmities of old age } & Ålderdoms bräcklighet \\
\hline & Ålderdoms bräckl \\
\hline \multirow{3}{*}{$\begin{array}{l}\text { Malnutrition/wasting } \\
\text { associated with old age }\end{array}$} & Ålderdoms svaghet \\
\hline & Ålderdoms svagh \\
\hline & Ålderdoms sv \\
\hline \multirow{3}{*}{ Child's disease } & Barnsjukdom \\
\hline & Barnsjuka \\
\hline & Barnsj \\
\hline \multirow{5}{*}{$\begin{array}{l}\text { Unknown } \\
\text { child's disease }\end{array}$} & Okänd barnasjukdom \\
\hline & Okänd barnsjukd \\
\hline & Ok barnsjuk \\
\hline & Ok b sjukd \\
\hline & Ok bsjuk \\
\hline
\end{tabular}

Causes of death during this time were often recorded as a description of events or symptoms. For example, one cause of death was recorded as Drunknad, omkommo på Ålands haf, under dit resan til Stockholm, which roughly translates as 'Drowned, perished in the Sea of Åland on the journey to Stockholm'. Other entries were simply descriptions that roughly translated as 'pain in the chest' or had multiple meanings such as 'stroke' or 'sudden impact'. In either case, the entry could refer to one or many different possible causes of 
death. Therefore, because many recorded causes of death could not be reliably associated with a specific modern cause of death, apart from measles and smallpox, deaths were grouped into broader categories. Table 5.2 outlines the selected categories and provides a description of the translated causes of death that were included in each. Examples of several common specific causes of death from Parish Records of Deaths and Burials and the approximate translations, using the method described above, are included in Appendix A.

Table 5.2. Cause of death categories and descriptions

Cause of death categories Description of death translations included in each category

Measles and smallpox Translations corresponding to the words mässling or smittkoppor, respectively.

Respiratory deaths Translations corresponding to known respiratory diseases or descriptions including terms such as cough or lungs.

Gastrointestinal Translations attributed to diarrhea or stomach pain, or description which include terms for stomach or gut.

Old age Translations including the term for old age; commonly listed as

Accidental

Other/unknown the cause for an individual over 60 years.

Translations corresponding to the term accident; the most common cause of accidental death is drowning. Any cause of death translation that does not belong to one of the categories above, could not be translated, or was left blank in the records.

\section{Understanding Archival Data in Demographic Research}

For historical demographers, archival records such as these are the primary sources of data; however, the scope of potential research is limited by the content, completeness, and reliability of the records being used (Eriksson, 1980b; Mielke et al., 1987). The unusual detail and reliability of vital records for Åland are likely due to the long-standing practice of record-keeping in the parishes and the university education of the parish ministers (Turpeinen and Kannisto, 1997). In addition, very small populations fostered social 
intimacy and it was likely that the clergy knew all, or nearly all, of their parishioners and officiated at all baptisms and burials (Eriksson, 1980b; Turpeinen and Kannisto, 1997). The demographic data in Åland are, from the perspective of demographic and historical research, not without their problems, but relatively reliable as long as one takes into account their weaknesses.

Primarily, the flaws in the Åland records are related to loss of records, differences between parish records, and the reliability of cause of death attributions (Mielke et al., 1984). Major events such fires and floods, which would lead to the destruction of records, were a rare occurrence and there is no indication that the loss of records created systematic biases (Mielke et al., 1982). Standardized procedures were put in place for clergy members to record the events of their parishes, resulting in relatively reliable records. Unfortunately, members of the clergy were not always consistent across villages and parishes in their detail. For example, records in one parish might have detailed information on the parents of baptized children while another parish's records had very little to no information recorded on the parents.

The central concerns for this research relate to the reliability of the recorded cause of death and the feasibility of translating the records to correspond to a modern cause of death that can be used for analysis. It is also important to remember that this information was not collected for the purposes of $21^{\text {st }}$ century research, regardless of whether that research is epidemiological or demographic in nature. Failure to understand how social, cultural, or economic factors influence the content and quality of the records can lead to false assumptions, faulty analyses, and an overall misunderstanding of the population and processes under study (Howell and Prevenier, 2001; Macfarlane, 1977). 


\section{CHAPTER 6: METHODS}

This study steps back from a specific identified cause of epidemic mortality to look at mortality from all recorded causes. The purpose of this study is to determine whether a measles epidemic results in mortality above what would be expected in a non-epidemic year - mortality that is not attributed to measles (excess non-epidemic mortality) - and what impact that excess mortality might have on the demographic structure of communities in Åland, Finland. To ensure that the aspects of measles epidemics being investigated are not common to all childhood epidemics, smallpox, another childhood disease that historically occurred with some regularity in the Åland archipelago, is used as a comparison. This chapter describes methods of analysis undertaken to answer three overarching research questions: 1) whether additional mortality occurs from other diseases during an epidemic of measles, 2) how the burden of mortality during a measles epidemic compares to epidemics with highly visible mortality, such as those due to smallpox, and 3) whether the demographic impact of a measles epidemic is similar to what would be expected from an epidemic of smallpox.

Graphic analyses focused on the number of deaths attributed to measles or smallpox to identify epidemic and non-epidemic periods for analysis. Analyses of mortality (agespecific death rates, mortality ratios, and statistical analysis of frequencies) were used to compare the burden of mortality between a non-epidemic period with that experienced during a measles epidemic and a smallpox epidemic. The remainder of analyses used the available data to complete an epidemiological overview of the mortality from each epidemic and a demographic analysis of the impact of that mortality. The specific methods used for each of these tasks are described below. The results of these analyses will be discussed in the next chapter. 


\section{Graphic Analyses: Identifying Epidemics and Non-epidemics}

This research required the identification of three study periods: a measles epidemic, a smallpox epidemic, and a non-epidemic. Temporal proximity of these events is necessary to ensure that there was not enough time for major changes in culture or demographic structure to impact the cultural or social response to these childhood epidemics. Each of these events in different populations, time periods, or with different cultural or social interventions, would produce very different epidemic landscapes and demographic outcomes.

For example, the introduction of the smallpox vaccine in 1805 , a social intervention to control the disease, changed the frequency of smallpox epidemics in the Åland Islands (Pitkänen et al., 1989). This altered the epidemic landscape of the archipelago because more children were surviving, and these surviving children were susceptible to other diseases such as measles. Analyses of $18^{\text {th }}$ century smallpox, or even measles, patterns would look very different from epidemics in the late 1880s, the early 1900s, and so on. Or, consider the 1875 epidemic of measles in the Pacific Islands, where extremely high rates of mortality were attributed to a completely susceptible population and reports that the indigenous population treated fevered children through efforts to cool the body such as dousing the child with cold water (Cliff and Haggett, 1985). These early epidemics created very different mortality profiles when compared to later epidemics when the population had partial immunity and had developed more experience in how to effectively care for the sick (Cliff and Haggett, 1985). Therefore, the study periods need to be within the same social and cultural population and occur in a reasonable time-frame, temporally speaking, but have enough separation to avoid any overlap which would call into question the effects of each epidemic and the proper identification of measles vs. smallpox. 
The numbers of measles and smallpox deaths were each plotted by calendar year generating time series that illustrate the patterns of measles and smallpox epidemics for the archipelago. As described further in Chapter 7, assessment of the temporal pattern of mortality allowed for the identification of three time periods that met the criteria for analysis of the impact of measles and smallpox mortality on the island communities: 181617, 1820-21, and 1823-24 (see Figure 7.1). The 1820-21 measles epidemic was the only measles outbreak large enough for analysis while the 1823-24 smallpox epidemic was the only period with a sufficient number of smallpox deaths for analysis that also occurred within a reasonable time-frame of a measles epidemic. Neither measles nor smallpox epidemics were apparent in 1816-17; thus, that period provides a baseline to use in assessing the specific impacts of the measles epidemic of 1820-21 and the smallpox epidemic of 1823-24.

\section{Age-specific Death Rates: Bridging Gaps in Data}

The analysis of historical epidemics is complicated by the available data surrounding the epidemic(s) of interest; the level of detail, reliability, and the frequency with which available records were collated. For example, the Åland Population Tables were compiled every five years as a census using the parish communion books. As a result, there

are reasonably accurate population data by age for the entire archipelago, but only in 5-year intervals. Another example is the reliability of the cause of death entries for the Åland archipelago in the early $19^{\text {th }}$ century. Archival sources vary in their completeness, detail, and reliability, and, for these reasons, it is essential that the research question and methodology are suited to the data, and that the data can provide the resolution needed for analysis. 
The limited annual population data from the Åland Islands create a barrier to understanding how smallpox or measles mortality impacted the archipelago during the two years during which each epidemic occurred. Conventional methods of mortality analysis average the deaths and population across the five-year census periods, an approach that smooths the large fluctuations that can occur in small populations between years. The primary concern with using this approach is that it creates stability but also masks the effects of epidemics which occur between or across census years, particularly in the case of drawn-out illnesses such as measles or smallpox. To study the effects of epidemic mortality, it is necessary to calculate intercensal population estimates for the archipelago. These estimates, mathematically derived, may be less representative of small populations with greater fluctuations in population cohorts from year-to-year, but they are essential for the analyses in this study. For the reasons stated above, population estimates in this study were restricted to the overall population of the Åland Islands to reduce instability and calculate reasonably reliable intercensal population estimates without introducing undo error.

The total population of the archipelago ranged from 12,392 to 13,757 inhabitants between 1815 and 1830. Table 6.1 provides the population distributions recorded in the Åland Population Tables for each 5-year census. Mean annualized growth rates were calculated for each age group using the observed population distribution from the Population Tables and the methods described in Preston et al. (2001). These rates were then applied to each age-class to calculate the intercensal age-specific population estimates for each year required to analyze the age-specific death rates for each of the epidemic study periods. The census data in the Population Tables are the closest estimates to a mid-year population available for archipelago, which means that the intercensal population estimates are the best reflection of the mid-year population for each year. 
Table 6.1. 5-year age-specific census population estimates from the Åland Islands population tables

\begin{tabular}{lrrrr} 
Age & 1815 & 1820 & 1825 & 1830 \\
\hline$<1$ & 351 & 307 & 395 & 376 \\
$1-4$ & 1,214 & 1,192 & 1,274 & 1,334 \\
$5-9$ & 1,123 & 1,318 & 1,248 & 1,487 \\
$10-14$ & 1,341 & 1,139 & 1,259 & 1,232 \\
$15-19$ & 1,228 & 1,341 & 1,051 & 1,277 \\
$20-24$ & 1,098 & 1,171 & 1,226 & 983 \\
$25-29$ & 913 & 1,033 & 1,140 & 1,157 \\
$30-34$ & 863 & 873 & 955 & 1,087 \\
$35-39$ & 841 & 807 & 834 & 878 \\
$40-44$ & 754 & 829 & 780 & 793 \\
$45-49$ & 694 & 654 & 728 & 692 \\
$50-54$ & 580 & 627 & 587 & 661 \\
$55-59$ & 468 & 463 & 601 & 545 \\
$60-64$ & 360 & 394 & 427 & 493 \\
$65-69$ & 268 & 261 & 326 & 335 \\
$70-74$ & 147 & 173 & 212 & 213 \\
$75-79$ & 97 & 101 & 124 & 137 \\
$80+$ & 52 & 51 & 61 & 77 \\
\hline Total & 12,392 & 12,734 & 13,228 & 13,757 \\
\hline \hline
\end{tabular}

To estimate the age-specific mortality of a 2-year epidemic period, linear averages of the number of deaths (from the parish records) and the population estimates across the relevant time periods were calculated. For example, the total number of deaths reported for each age between 1816 and 1817 were summed and divided by 2 to estimate the average mortality of the 2-year time period (based on methods in Sparks, 2007). It should be noted that the mortality counts for this analysis did not include stillbirths or individuals of unknown age. Age-specific mortality rates for all ages other than infants were calculated as the average number of deaths during the time period divided by the mid-year population estimate (Appendix B). These rates were then multiplied by 1,000 to present the number of deaths occurring per 1,000 residents. Infant mortality rates use the number of live births in 
the denominator instead of the mid-year population. Many infant deaths occur in the first few weeks of life and are not evenly distributed throughout the year. Consequently, any calculation of infant mortality using the mid-year population is less informative because it cannot accurately represent the average size of the population at risk (Rowland, 2003). The use of live births as a denominator is more reliable because the number of births can change dramatically between years and births records are available for the Åland Islands for each year.

Trapp et al. (1983) concluded that the infant mortality of Åland in the early $19^{\text {th }}$ century was considerably higher (62 infant deaths higher on average) than that observed in the surrounding countries of Sweden and Finland. Infant mortality can provide an overall marker of the health of a population (Merrill and Timmreck, 2006), and the primary focus of this study was to assess the impact of childhood epidemic mortality on the population. To that end, infant mortality data were obtained for Sweden and Finland from the Human Mortality Database and Turpeinen (1979b), respectively. These data are charted in Figure 7.2 alongside the infant mortality of the archipelago to provide a comparison of the overall health of the surrounding areas so that the impact of the overall conditions in the archipelago, including epidemic mortality, on the health of the population can be observed.

\section{Excess Mortality and Frequency Analysis}

Excess mortality ratios were calculated for the archipelago based on all deaths and non-epidemic deaths, using the 1816-17 period as a baseline. Excess mortality was calculated by dividing the observed mortality in the epidemic periods by the expected baseline mortality, a generalized adaptation of the proportionate mortality ratio methodology (Merrill and Timmreck, 2006). Because they are unrelated to epidemic mortality, accidental deaths were removed. A second set of excess mortality ratios were calculated using 
observed numbers of deaths, but this set excluded epidemic mortality from measles and smallpox in addition to accidental mortality. These analyses provided an approximation of the increased burden of mortality during epidemics of childhood diseases over and above that due to the epidemic diseases themselves. Once excess mortality was established, subsequent analyses focused on identifying differences in the distribution of deaths during epidemic periods.

Chi-square analysis was used to compare the number of deaths (without accidental or epidemic causes) and the population size between each epidemic period and the 1816-17 baseline. This evaluated whether the second excess mortality ratio was significantly different from the baseline period. There were two analyses, each with 2 rows (deaths and population) and 2 columns (baseline and epidemic period). This value was evaluated at a significance of $0.05(\alpha=3.84)$ for 1 degree of freedom.

A frequency table of deaths from different causes was created using the translation and categorization method discussed in Chapter 5 (see Table 6.2). There were 2 deaths from smallpox during the 1820-21 measles epidemic. Based upon the frequencies in Table 7.3 and other studies (see, for example, Mielke et al., 1984; Pitkänen et al., 1989), it is clear that measles and smallpox infections were known to have occurred at the same time. While it is possible that these 2 deaths were misdiagnosed, it is more likely that these were sporadic cases of smallpox in a population where the susceptibility to smallpox, or some other social or cultural factor, did not allow for epidemic transmission to occur and thus smallpox was not actively spreading throughout the archipelago at this time.

A second chi-square analysis was employed using the counts in each cause of death category to evaluate whether there were differences in the distribution of mortality that were not caused by either measles or smallpox; consequently, all measles and smallpox deaths were removed from the counts prior to analysis. Expected values were calculated by 
multiplying the proportion of deaths for each category during the 1816-17 baseline period by the total number of deaths for each epidemic period. The chi-square value was evaluated at a significance of 0.001 .

Table 6.2. Observed numbers of deaths, grouped into seven categories, during three study periods

\begin{tabular}{lccc} 
Cause of death & $\begin{array}{c}1816-17 \\
\text { non- } \\
\text { epidemic }\end{array}$ & $\begin{array}{c}1820-21 \\
\text { measles } \\
\text { epidemic }\end{array}$ & $\begin{array}{c}1823-24 \\
\text { smallpox } \\
\text { epidemic }\end{array}$ \\
\hline Measles & 0 & 89 & 0 \\
Smallpox & 0 & 2 & 155 \\
Respiratory & 130 & 140 & 75 \\
Gastrointestinal & 52 & 42 & 47 \\
Old age & 50 & 111 & 58 \\
Accidental & 24 & 17 & 37 \\
Other/unknown & 309 & 505 & 331 \\
\hline Total number of deaths & $\mathbf{5 6 5}$ & $\mathbf{9 0 6}$ & $\mathbf{7 0 3}$ \\
\hline \hline
\end{tabular}

To provide information on how each category of mortality contributed to the overall mortality in the archipelago, proportionate mortality ratios (PMR) were calculated for each time-period. The ratio was calculated by dividing the number of deaths for each category by the total number of deaths as suggested in Merrill and Timmreck (2006). To remove the effects of accidental deaths, which were unlikely to be related to the presence or absence of an epidemic, these deaths were excluded from both the numerator and denominator in this analysis. These analyses of mortality were used to assess the presence of excess mortality and how epidemic mortality differed between each study period. 


\section{Demographic Impacts of Epidemic Mortality}

Further analyses focus on the impact of epidemic mortality on the demographic structure of the Åland communities. The composition of a population is the foundation that demographic processes, such as mortality or fertility, act upon. The age-specific structure of the population determines the population at risk for death and disease as well as the population that may be contributing to the next generation, and thus influencing population growth. Population pyramids illustrate the age and sex distribution of the population for the measles and smallpox epidemic periods (1820-21 and 1823-24, respectively) in comparison to the baseline non-epidemic period (1816-17). Generalized fertility rates (GFR), crude death rates (CDR), sex differences in mortality, and life expectancy at birth from 1815-1830 provide insight into patterns of fertility, mortality, and overall health in the archipelago over time.

Life expectancy at birth is one of the common methods used by demographers to compare the effects of mortality over time within a population. Age-specific census data for $1815,1820,1825$, and 1830 were used to construct single year life tables using the same method for age-specific intercensal population estimates previously discussed and life table methods in Rowland (2003) and Preston et al. (2001). Fertility, mortality, sex differences, and dependency ratios were also evaluated to assess the impact of mortality during the measles epidemic on the demographic structure of the Åland Islands.

GFRs were calculated by dividing the total number of live births in each year by the census and intercensal estimates of females aged 15-49 in the population (Rowland, 2003). These rates, per 1,000 females aged 15-49, are charted alongside the CDRs in Figure 7.7 (see Chapter 7: Results) to illustrate the interaction between fertility and mortality in the Åland communities and to identify changing patterns in childbirth that could be related to 
either the measles or smallpox epidemics. GFRs and CDRs were chosen because of the potential for instability in the yearly age-specific population estimates.

When examining mortality in a population, it is important to consider whether there are differential impacts by sex across all ages. To avoid the effects of differential sex distribution in the population, a sex ratio was created using the age-specific death rates for each sex and study period (see, Rowland, 2003). As suggested by Rowland (2003), the agespecific mortality rates for males were divided by the age-specific mortality rates for females and multiplied by 100 to create the sex ratio used in this analysis. Note, though, that accidental deaths can skew the view of mortality because they occur far more often in the male portion of the population. Since these deaths do not reflect the effects of epidemic mortality, they were removed before calculating the age-specific mortality rate per 1,000 population for both males and females. This approach creates a ratio in which 100 is the baseline and any value over 100 is the percentage of excess male mortality.

The analyses above were chosen based upon the availability and quality of the archival data during each associated stage of research. This approach was designed to provide the best possible overview of the impact of the 1820-21 measles epidemic when compared to the 1823-24 smallpox and 1815-16 non-epidemic periods. The results of these analyses will demonstrate the increased burden of mortality for measles, the differential impact of measles mortality by age and sex, and the surprising lack of long-term demographic impacts resulting from either epidemic. 


\section{CHAPTER 7: RESULTS}

The island communities of Åland, Finland during the $19^{\text {th }}$ century consisted of a reasonably isolated population (Mielke et al., 1982,1987) large enough to sustain intermittent epidemics (Cliff and Haggett, 1985), and, most importantly, there are extant demographic records from the islands with enough detail to support epidemic research. The identification of a measles epidemic, a smallpox epidemic for comparison, and a neutral period were the first steps in the design of this analysis. Observation of the time series of measles and smallpox deaths indicate that an appropriate three study periods to analyze during the course of this research included a non-epidemic period from 1816 to 1817, an 1820-21 measles epidemic, and an 1823-24 smallpox epidemic (Figure 6.1).

The 1820-21 measles epidemic was chosen because it was larger than any other measles epidemic from the start of reliable recording (1780) prior to the start of the second epidemiological transition in Finland, which began in the last quarter of the $19^{\text {th }}$ century (Turpeinen and Kannisto, 1997). Both measles and smallpox occurred in roughly cyclical patterns during the $18^{\text {th }}$ and early 19 th century. Neither disease was endemic to the archipelago, so each had to be introduced to a sufficiently large susceptible population in order for epidemic transmission to occur.

The Åland archipelago was home to a population of 11,000 to 14,000 individuals between 1780 and 1830 (a type II population as described in Chapter 4). A spectral analysis of smallpox epidemics reported by Mielke and colleagues $(1984 ; 1987)$ determined that smallpox epidemics occurred in approximately 7-year cycles prior to the 1805 introduction of smallpox vaccination. Deaths from measles were observed during the 1785 and 1794 epidemics of smallpox (see figure 7.1), suggesting that the 7-year cycle proposed for smallpox by Mielke and colleagues reflects the amount of time required for the archipelago 
to rebuild a susceptible population (primarily through births) large enough for epidemic transmission whether that epidemic is measles or smallpox.

After the introduction of vaccination (1805) reduced the occurrence of smallpox epidemics, measles does not make a notable appearance in the death records until 1815 when 17 burials were attributed to measles mortality. It was approximately 12 years, not 7 years, before a large enough susceptible population could build back up-one which could sustain epidemic transmission of a childhood disease. This gap in the 7-year cycle of childhood epidemics was most likely the result of the mortality crisis that took place during the 1808-09 War of Finland where various diseases of overcrowding (from the occupation of Russian troops) resulted in 1400 deaths and a significant decrease in the short-term birth rate (Mielke, 2003; Mielke and Pitkänen, 1989).

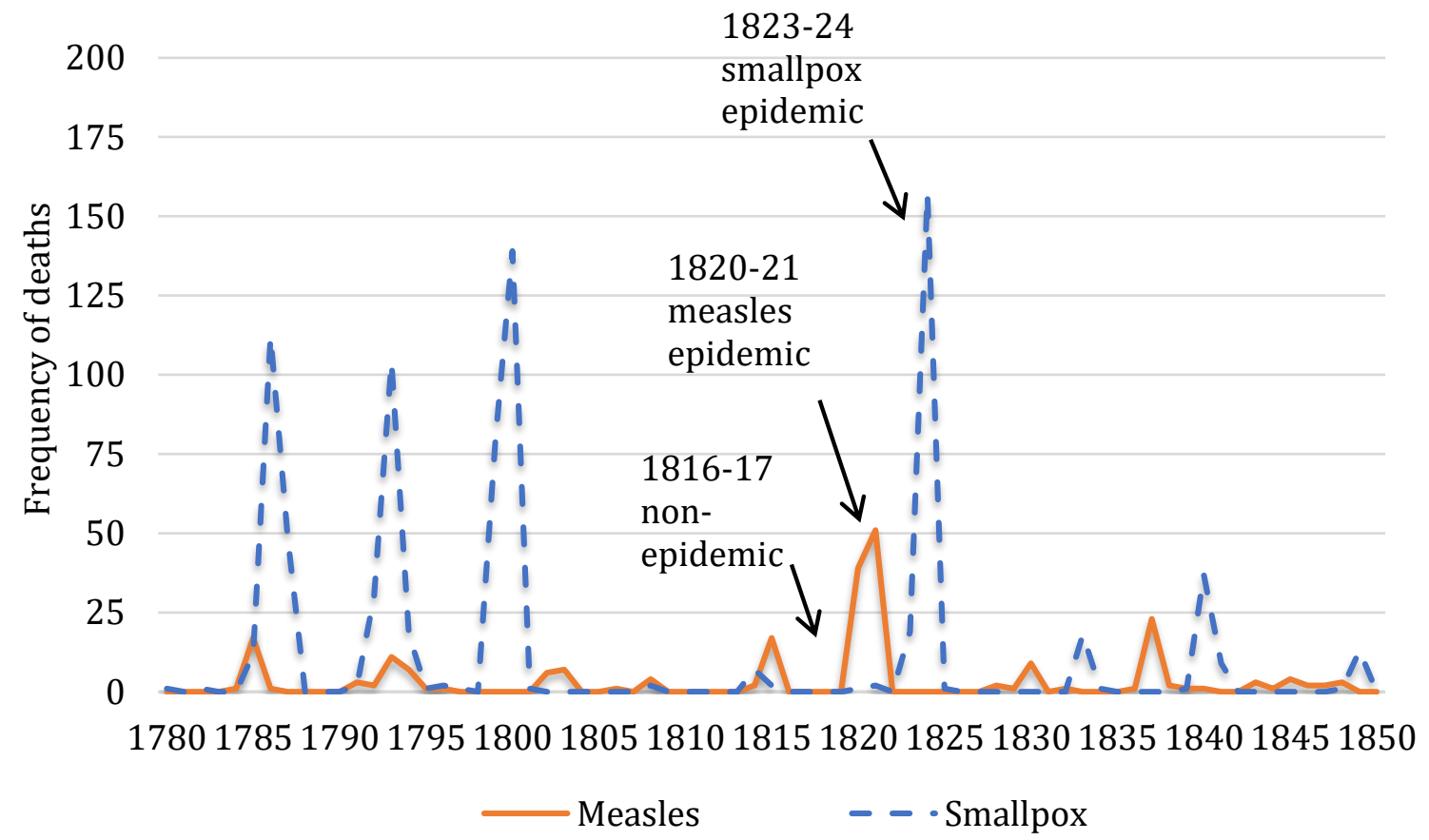

Figure 7.1. Graphic analysis of measles and smallpox deaths in Åland, Finland 1780-1850. 
Smallpox vaccination and the 1808-09 wartime mortality crisis are the primary reasons that the cycle of childhood epidemics was broken and the first measles epidemic subsequent to the war with a proportion of deaths large enough to study did not occur until 1820. Gaps in vaccination, poor vaccine efficacy, and the relatively low childhood mortality that accompanies measles epidemics are the most likely reasons the 1823-24 smallpox epidemic followed so closely behind the measles epidemic. Measles was not as visible in the historic record as smallpox, but as the primary susceptible population for both diseases experienced less smallpox mortality, measles infection emerged, resulting in enough deaths to clearly suggest an archipelago-wide epidemic had most likely occurred between 1820 and 1821.

The pattern of measles epidemics, as represented by spikes in the numbers of recorded deaths across time, is not quite as defined and appears less regular than that seen with smallpox mortality (Figure 7.1) because deaths attributed to measles account for a much smaller proportion of the infected population (Heymann, 2008). This is most likely a function of the visibility of measles epidemics in the death records, however. For example, between 1802 and 1803 only 13 burials attributed to measles mortality were recorded. A case fatality rate as high as 30\% would indicate approximately 43 cases of measles; however, the average case fatality rate for measles is only $3 \%$ (Heymann, 2008), which would suggest more than 400 cases in the archipelago. In short, a very small number of measles-attributed deaths could reflect a full measles epidemic; however, without measles case data, mathematical attempts to recreate the size of the epidemic are exercises in probability that can only provide bounds on the real epidemic size. The remainder of this study focuses on the mortality of 1820-21 epidemic, how it compares to the subsequent smallpox epidemic, and how measles mortality impacted the communities of the Åland Islands. 


\section{Age-specific Death Rates}

Age-specific mortality rates provide further insight into the mortality patterns and impact of measles and smallpox mortality in the 1820s. It is well known that mortality rates are highest among the youngest and oldest segments of a population-the most vulnerable age classes (Bengtsson and Broström, 2009; Omran, 1971; Preston and Haines, 1991). Infant mortality rates provide an approximation of the overall health of a population

(Rowland, 2003). Analyses by Trapp et al. (1983) concluded that the infant mortality of Åland between 1751 and 1935 was more similar to the high infant mortality of Eastern Europe when compared to Western Europe, which means there may be underlying aspects of Åland society or culture affecting health in the archipelago. To understand how underlying health patterns in the archipelago may have influenced mortality rates during an epidemic, infant mortality rates were calculated from 1815 to 1830 and charted in comparison to rates from Sweden and Finland (Figure 7.2).

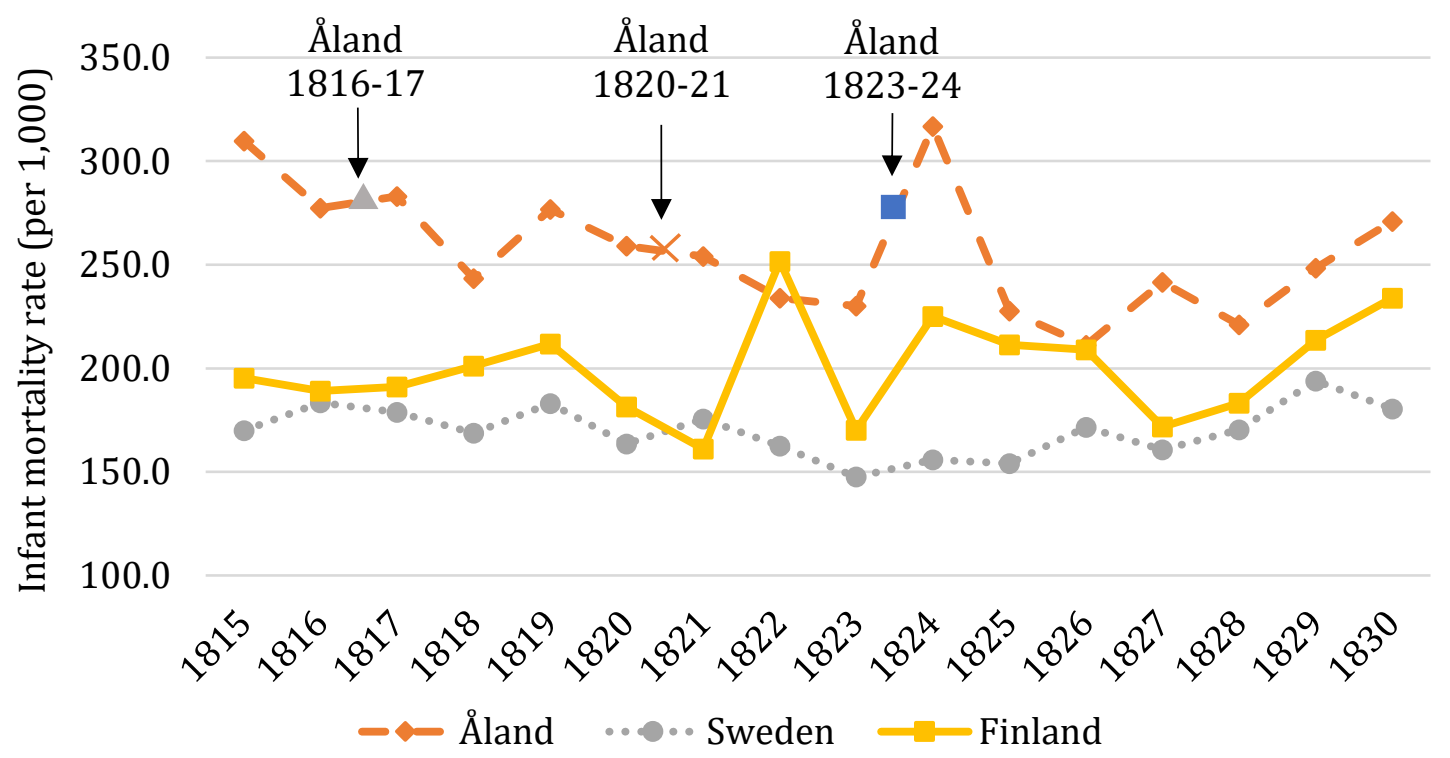

Figure 7.2. Infant mortality rates for Åland, Sweden (Human Mortality Database), and Finland (Turpeinen, 1979a). 
As expected from previous studies (Trapp et al., 1983; Turpeinen, 2000), infant mortality rates in Sweden are significantly lower than the infant mortality rates of Åland at both the $95 \%$ and $99 \%$ confidence intervals for all years from 1815 to 1830 (see Appendix C). Data were unavailable to calculate confidence intervals for Finland; however, prior to 1822, the infant mortality rates were considerably lower than that observed for Åland. The substantial peak in infant mortality observed in Finland in 1822 is thought to be due to an outbreak of smallpox (Pitkänen et al., 1989), but overall, infant mortality rates are consistently higher for Åland. This is most likely due to cyclical smallpox epidemics and other, less historically identifiable, diseases in the archipelago potentially coupled with social, cultural, economic or other factors that increase infant mortality (see Chapter 3).

Similar to the unusual W-shaped age-specific mortality of the 1918 Spanish flu, which resulted from high excess mortality among young and middle-aged adults (Chowell et al., 2010; Morens and Fauci, 2007; Olsen et al., 2006), major diseases or events can change the shape of age-specific mortality in a population. Figure 7.3 charts the age-specific mortality of Åland for each study period, the results of which provide insight into an unusual break from the traditional pattern of mortality during the 1820-21 measles epidemic. While infant mortality was similarly high in all 3 study periods, it is the mortality of the older age classes as well as school-aged children that is strikingly different during the measles epidemic.

The risk of infection, and subsequent mortality, for measles or smallpox is dependent upon the timing of the reintroduction of disease following epidemics (discussed above) and the age distribution of susceptibility. Measles and smallpox are both highly infectious childhood diseases which occur repeatedly in susceptible populations and result in long-term immunity. Studies have estimated that, prior to measles vaccination, over $90 \%$ of most populations had been exposed to measles by 20 years of age (Benjamin and Gore, 
1952; Heymann, 2008). Studies of smallpox have pointed out how, prior to smallpox vaccination, cases and deaths were primarily restricted to the youngest segments of the population (Mercer, 1985; Pitkänen et al., 1989).

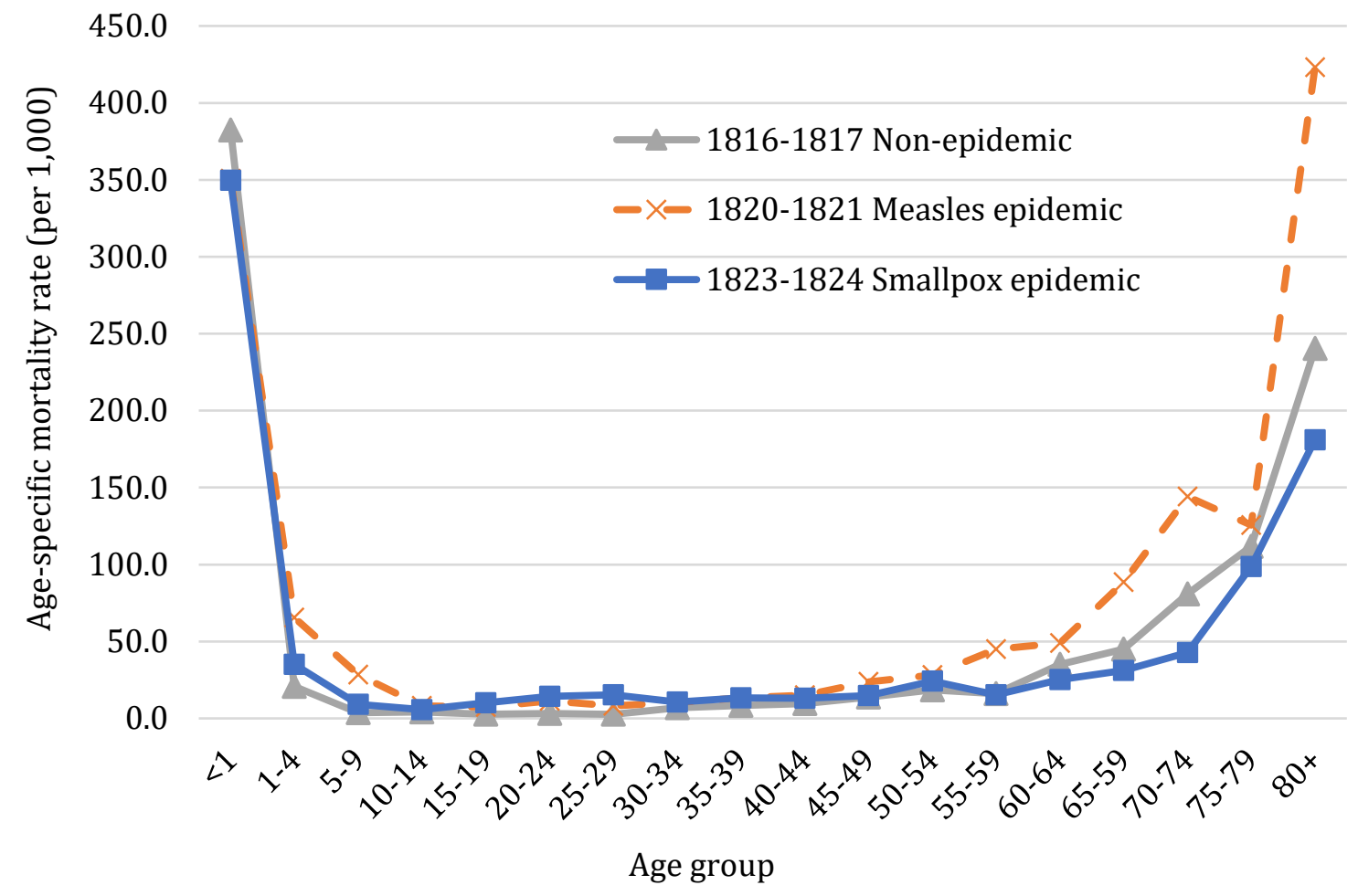

Figure 7.3 Age-specific death rates in Åland comparing a non-epidemic period to a measles epidemic and a smallpox epidemic.

The introduction of smallpox vaccination in Finland caused a small increase in adult morbidity and mortality in later epidemics, most likely due to insufficient immunity, but most cases and deaths were still in the youngest ages (Pitkänen et al., 1989). For these reasons, the age distributions of measles and smallpox mortality are expected to have similar patterns where the majority of cases and disease-specific mortality occurred in the youngest age classes. Surprisingly, the non-epidemic period had the highest age-specific mortality for Åland infants; though high infant mortality was not unusual for the islands 
regardless of the presence or absence of identifiable epidemics. Yet, the 1820-21 measles epidemic study period had increases in mortality between ages 1 and 9 and marked increases in older-age mortality over both the control and smallpox periods.

It is difficult to separate the effects of smallpox vaccination from mortality patterns during the smallpox period. Vaccination could result in lower smallpox mortality during the 1823-24 epidemic than seen in previous smallpox epidemics. Except for individuals under age 20 (those most likely to have been vaccinated for smallpox prior to the epidemic), mortality for all other age groups during the smallpox epidemic should be comparable to most historical smallpox epidemics in this region of the world. It is possible that vaccination resulted in lower smallpox mortality for ages 1 to 9 during the 1823-24 smallpox period which may make measles mortality during the 1820-21 epidemic look higher than expected. However, this does not explain the unusual pattern of mortality at older ages during the measles epidemic. The higher mortality seen during the 1820-21 measles epidemic, especially at older ages, suggests that the measles epidemic mortality experience is different from that of a smallpox epidemic or during a non-epidemic period for the oldest members of the communities. This unusual pattern of mortality for these three age groups will be further discussed in the next section where analysis of the distribution of disease categories and examination of other relevant disease translations provide further insight into the mechanisms increasing mortality in the older segments of Åland communities.

\section{Excess mortality and frequency analysis}

Further exploration of this differential mortality experience used excess mortality ratios to assess differences in the burden of disease. In addition, frequency analyses were used to examine differences in the distribution of deaths between each study period. The disease categories described in Table 5.2 were used for these analyses, and the counts of 
deaths in each category were used in the calculation of excess mortality ratios and chisquare frequency analysis. As indicated in Chapters 5 and 6, for some analyses measles and smallpox were removed to assess the burden of mortality without the influence of epidemic deaths. Accidental deaths were also removed from some analyses as these deaths are unpredictable and do not reflect the health or disease burden of the study communities.

Excess mortality ratios provide a measure of the burden of mortality during the periods containing the measles and smallpox epidemics, measured relative to the baseline period (Table 7.1). The closer the value is to 1 , the more similar the mortality is to the baseline for that period. Results of this analysis indicate that deaths from all causes (without accidental deaths) during the measles epidemic were approximately $64 \%$ higher than the baseline, but deaths from all causes (without accidental deaths) were only 23\% above the baseline during the smallpox epidemic.

Table 7.1 Excess mortality ratios for the Åland archipelago

\begin{tabular}{lccc} 
Study period & $\begin{array}{c}1816-17 \\
\text { non-epidemic }\end{array}$ & $\begin{array}{c}1820-21 \\
\text { measles } \\
\text { epidemic }\end{array}$ & $\begin{array}{c}1823-24 \\
\text { smallpox } \\
\text { epidemic }\end{array}$ \\
\hline $\begin{array}{l}\text { Total number of deaths } \\
\text { (without accidental deaths) }\end{array}$ & 541 & 889 & 666 \\
$\begin{array}{l}\text { Excess mortality ratio } \\
\text { (without accidental deaths) }\end{array}$ & - & 1.64 & 1.23 \\
\hline & 541 & 798 & 511 \\
\hline $\begin{array}{l}\text { Total number of deaths } \\
\text { (without epidemic/accidental deaths) }\end{array}$ & & & \\
$\begin{array}{l}\text { Excess mortality ratio } \\
\text { (without epidemic/accidental deaths) }\end{array}$ & - & 1.48 & 0.94 \\
\hline \hline
\end{tabular}

To eliminate the effects of epidemic mortality, a second excess mortality ratio was created by removing all accidental deaths as well as deaths due to the disease causing the 
epidemic in question. When smallpox was removed, the analysis indicated that other causes of death resulted in $6 \%$ lower mortality than seen during the non-epidemic period. In contrast, during the measles epidemic the burden of death (without considering deaths from measles or accidents) was still 48\% higher than during the non-epidemic period. These results clearly indicate the presence of excess mortality not attributed to measles during a measles epidemic. Examination of the age-specific death rates (Figure 7.3) indicates that much of the excess mortality from other causes of death occurs in the older segments of the population during the measles epidemic study period. This mortality is caused by other diseases or poor health outcomes which may be the result of a measlesinduced immunocompromised segment of the population or perhaps an unusual blend of outbreaks occurring at the same time.

A chi-square analysis was used to evaluate if the excess mortality ratios of 0.94 and 1.48 were significantly different from baseline non-epidemic period (which would, by definition, have an excess mortality ratio of 1). As expected, the measles epidemic was significantly different from the 1816-17 non-epidemic period $\left(\chi^{2}=45.78\right.$, d.f. $\left.=1, p<0.001\right)$; confirmation that there is significantly higher mortality that is not attributed to measles during this measles epidemic. In contrast, the excess mortality not attributed to smallpox or accidental deaths was not significantly different than what would be expected by chance $\left(\chi^{2}\right.$ $=2.62$, d.f. $=1, \mathrm{p}>0.1$ ). In short, during the smallpox period, all excess mortality was attributable to either smallpox deaths or accidental deaths.

Additional chi-square frequency analyses were conducted to shed light on how the distribution of deaths differed between the study periods. Results indicate that the distribution of non-epidemic deaths during both the measles and smallpox epidemics were significantly different from the distribution of deaths during the baseline period. The 
aggregate chi-square value for excess mortality from other causes of death during the measles and smallpox epidemics are significant at the 0.001 level (Table 7.2).

Table 7.2. Chi-square analysis comparing the frequency of deaths from specific causes for periods during the 1820-21 measles and 1823-24 smallpox epidemics

\begin{tabular}{cccccc} 
Time period & Cause of death & Observed & Expected 1 & $\begin{array}{c}\text { Chi-square } \\
\text { value }\end{array}$ & $\begin{array}{c}\text { Adjusted }^{2} \\
\text { residual }^{2}\end{array}$ \\
\hline & Respiratory & 140 & 187.52 & 12.04 & $\mathbf{- 5 . 9 6}$ \\
1820-21 & Gastrointestinal & 42 & 75.01 & 14.53 & $\mathbf{- 6 . 2 2}$ \\
measles & Old age & 111 & 72.12 & 20.95 & $\mathbf{7 . 7 1}$ \\
epidemic & Accidental & 17 & 34.62 & 8.97 & $\mathbf{- 4 . 8 2}$ \\
& Other/unknown & 505 & 445.73 & 7.88 & $\mathbf{7 . 1 2}$ \\
\hline
\end{tabular}

Chi-square value $=64.37$

Critical value $(.001,4)=13.28$

\begin{tabular}{cccccc}
\hline \hline & Respiratory & 75 & 126.09 & 20.70 & $\mathbf{- 6 . 4 1}$ \\
$\begin{array}{c}\text { 1823-24 } \\
\text { smallpox }\end{array}$ & Gastrointestinal & 47 & 50.44 & 0.23 & -0.65 \\
epidemic & Old age & 58 & 48.50 & 1.86 & 1.89 \\
& Accidental & 37 & 23.28 & 8.09 & $\mathbf{3 . 7 5}$ \\
& Other/unknown & 331 & 299.70 & 3.27 & $\mathbf{3 . 7 6}$ \\
\hline
\end{tabular}

Chi-square value $=34.15$

Critical value $(.001,4)=13.28$

1The 1816-17 non-epidemic period was used as the reference comparison for all categories. ${ }^{2}$ Bold values indicate statistical significance compared to \pm 1.96 , the critical z-values for $\alpha=.05$.

The individual components for both epidemics indicate significant differences in non-epidemic causes of death between the two epidemics. For example, during both the measles and smallpox epidemics, fewer than expected deaths were attributed to respiratory causes and more deaths were indicated as being due to other/unknown causes. During the measles epidemic, there was a significant increase in the number of deaths attributed to old age and significantly fewer deaths from gastrointestinal causes. These results suggest that 
measles and smallpox have differential effects on the distribution of non-epidemic causes of death.

Proportionate mortality ratios provide further assessment of the categories of mortality in this study. By charting the PMR for each cause of death group across time, it is possible to look at how the burden of mortality from each category changes prior to, and following, the measles and smallpox epidemics (Figure 7.4). The most striking observation is the large proportion of deaths that are attributed to the Other/Unknown category.

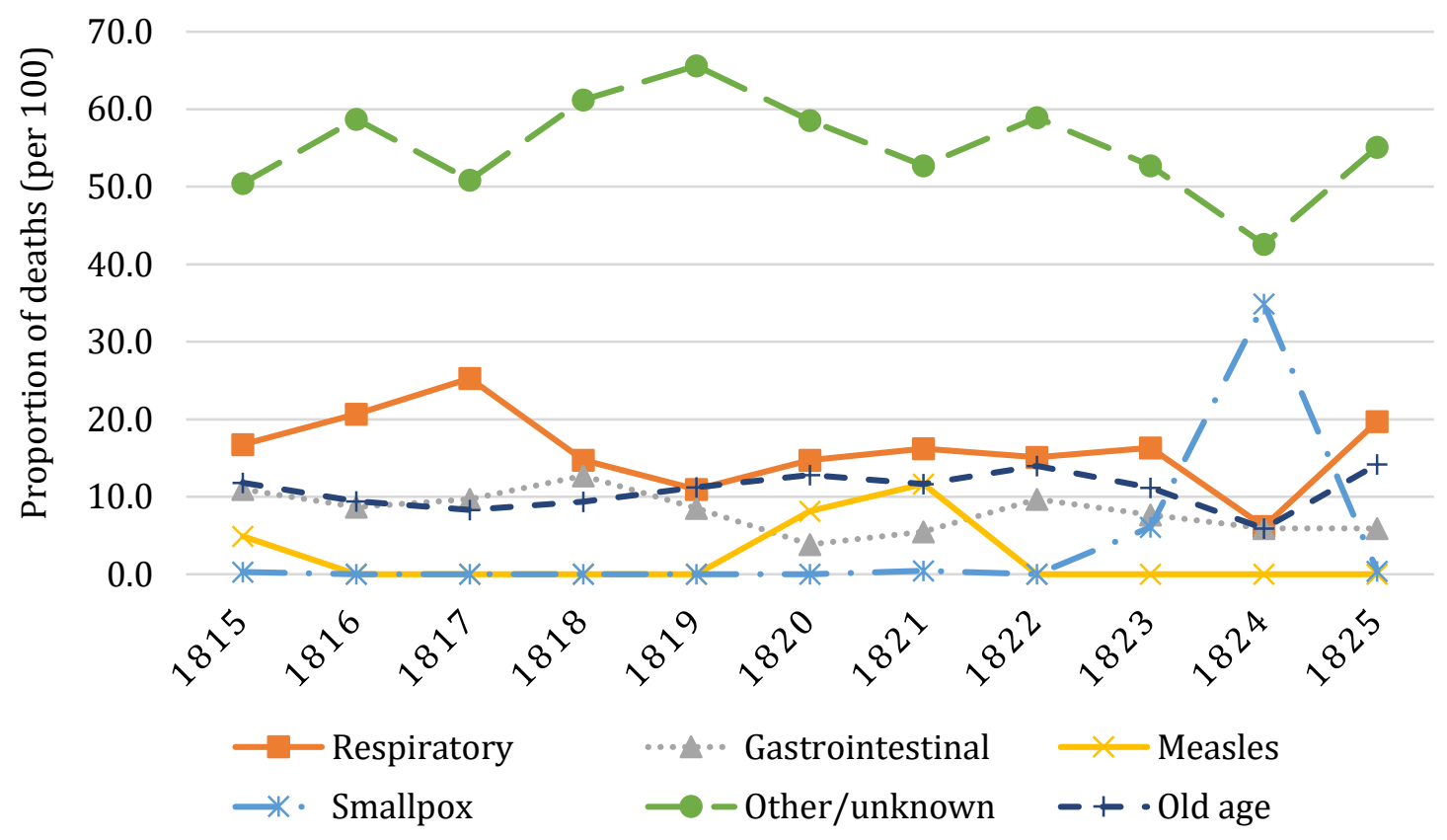

Figure 7.4. Comparison of the proportionate mortality ratio from each cause of death to illustrate mortality trends in epidemic and non-epidemic years (excludes accidental deaths).

Variation in this category is to be expected as the presence of known and unknown disease may fluctuate from year to year. For example, the high mortality of smallpox in 1824 results in the proportion of deaths from smallpox increasing, which means that fewer 
individuals are left to succumb to other causes of death. Subsequently, there is a much larger drop in the Other/Unknown category in 1824 compared to other years. In turn, the presence of other, less clearly identifiable epidemics, would cause the proportion of death represented by this category to increase. In short, all causes of death categories will vary based upon the other potential causes of death present in the population at any given time; however, the Other/Unknown category is consistently much higher than the other causes of death and may be useful in indicating other mortality processes occurring in the population.

The "unknown" category encompasses causes of deaths that were missing or where the translation was not a reliable indicator of the true cause of death. For example, the often used "unknown childhood disease" does not provide a diagnosis that can be used for specific analysis as it could refer to any number of different conditions, infectious or noninfectious, that afflict children. The "other" category includes various translations of diseases such as "rapid illness", "chest inflammation", or "internal pain" which cannot be reliably correlated to a modern equivalent (Table 7.3). In contrast, some cause of death translations are recognizable, such as 'malaria' or 'scarlet fever'; however, it is important to remember that the cause of death may not in fact be either of these diseases. For example, 76 deaths during the 1820-21 period were attributed to malaria. These deaths may have been caused by malaria, or, the presence of malaria in the islands may have led to the misdiagnosis of another disease with similar symptoms-a circumstance which could artificially increase the prevalence of malaria in the population. From another point of view, a portion of the 50 deaths from fever during this time period could have actually been the result of an inability to diagnose the death as being caused by malaria. With uncertain diagnoses, it becomes difficult to assess the actual burden of disease in a community or how that disease may be interacting with other diseases such as measles or smallpox. More extensive research on the reliability of these diagnoses and translations is necessary before 
they can be determined reliable for individual analysis. Still, some insight can be gained by looking at the breakdown of translations for age groups that had clear excess mortality (5-9, $50+)$.

Table 7.3. A sample of translations that were included in the Other/unknown cause of death category

\begin{tabular}{lccc}
$\begin{array}{l}\text { Unknown or other } \\
\text { cause of death }\end{array}$ & $\begin{array}{c}1816-17 \\
\text { non- } \\
\text { epidemic }\end{array}$ & $\begin{array}{c}\text { 1820-21 } \\
\text { measles } \\
\text { epidemic }\end{array}$ & $\begin{array}{c}1823-24 \\
\text { smallpox } \\
\text { epidemic }\end{array}$ \\
\hline Fever & 9 & 50 & 13 \\
Malaria & 3 & 76 & 4 \\
Scarlet fever & 0 & 17 & 0 \\
Swelling & 14 & 71 & 22 \\
Unknown childhood & 59 & 111 & 94 \\
disease & 115 & 76 & 81 \\
Unknown death & 52 & 33 & 22 \\
No cause listed & & &
\end{tabular}

To illustrate the impact of diagnoses on calculated mortality rates, consider the causes of death reported in the Other/unknown for children aged 1-4 (Table 7.4) and 5-9 (Table 7.5) during the measles epidemic. While these diagnoses may not be fully accurate, they can provide insight into the symptoms experienced by the decedents and the perception of disease in the archipelago. Children aged 1-9 experienced higher levels of mortality during the measles epidemic when compared to either the smallpox or the nonepidemic period. It is possible that mortality for this age group would look similar to smallpox if vaccination was not present in the archipelago; however, the role of measlesinduced immunosuppression (as discussed in Chapter 4) should still be considered. Tables 7.4 and 7.5 contain counts of cause of death translations for children aged 1 through 9.

Respiratory and gastrointestinal symptoms are known to accompany complications from measles (Perry and Halsey, 2004), though most measles deaths are from secondary 
infections. This may explain increases in causes of death identified by symptoms such as unknown illness, fever, edema, tuberculosis, and tonsillitis (or something similar). In contrast, deaths from scarlet fever could be a second epidemic in the archipelago, or a misdiagnosis of measles. Consequently, co-occurring morbidities such as pertussis, malaria, or scarlet fever cannot be ruled out as contributing to excess mortality during the measles epidemic in this analysis.

Table 7.4. Breakdown of identifiable cause of death translations for individuals aged 1 to 4 years.

\begin{tabular}{lccc}
$\begin{array}{l}\text { Age 1-4 cause of death } \\
\text { translations }\end{array}$ & $\begin{array}{c}1816-17 \\
\text { non-epidemic }\end{array}$ & $\begin{array}{c}1820-21 \\
\text { measles } \\
\text { epidemic }\end{array}$ & $\begin{array}{c}1823-24 \\
\text { smallpox } \\
\text { epidemic }\end{array}$ \\
\hline Measles & 0 & 35 & 0 \\
Smallpox & 0 & 0 & 48 \\
Gastrointestinal & 6 & 9 & 5 \\
Respiratory & 9 & 12 & 5 \\
pertussis & 7 & 0 & 0 \\
tonsillitis & 0 & 1 & 0 \\
tuberculosis & 0 & 0 & 0 \\
indeterminant & 2 & 11 & 5 \\
Other & 5 & 53 & 11 \\
fever & 3 & 11 & 3 \\
typhus & 0 & 0 & 0 \\
edema & 0 & 12 & 2 \\
malaria & 0 & 13 & 1 \\
syphilis & 0 & 4 & 0 \\
scarlet fever & 0 & 4 & 0 \\
indeterminant & 2 & 9 & 5 \\
Unknown & 20 & 47 & 16 \\
\hline Total & 40 & 156 & 85 \\
\hline \hline
\end{tabular}

Table 7.5. Breakdown of identifiable cause of death translations for individuals aged 5 to 9 years. 


\begin{tabular}{lccc}
$\begin{array}{l}\text { Age 5-9 cause of death } \\
\text { translations }\end{array}$ & $\begin{array}{c}1816-17 \\
\text { non-epidemic }\end{array}$ & $\begin{array}{c}1820-21 \\
\text { measles } \\
\text { epidemic }\end{array}$ & $\begin{array}{c}1823-24 \\
\text { smallpox } \\
\text { epidemic }\end{array}$ \\
\hline Measles & 0 & 14 & 0 \\
Smallpox & 0 & 0 & 16 \\
Gastrointestinal & 0 & 3 & 0 \\
Respiratory & 1 & 7 & 2 \\
pertussis & 1 & 0 & 0 \\
tonsillitis & 0 & 3 & 0 \\
tuberculosis & 0 & 1 & 1 \\
indeterminant & 0 & 3 & 1 \\
Other & 4 & 34 & 1 \\
fever & 1 & 5 & 0 \\
typhus & 1 & 0 & 0 \\
edema & 1 & 10 & 0 \\
malaria & 0 & 1 & 0 \\
syphilis & 0 & 3 & 0 \\
scarlet fever & 0 & 7 & 0 \\
indeterminant & 1 & 8 & 1 \\
Unknown & 2 & 10 & 1 \\
\hline Total & 7 & 68 & 20 \\
\hline \hline
\end{tabular}

The presence of measles appears to accompany a shift in mortality to other diseases or health conditions that are less identifiable and generate greater mortality in the population over 50 years of age. Table 7.6 includes counts of disease categories and selected translations within the respiratory and other categories to provide more insight into the burden of diseases affecting the older individuals of the population. Significant increases in causes of death from "old age", other, or unknown diseases are important, but cannot explain the disease processes causing excess mortality in the archipelago. Examination of the translations in the "other" category, such as tuberculosis and malaria, suggest a situation of co-circulating diseases. In contrast, translations of pneumonia, pleurisy, fever, or edema may suggest secondary infections. Pneumonia is a common secondary infection (which would be difficult to separate from pleurisy at this time) and fever and edema are symptoms that correspond to an inflammatory immune response. The potential impact of 
measles exposure and immune suppression on the older portion of the population will be discussed in detail in the next chapter.

Table 7.6. Breakdown of identifiable cause of death translations for individuals aged 50 or more years.

\begin{tabular}{lccc}
$\begin{array}{l}\text { Age 50+ Cause of death } \\
\text { translations }\end{array}$ & $\begin{array}{c}1816-17 \\
\text { non-epidemic }\end{array}$ & $\begin{array}{c}1820-21 \\
\text { measles } \\
\text { epidemic }\end{array}$ & $\begin{array}{c}1823-24 \\
\text { smallpox } \\
\text { epidemic }\end{array}$ \\
\hline Old age & 45 & 111 & 56 \\
Gastrointestinal & 10 & 8 & 3 \\
Respiratory & 56 & 66 & 27 \\
pneumonia/pleurisy & 19 & 19 & 9 \\
tuberculosis & 17 & 25 & 9 \\
indeterminant & 20 & 22 & 9 \\
Other & 28 & 84 & 43 \\
malaria & 1 & 27 & 2 \\
stroke & 9 & 6 & 11 \\
rapid illness & 2 & 6 & 5 \\
edema & 5 & 17 & 10 \\
tumor/cancer & 1 & 3 & 2 \\
fever & 3 & 14 & 0 \\
indeterminant & 7 & 11 & 13 \\
Unknown & 9 & 10 & 6 \\
\hline Total & 148 & 279 & 135 \\
\hline \hline
\end{tabular}

These analyses indicate that during the measles epidemic there was a significant increase in non-measles mortality from "old age" and other or unknown causes of death and a significant decrease in the other categories of death (Table 7.2). In comparison, results suggest that there was a significant increase in non-smallpox mortality only for other, unknown, and accidental deaths. Similar to the measles epidemic, respiratory deaths were significantly lower during the smallpox epidemic. Of interest is the fact that the proportionate mortality ratios for both respiratory and other/unknown categories were elevated during 1816-17 baseline period (Figure 7.4). The increased proportion of deaths 
from respiratory and other/unknown causes during the 1816-17 period suggests the presence of either multiple co-circulating respiratory illnesses (such as tuberculosis and pneumonia/pleurisy) or an epidemic of a respiratory disease that does not always present with characteristic symptoms.

Overall, this analysis demonstrates, at a minimum, that the presence of measles does not reduce the impact of other causes of death (perhaps due to low overall mortality of measles in comparison to smallpox). During the smallpox epidemic, all excess mortality could be attributed to smallpox and there were no significant changes in other cause of death categories. This is most likely due to the removal of susceptible children who died of smallpox instead of other respiratory diseases. In contrast, unusually high mortality rates, larger than either the baseline or the smallpox epidemic, for individuals age 55 or older were observed in the death records during the measles epidemic. The presence of excess mortality during the measles epidemic is undeniable; however, the link between measlesinduced immune suppression (discussed in Chapter 4) and excess mortality is not conclusive. The known biological interaction with measles and the immune system and the potential implications for excess mortality during the measles epidemic will be explored further in the next chapter.

\section{Long-term Demographic Consequences of Epidemic Mortality}

It has been demonstrated that high mortality events, also referred to as crisis mortality, can have long lasting demographic impacts, particularly in smaller populations (Mielke and Pitkänen, 1989; Palloni, 1987; Watkins and Menken, 1988). Åland communities clearly experienced non-epidemic excess mortality above that expected during an epidemic period. This section is focused on understanding what effect, if any, that excess mortality had on the demographic structure of the archipelago. Demographic analyses are used to determine 
differences in mortality experiences by sex and the overall impact of birth rates and fertility on the population structure to assess whether excess mortality occurring during a measles epidemic resulted in major demographic impacts on Åland communities.

To compare epidemic mortality between study periods, it is necessary to ensure that each study period has a similar population composition. Figures 7.5 and 7.6 provide population pyramid comparisons between each epidemic study period (measles in 1820-21 and smallpox in 1823-24) to the baseline non-epidemic period in 1816-17. Each population pyramid demonstrates small differences between the two study periods, but an overall similarity in population structure. Notably, each also demonstrates the wide base expected in a population that is not employing measures to limit conception or birth as well as slightly larger male populations at younger ages.

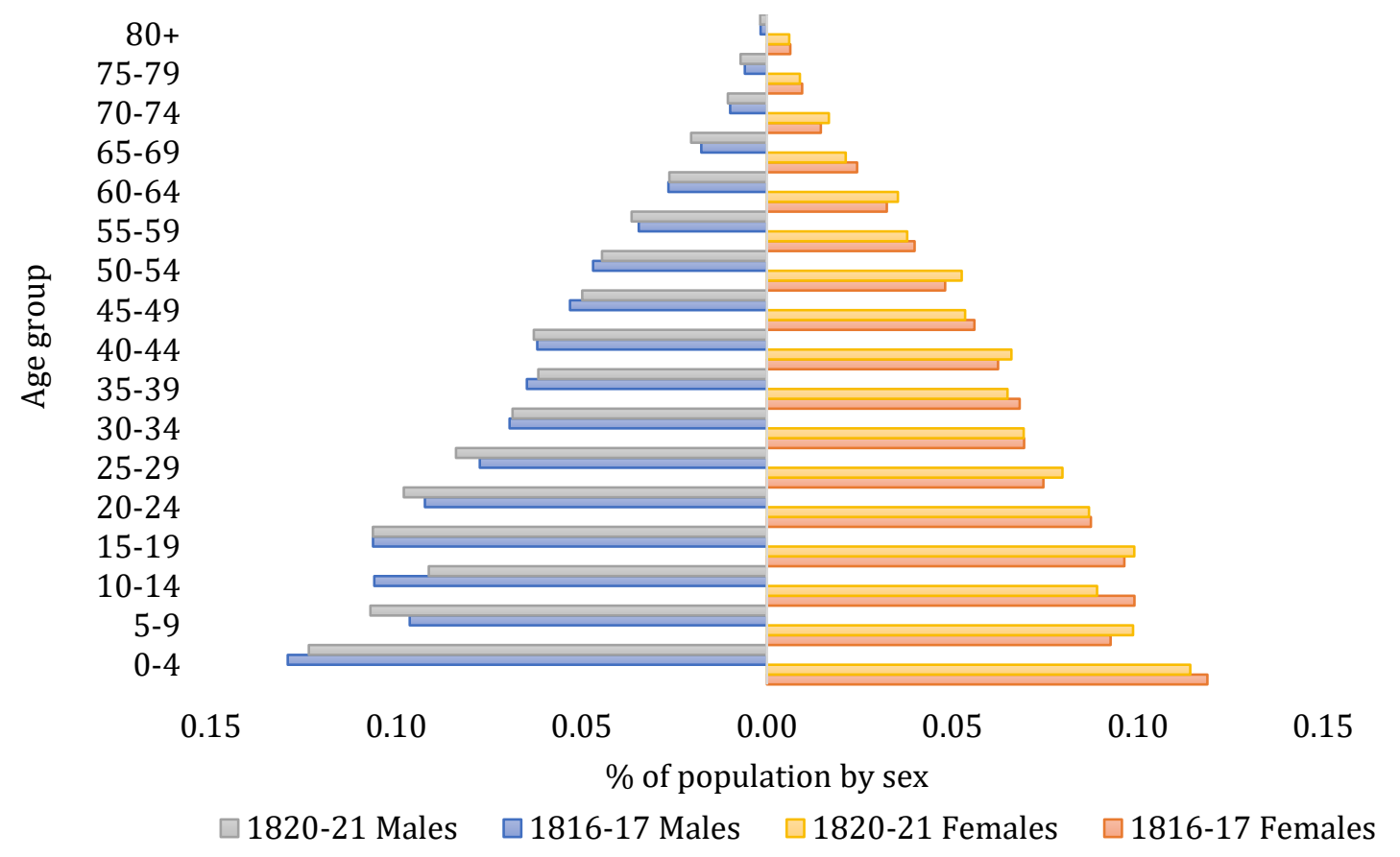

Figure 7.5. Population pyramid comparing the 1816-17 baseline population to the 1820 21 measles epidemic period population. 


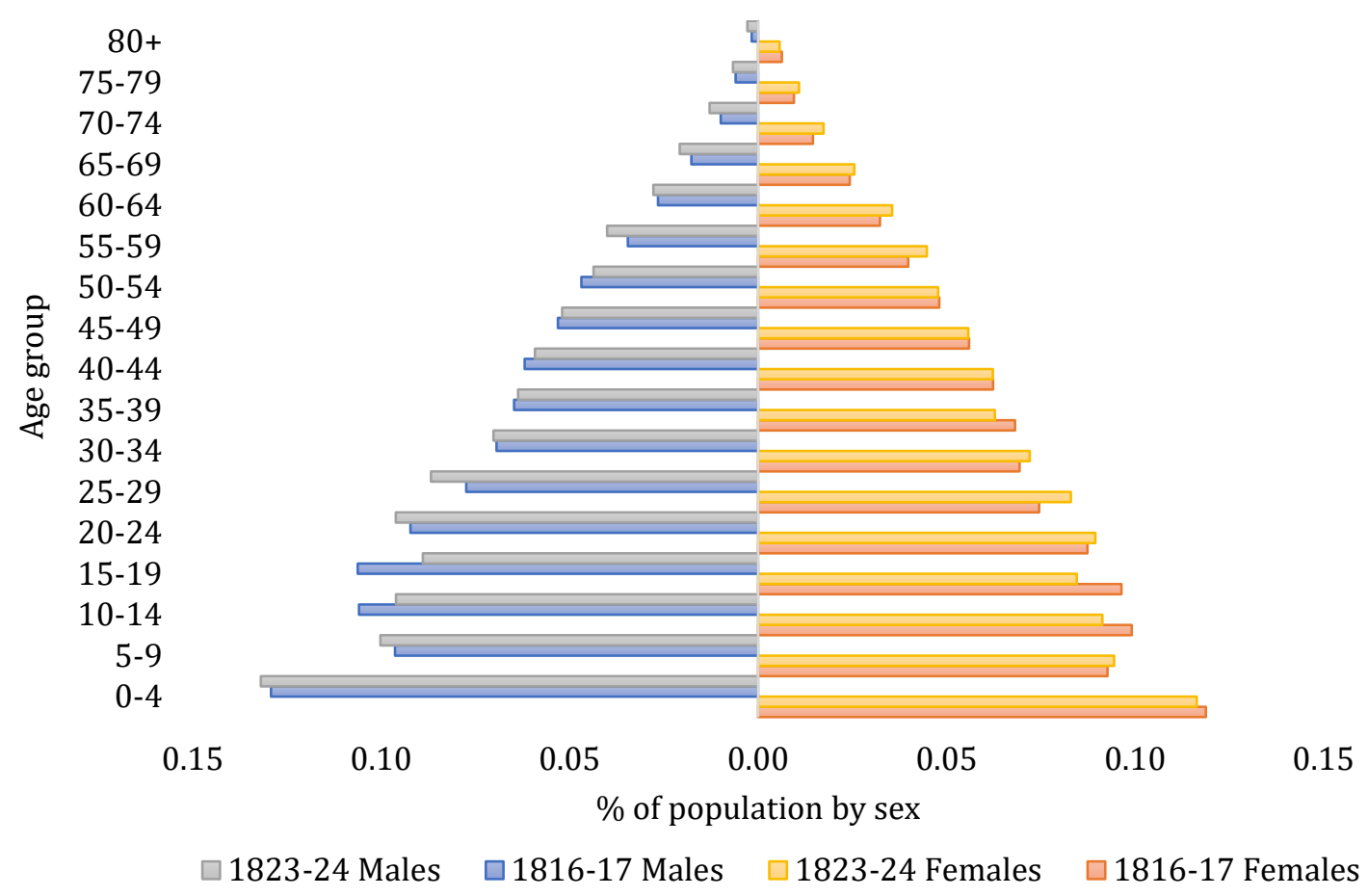

Figure 7.6. Population pyramid comparing the 1816-17 baseline population to the 1823 24 smallpox epidemic period population.

Life expectancy at birth $\left(\mathrm{e}_{0}\right)$ is a measure often used to evaluate the mortality experience of a population, and life expectancy values reflect the mortality occurring in a population at a given period in time. Life tables were constructed using intercensal population estimates for the island-wide population of Åland (see Appendix D). Table 7.7 provides a comparison of life expectancy values at selected ages for each study period. Mortality from all causes was especially elevated for both children and older individuals during the measles epidemic, while mortality during the smallpox epidemic was only slightly elevated at any age. In the older segments of the population, life expectancy values are comparable between the smallpox and non-epidemic periods. This comparison illustrates that the impact on life expectancy at birth, and at other ages, is much greater in the Åland Islands during the measles epidemic. 
Table 7.7. Average life expectancy at selected ages

\begin{tabular}{lccc} 
Age group & $\begin{array}{c}1816-17^{*} \\
\text { non-epidemic } \\
\text { period }\end{array}$ & $\begin{array}{c}1820-21^{*} \\
\text { measles } \\
\text { epidemic }\end{array}$ & $\begin{array}{c}1823-24^{*} \\
\text { smallpox } \\
\text { epidemic }\end{array}$ \\
\hline Birth & 38.94 & 26.21 & 33.92 \\
$5-9$ & 56.76 & 42.51 & 49.33 \\
$15-19$ & 48.91 & 39.98 & 42.73 \\
$45-49$ & 24.33 & 19.22 & 26.19 \\
$65-69$ & 11.09 & 8.17 & 13.85 \\
$70-74$ & 8.36 & 6.31 & 10.70 \\
$75-79$ & 6.35 & 5.08 & 7.61 \\
$80+$ & 4.33 & 2.32 & 5.54 \\
\hline \hline
\end{tabular}

*average life expectancy for 2-year period by age group

Figure 7.7 provides an overview of the average age at death (sum of age and life expectancy) for the same age groups from 1815 to 1830 . The declines in life expectancy are, as expected, clearly visible during the epidemic periods. Between 1815 and 1830, infants and children age 5-9 reflect the most variability in life expectancy. This is likely because younger individuals are more susceptible to childhood diseases and the mortality experience of a population levels out as individuals approach adulthood. As life expectancy is a function of mortality, the population rebounds quickly once major mortality-causing events are over. Still, there are some decreases in life expectancy for infants and young adults in 1829 and 1830 suggesting the presence of one large or several small negative health events in the population that were not easily visible in the burial records. For historical studies in which recorded causes of death may not readily identify major causes of mortality (such as influenza or dysentery), life expectancy at birth may help to identify historical years in which mortality should be more carefully investigated.

During large mortality events, fertility can be affected if young girls and women of child-bearing years suffer mortality disproportionate to non-epidemic years. The age- 
specific mortality rates discussed above indicate that excess mortality was observed in individuals aged 1-14 and 50 years or older. Figure 7.8 demonstrates a slow decline in the generalized fertility rate between 1816 and 1820, followed by a slow increase from 1821 to 1828. When compared to the crude death rate, it appears as though there may be a negative relationship in which fertility increases as mortality decreases, and vice versa.

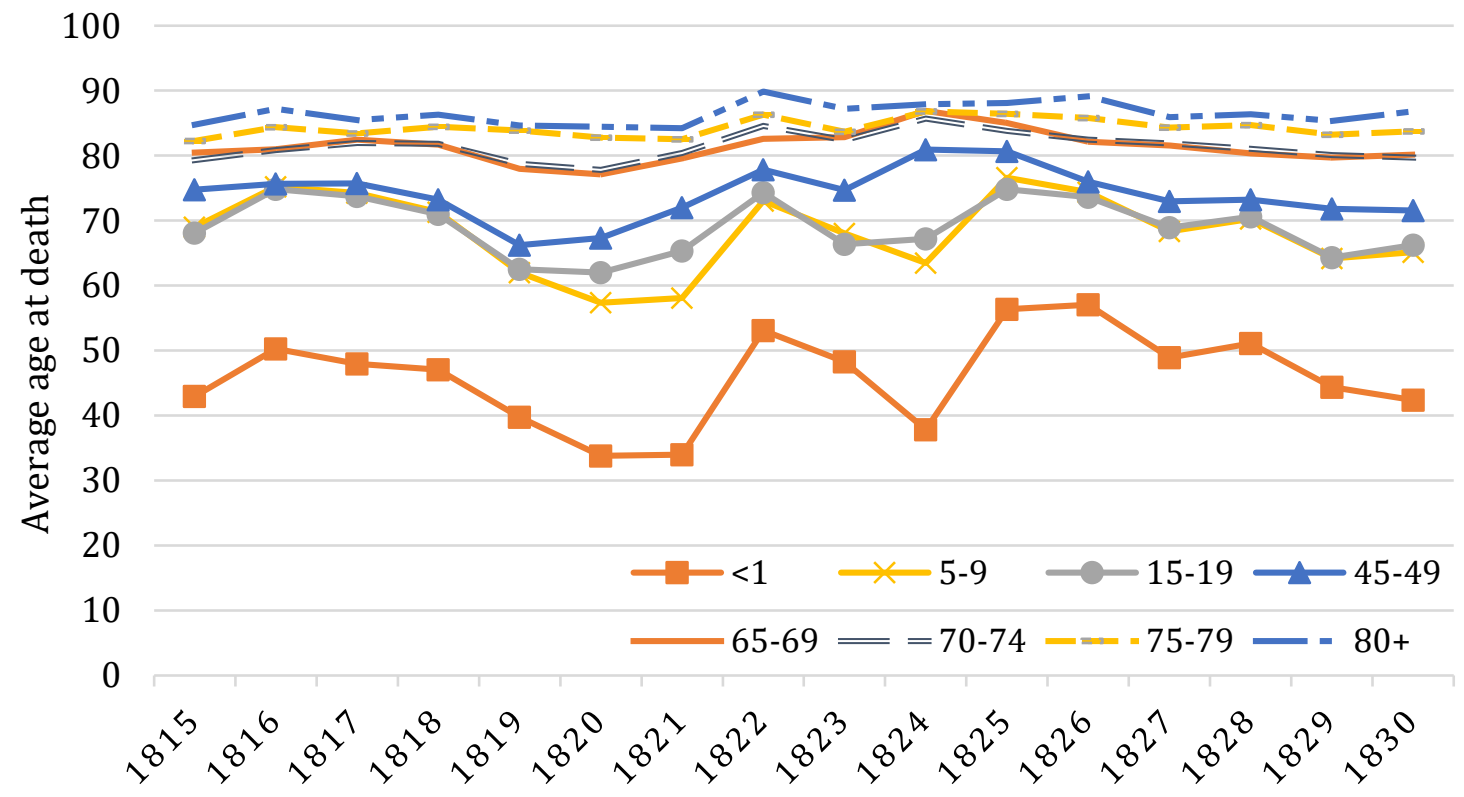

Figure 7.7. Expected age at death, calculated as the sum of the lowest age in the interval and the life expectancy of that age interval for years 1815 to 1830.

Further analyses looked at the male-to-female sex ratios to determine if there were differences in mortality between the sexes that might have a demographic impact on the archipelago's communities. Sex ratios, when calculated across age-groups, are a useful way to look at the demographic makeup of a population as a whole in relation to the mortality of that population. Accidental deaths were removed from this analysis because more males die from accidents than females and these deaths do not reflect the effects of epidemic mortality on the population. To avoid misinterpretation due to more males or females in a 


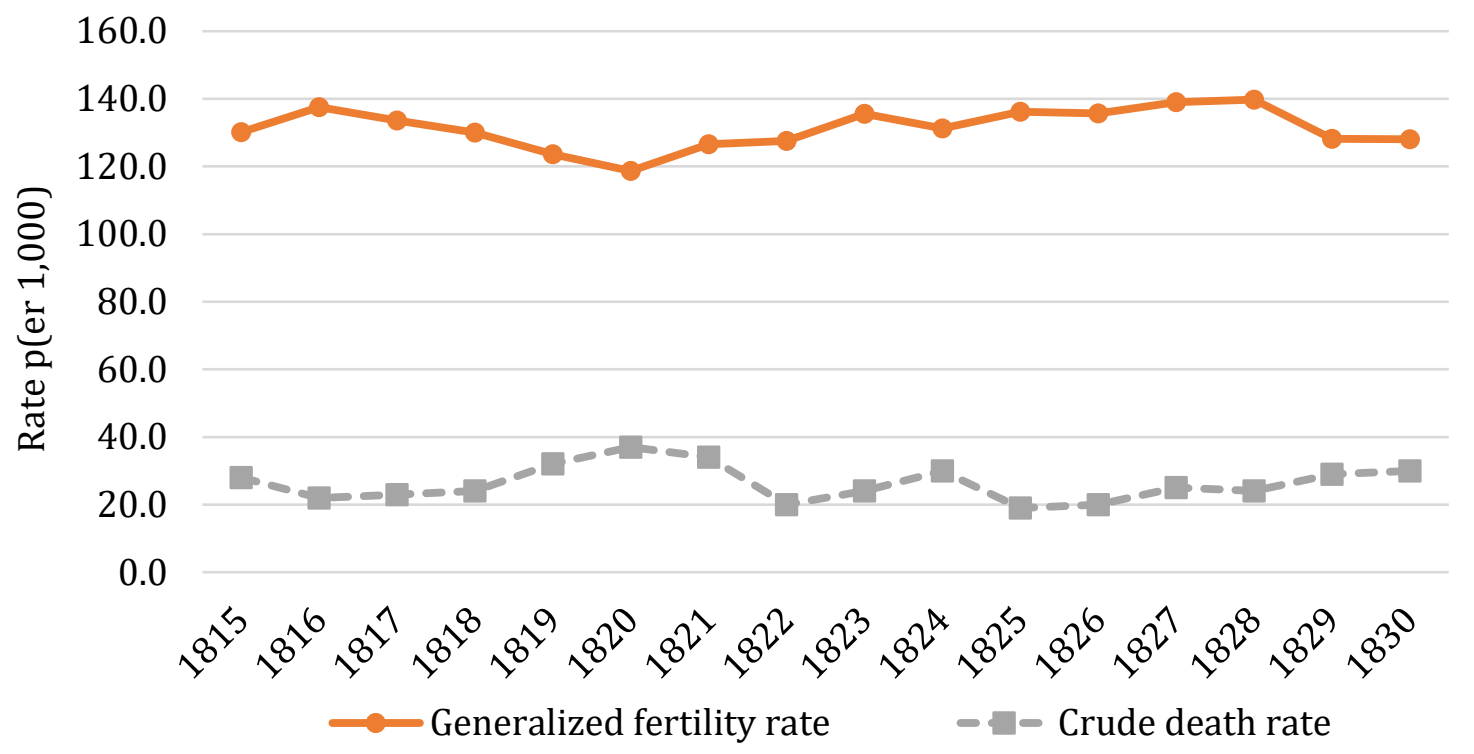

Figure 7.8. Crude death rates and generalized fertility rates per 1,000 people from 1815 1830.

population, this analysis used ratios of male death rates to female death rates for each age category in each study period. Table 7.8 illustrates the differences in male and female mortality between each study period.

The non-epidemic period shows more age classes with higher female mortality when compared to the two epidemic periods. The sex ratios in Table 7.8 illustrate that both measles and smallpox epidemics are accompanied by increased male mortality; however, the increased male mortality during the measles epidemic is much more pronounced than either of the other two periods. Still, there are no clear patterns which might explain why excess male mortality occurs more often during each epidemic period. Figure 7.9 shows the excess male mortality, in combined age groups, for the entire archipelago between 1815 and 1830 (all accidental deaths removed).

The age groups charted in Figure 7.9 were selected based on expected mortality patterns during a childhood epidemic and the age-specific mortality patterns observed in Figure 7.3. The infant age class was chosen because it is a particularly vulnerable segment of 
the population and the factors impacting infant mortality may not apply to other age groups. The age group from 1 to 19 years was chosen because the classic model of childhood epidemics such as measles and smallpox highlights individuals under 20 years of age as the primary susceptible population. The age group from 20 to 49 was chosen for the similarity in mortality between all three study groups, while the last age group was designated from 50 years on because of the unusually high mortality of individuals over 50 years of age during the measles epidemic (see Figure 7.3).

Table 7.8. Sex ratio of age-specific death rates, males per 100 females.

\begin{tabular}{lccc} 
Age & $\begin{array}{c}1816-17 \\
\text { non-epidemic } \\
\text { period }\end{array}$ & $\begin{array}{c}1820-21 \\
\text { measles } \\
\text { epidemic }\end{array}$ & $\begin{array}{c}1823-24 \\
\text { smallpox } \\
\text { epidemic }\end{array}$ \\
\hline$<1$ & 99.4 & 147.1 & 125.1 \\
$1-4$ & 92.1 & 171.1 & 112.5 \\
$5-9$ & 43.3 & 148.7 & 138.4 \\
$10-14$ & 184.3 & 330.2 & 143.2 \\
$15-19$ & 25.5 & 210.2 & 107.4 \\
$20-24$ & 71.1 & 155.5 & 161.7 \\
$25-29$ & - & 187.5 & 123.4 \\
$30-34$ & 42.2 & 113.8 & 116.0 \\
$35-39$ & 84.6 & 89.0 & 77.1 \\
$41-44$ & 32.4 & 206.9 & 75.6 \\
$45-49$ & 36.5 & 201.6 & 148.1 \\
$50-54$ & 128.2 & 190.2 & 191.0 \\
$55-59$ & 129.7 & 111.6 & 144.3 \\
$60-64$ & 148.4 & 92.1 & 176.7 \\
$65-69$ & 77.3 & 86.8 & 360.6 \\
$70-74$ & 129.8 & 107.2 & 106.7 \\
$75-79$ & 67.3 & 152.8 & 184.0 \\
$80+$ & 162.2 & 94.0 & 71.0 \\
\hline \hline
\end{tabular}

Note: The missing value in 1816-17 for ages 25-29 is because there were no female deaths; the calculation could not be completed. Highlighted values indicate greater female mortality compared to male mortality. 

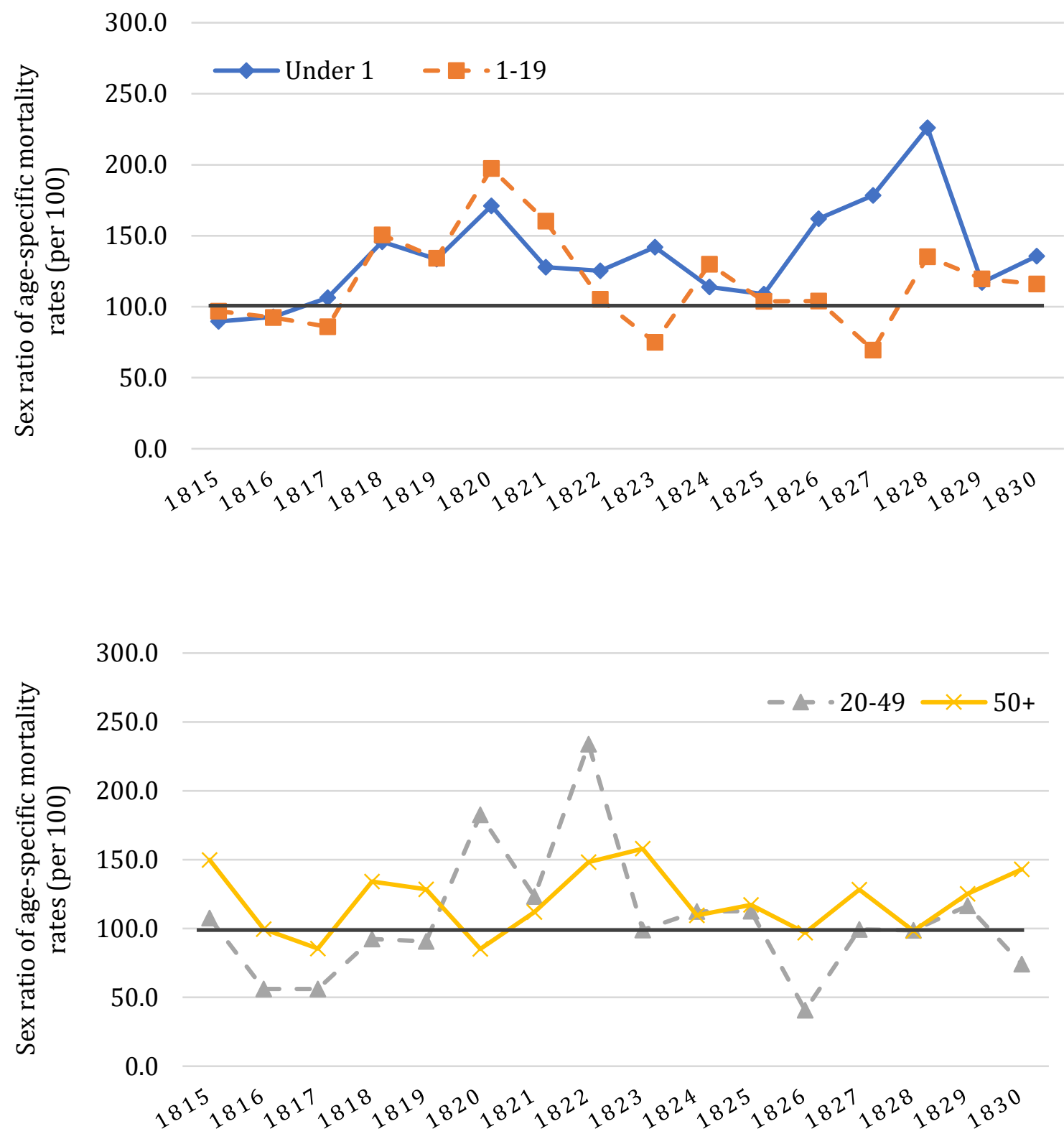

Figure 7.9. Sex ratio of age-specific death rates for the whole population of Åland (no accidents), illustrating male excess mortality. Top: Infants and combined ages of 1-19. Bottom: Combined ages of 20-49 and 50+.

Infant mortality is very high in the archipelago. Consequently, charting the trends across 16 years provides a better understanding of whether the excess male mortality is unusual during the epidemic periods. Based upon this analysis, excess male mortality is 
more the norm than an exception. The patterns of childhood epidemics (measles in particular) suggest that the majority of a population similar in size to Åland would be expected to have immunity by age 20 (Cliff et al., 1993; Heymann, 2008). Individuals age 1 to 19 show more variation in the sex ratio, but overall more male excess mortality-though no clear pattern that would explain the cause. In comparison, mortality for ages 20-29 illustrates spikes in mortality between 1820-23, while there is no discernable pattern for ages 50 and over.

Overall, the only clear and definitive differences in mortality between the sexes were the overall greater excess male mortality during the epidemic periods and the much greater male mortality during the measles epidemic. While further studies might provide more insight into the cause of the excess male mortality during epidemic periods, the data are not sufficient at this time, for this population, to initiate further analyses.

These analyses demonstrate that excess mortality, not attributable to measles, occurs during a measles epidemic and primarily alters patterns of mortality in ages 50 and over. Because the excess mortality observed in the highest age classes, the impact on the demographic structure of the population is minimal as the oldest age classes do not contribute to population growth or fertility. In short, the excess mortality experienced in the Åland Islands during the measles epidemic was not great enough to change the demographic structure of the population or result in any long-term demographic trends.

The mortality analyses here provide evidence that childhood epidemics such as measles and smallpox result in different mortality experiences both between the epidemics and across parishes and sexes. It is clear that the mortality experience of the archipelago is different than either the baseline period or the smallpox epidemic period when measles is present. Excess mortality, however, does not necessarily result in long-term demographic 
shifts for the population. In fact, it has been suggested that the high fertility rates following the 1808-09 War of Finland mortality crisis in Åland led to the rapid recovery of the population (Mielke and Pitkänen, 1989). Chapter 8 will further discuss the implications of the excess mortality during measles epidemics uncovered during these analyses and the differential mortality experiences of the archipelago's inhabitants during each epidemic and non-epidemic period. 


\section{CHAPTER 8: DISCUSSION AND CONCLUSIONS}

The research presented here is an exploration of mortality surrounding childhood epidemics of measles and smallpox and the demographic impacts of that mortality on the early $19^{\text {th }}$ century communities of the Åland Islands, Finland. This research illustrates that the mortality experiences of the Åland communities were significantly different between a non-epidemic period, a smallpox epidemic, and a measles epidemic. During the measles epidemic there was non-epidemic mortality in excess of that which would be expected during a non-epidemic year and which cannot be accounted for by deaths attributed to measles. Despite this result, there was little disruption in the demographic processes of the archipelago.

The Åland archipelago is comprised of numerous islands with varying levels of physical and social isolation and a total population of approximately 12,000 to 14,000 inhabitants between 1815 and 1830, too small to continuously maintain measles and smallpox outbreaks. Diseases such as these had to be introduced to the islands through outside contact. Each introduction provided the potential for a new outbreak, but an epidemic would not occur unless the susceptible population at that time was large enough to support transmission to a considerable portion of the population. For both measles and smallpox, recovery from infection (or vaccination) confers long-term immunity from the disease (Heymann, 2008), which means that the susceptible population is built up primarily through births and traditionally comprised of children.

Smallpox epidemics in the islands occurred in cycles of approximately 7 years in the archipelago (Mielke et al., 1984). This suggests that it took approximately that long for the younger age-groups to grow to a size that could sustain an epidemic of childhood disease given the population size, isolation, other mortality processes occurring in Åland 
communities, and the timing of the introduction of the disease. With the exception of the 1823-24 epidemic, the introduction of smallpox vaccination at the beginning of the 19th century reduced smallpox mortality and changed both the pattern of childhood epidemics and the prevalence of measles and smallpox in the archipelago. As measles and smallpox often appear in the historical records together (Creighton, 1965) it is clear that these pathogens were co-circulating; however, in Åland, mortality records suggest a fadeout of measles infection while smallpox mortality climbed as infection spread through the population. As smallpox, a major cause of mortality, was removed from the population, other diseases, such as measles, now had a sufficiently large susceptible population to spread through the population.

\section{Excess Mortality}

The first goal of this study was to examine mortality surrounding a measles epidemic and determine whether the communities of Åland experienced excess mortality that was not attributed to measles. Survivors of measles infection develop antibodies that provide lifetime immunity to infection; however, the immune response to measles infection that generates the characteristic rash also signals alterations that reduce the effectiveness of the host immune system for weeks or months following recovery (discussed in Chapter 4) (de Vries et al., 2012; Griffin, 2010; Griffin and Ward, 1993; Mina et al., 2015). The potential for measles infection to generate immune suppression raises the question of whether measles is an inherently syndemic disease (see Chapters 2 and 4).

This research confirms a large increase in mortality during the 1820-21 epidemic that was not directly attributed to deaths from measles infection. Mortality of the population was $6 \%$ lower than the baseline during the smallpox period but still $48 \%$ higher than the baseline for the period spanning the measles epidemic. While infant mortality was 
consistently high across all study periods, unusual increases in mortality were observed for children ages 5 through 9 and the older population over 50 years of age. Examination of the distribution of categories of disease provide further insight into the potential mechanisms triggering excess mortality in these age groups during the measles epidemic.

With the exception of measles and smallpox, the reliability of the recorded cause of death is very questionable in the early $19^{\text {th }}$ century archival records for Åland. For this reason, translations of the recorded cause of death are grouped into categories of respiratory, gastrointestinal, old age, accidental, and other/unknown. Frequency analysis shows that the distribution of the cause of death categories was significantly different when comparing each study period, and the period encompassing the measles epidemic showed declines in respiratory and gastrointestinal illnesses and an increase in deaths from "old age" and "other/unknown" causes. When considering the implications of these results, it is important to remember that disease mortality from one cause will alter the susceptible population available to contract other diseases, and thus alter the disease mortality from other causes.

Infant mortality was consistently high between all three study periods, suggesting that the factors contributing to this mortality were not identifiably altered by the presence or absence of measles and smallpox infections. The unknown category includes records of burials where no cause of death was listed, or the cause literally translates as "unknown childhood disease"; $67 \%$ of infant deaths were attributed to the unknown category. This suggests that infants were dying before identifiable disease characteristics appeared. Maternal antibodies provide protection from infectious diseases such as measles and smallpox for several months after birth (Heymann, 2008; Perry and Halsey, 2004), so it is of interest that $70 \%$ of infant deaths were for infants 6 to 11 months of age. Waning antibodies could make the infants susceptible to measles or smallpox infection, as a consequence of 
which the infant died from complications or secondary infections prior to the identification of the childhood disease; however, a simpler explanation is that infants were mostly likely dying from other common diseases that regularly occurred in the archipelago. Åland mothers were known to supplement infant feeding with chewed up bits of food and a mixture of milk, water, and flour (Moring, 1998), exposing infants to infections related to unclean utensils and transmission of illness from caretaker to child. In addition, crowding that occurred in the archipelago during the winter months may have increased exposure to other circulating diseases, such as respiratory infections, and the cold, wet conditions of winter would likely have contributed to risk of death from these diseases.

Excess mortality at ages 1-9 during the measles epidemic can be attributed to 14 deaths from measles, 19 respiratory-related deaths, 87 deaths from the other category, and 57 deaths attributed to unknown disease. As discussed above, unknown causes of death do not shed light on potential syndemic interactions with measles; however, excess mortality may be better understood in terms of respiratory, gastrointestinal, and causes listed in the "other" category. While respiratory illnesses are fewer than expected during the measles epidemic, deaths from respiratory causes are higher than observed during the smallpox epidemic. Analysis of the identified cause of death provides two possible explanations. The small increase in respiratory deaths during the measles epidemic for children aged 1 through 9 could indicate high risk of mortality from secondary respiratory infection following recovery from measles (linked to immunosuppression). Conversely, each epidemic period may have had fewer than expected respiratory deaths because these deaths were not being identified as caused by respiratory illness, specifically. Co-infection with other respiratory pathogens might have accompanied measles or smallpox infection but may have been omitted as contributory causes of death, making them essentially invisible in the historical record. 
During the measles epidemic there were also significantly fewer gastrointestinal deaths than expected; a result that was not observed during the smallpox epidemic. Measles complications from gastrointestinal complaints such as prolonged diarrhea have been documented in outbreaks from the Faroe Islands (Panum, 1939), Bangladesh (Koster, 1988; Koster et al., 1981), and Guatemala (Scrimshaw et al., 1966). This reduction in gastrointestinal deaths appears at the same time as measles infection; however, it is not clear if measles infection could be causing gastrointestinal symptoms (Perry and Halsey, 2004) or if a compromised immune system resulting from measles infection is providing the opportunity for a deadly co-infection with another disease (Griffin et al., 1994). In either case, gastrointestinal issues that accompanied fatal measles infection were most likely not listed as the cause of death in the parish records.

The "other" category also includes several cause of death designations that shed light on the excess mortality observed for children aged 1-9 years. Of 17 deaths attributed to scarlet fever, 11 occurred in this age group. A simple explanation could be that recorded deaths from scarlet fever represent a second epidemic. It could also suggest misdiagnoses-confusion between scarlet fever and measles deaths. Still, there were also more translations of "fever" (16 deaths) or "swelling" (22 deaths) that were not observed in either the smallpox or baseline period. These symptoms can be indications of a secondary infection from measles-induced immune suppression creating higher risk of infection and death from other diseases following recovery from measles. This suggests the possibility that the number of deaths from scarlet fever, fever, and swelling in the other category increased for children aged 1-9 during the 1820-21 epidemic and was a consequence of reduced immune competence caused by exposure to measles.

Excess mortality for individuals 50 years or older is more difficult to explain in the context of measles-induced immune suppression. It is obvious that the pattern of 
mortality for this segment of the population is much higher than expected, and immune system function begins to diminish as individuals age, resulting in less effective responses to pathogens (Montecino-Rodriguez et al., 2013). The question is whether exposure to measles infection could contribute to the decline in immune function among the elderly or those already suffering from immune dysfunction. An elderly population that has naturally acquired immunity is thought to be protected from the impact of measles immunosuppression because their antibodies will clear the infection before it reaches the stage that triggers a reduction in immune function. Unfortunately, extensive literature searches have provided no further information on the potential impact of measles exposure on the immune response of an adult population presumed to have naturally acquired immunity.

If antibody protection against measles does not wane with age, another explanation could be that a large proportion of the elderly population had never been exposed to measles infection. If susceptible, natural declines in immune response could combine with measles-induced immunosuppression to cause death from complications or a secondary infection before the individual developed the diagnostic rash that make measles infection identifiable. Still, there are no unusual increases in mortality during the measles epidemic for individuals between 20 and 49 years, and nearly all measles deaths were of individuals under 20 years of age. If large portions of the population had escaped measles exposure, it would be reflected in all age groups, not just the elderly. While a few individuals may have been susceptible to measles infection, the majority of the population over 50 were most likely exposed to measles and developed protective antibodies against infection during childhood. The diagnosis of death from "old age" cannot shed further light on the mechanisms resulting in increased mortality; however, some evidence for other explanations can be seen by examining the "other" category. 
For both epidemics, there were significantly more deaths than expected in the other/unknown category compared to the baseline period. During the 1820-21 measles epidemic there were 76 deaths from malaria, and 27 of these were individuals age 50 or older (compared to 2 deaths during the smallpox epidemic and 1 during the baseline period). In addition, there was a large increase in deaths from "fever" which could also be a reference to malaria infection. Malaria was known to be endemic in the Åland Islands during the late $17^{\text {th }}$ and early $18^{\text {th }}$ century (Mielke et al., 1987). While mortality was said to be exceptionally high for both children and adults in the archipelago (Mielke et al., 1987), Torres and Núñez (2005) suggest that malaria (probably Plasmodium vivax) was not a primary cause of mortality in Finland between 1750 and 1850. The most likely explanation is that measles and malaria were both circulating in the archipelago at the same time; however, there is no clear syndemic relationship between measles and malaria infections that can be determined by the data available for this research.

\section{Demographic Impacts of Epidemic Mortality}

The second goal of this study was to examine the demographic structure of the Åland archipelago to understand what long-term impact, if any, excess measles mortality had on the communities. Comparisons to smallpox were used to evaluate whether the excess mortality that occurred during the measles epidemic resulted in changes to the demographic structure of the population that would be unexpected during or following an epidemic of another childhood disease. The demographic changes of interest were related to overall age structure, crude birth and deaths rates, generalized fertility rates, and differences in mortality between males and females. Analyses did not indicate any longterm changes to these demographic measures following either the measles or smallpox epidemics. 
Analysis of the age structure of the population (population pyramids) compared the baseline non-epidemic period (1816-17) to both the measles epidemic period (1820-21) and the smallpox epidemic period (1823-24). While there are some variations in age and sex, the overall structure of the age pyramids demonstrates similar age and sex structure in the archipelago for all three study periods. In the first half of the $19^{\text {th }}$ century, the Åland archipelago experienced slower population growth, $0.5 \%$, compared to nearby mainland Finland (1.0\%) or Sweden (0.8\%) (Mielke et al., 1987). Mielke et al. observed that population growth was checked by emigration resulting in stagnation and population declines. The steadiness of the age and sex structure during the baseline and epidemic periods suggests that population losses from high mortality events may be balanced out through reduced emigration and high fertility.

The pattern of generalized fertility rates (GFRs) fluctuates between 118 and 140 births per 1,000 women of childbearing years from 1815 through 1830. The highest observed GFRs were during 1816 (137.5), 1827 (139.04), and 1829 (139.77). In contrast the lowest GFR was observed during the 1820 measles epidemic with a value of 118.67. There is also a small decrease in 1824 during the smallpox epidemic. While the pattern of decreasing fertility is not conclusively linked to the measles or smallpox epidemic, it does suggest a connection that needs to be explained.

Variations in the GFR are either from changes in the number of births (numerator) or the number of women of childbearing years (denominator). Epidemic mortality could reduce the number of women of childbearing years, and thus the number of children born. However, age-specific death rates calculated for each study period were largely consistent for women between the ages of 15 and 49 across the non-epidemic and epidemic study periods. In addition, sex ratios (discussed further below) indicate a higher proportion of male mortality during epidemic years for all but ages 35-39 and 41-44. This suggests that 
female mortality may not be the cause of this pattern. Infant mortality is not considered in the GFR calculation, and, therefore, epidemic mortality should not greatly impact this measure. However, in the early $19^{\text {th }}$ century Åland archipelago, infants who died before baptism were not always registered in the parish (Pitkänen, 1977; Turpeinen and Pitkänen, 1979). A possible explanation for the reduced GFR during the measles and smallpox epidemics could be a higher than normal number of infant deaths before baptism. In short, the GFR fluctuations could be related to flaws in record keeping practices exacerbated by higher than usual mortality. Still, the GFR recovered quickly and this measure provides no indication of long-term effects of epidemic mortality.

In comparison to the fertility rate, the crude death rate (CDR) does reflect periodic peaks of high mortality caused by major mortality events such as wars, epidemics, and famine. The CDR pattern clearly illustrates that the highest crude death rate between 1815 and 1830 was during the 1820 measles epidemic. In comparison, the smallpox epidemic during 1823 and 1824 did not have as large of an impact on CDRs, and while a small decline is noticeable, both quickly recover to pre-epidemic levels. In short, mortality during the measles epidemic had a greater impact on CDR and GFR compared to the smallpox epidemic; however, both measures recovered quickly following each epidemic.

During the baseline period, females experienced higher mortality at almost all ages, but males experienced mortality above that of females at nearly all ages during both epidemic periods. Studies have shown that males experience higher morbidity and mortality during their lifetime when compared to females (Muenchhoff and Goulder, 2014). This has been attributed to innate differences in the immune response between males and females (Muenchhoff and Goulder, 2014) and may explain the shifting pattern of male excess mortality during both the measles and smallpox epidemics. 
Average life expectancy values also reflected the immediate impact of excess mortality during the measles epidemic, and increased mortality during the smallpox epidemic. All three study periods display a well-recognized phenomenon for predemographic transition populations in which life expectancy at birth is lower than that for individuals who survive the first year of life. Average age at death, the sum of life expectancy and age, illustrates large differences in survival during both the measles and the smallpox epidemic periods. For example, individuals aged 5-9 years could be expected to live an average of 76 years during the non-epidemic period, but this changes to 65 years during the smallpox epidemic and 57.73 years during the measles epidemic. While the life expectancy values during the smallpox epidemic period (e.g. $e_{5-9}=49.33$ ) are lower than the baseline (e.g. e $\left._{5-9}=56.75\right)$ in younger age groups, they are higher than the life expectancies calculated during the measles epidemic $\left(\mathrm{e}_{5-9}=42.51\right)$. In contrast, life expectancy during the smallpox epidemic is higher than both the measles and non-epidemic period at older ages. Still, average age at death is largely reduced during both the smallpox and measles epidemics (for ages under 20 years) and for the measles epidemics from age 45 to 74 . All measures return to pre-epidemic period levels almost immediately. These are indicators that measles epidemic had a stronger impact on survival in the communities, but they do not provide any evidence of a long-term demographic impact.

This analysis of mortality in early 19th century Åland archipelago suggests that the presence of either measles or smallpox significantly increased the total mortality and the distribution of deaths from non-epidemic diseases. In the early $19^{\text {th }}$ century, prior to the second epidemiological transition, populations often experienced spikes in mortality caused by the circulation of various viral, bacterial, or parasitic diseases. There is clear evidence that the mortality during the measles epidemic far exceeded that attributed to the epidemic, 
and, analyses also indicate that the level of non-measles mortality was far in excess of what was expected during a non-epidemic period or observed during the smallpox epidemic. While measles induced immunosuppression can account for excess mortality observed between ages 1 and 9, there is less certain evidence that it contributes to infant mortality or mortality at older ages. Analysis of the mortality crisis during the 1808-09 War of Finland also showed unusually high patterns of mortality at ages over 40 years; the result of multiple co-circulating pathogens which may be a better explanation for the phenomena observed in this study. Further research is needed to determine the role of measles epidemics in mortality from these other potential causes of death prior to, and following, the second epidemiological transition.

There has been debate over whether preindustrial mortality crises significantly impact demographics of a community, as the high fertility and increased rates of marriage and re-marriage appear to compensate for large population losses (Mielke and Pitkänen, 1989). The mortality during the 1808-09 War of Finland was approximately $10 \%$ over two years while the mortality during the measles epidemic was approximately $7 \%$, smallpox 5\%, and the non-epidemic period 4\%. The War of Finland (1808-09) was shown to have some small long-lasting effects on population growth; however, fertility and nuptiality were only impacted for a short duration and quickly recovered (Mielke, 2003; Mielke and Pitkänen, 1989). During the crisis mortality of the war, a large proportion of deaths were observed in the older segments of the population; a proportion increase of 10 to 13 times the expected rate for individuals aged 40 to 64 (Mielke and Pitkänen, 1989). It appears as though the concentration of excess mortality in the older segments of the population, observed during the 1808-09 war and the period spanning the measles epidemic, reduced the impact of mortality on demographic processes occurring in these small communities. 


\section{Implications, Limitations, and Conclusions}

Historically, childhood diseases have shaped populations, and the social and cultural response to these diseases have in turn shaped the public narrative surrounding childhood epidemics. Still, measles is not discussed in the literature, historical or current, with the same urgency or fear observed in discussions of smallpox. The public perception of any disease influences the narratives built through research, which in turn shapes the social and cultural responses on both local and global scales (Briggs, 2010). With the exception of research conducted on epidemics in which most of the population is susceptible to measles infection, studies of measles mortality almost never consider mortality at older ages or that which is not directly linked to measles infection. While this study is not conclusive, the results are compelling and suggest that there may be a gap in the literature surrounding measles epidemics.

The disruption of childhood disease patterns that resulted from vaccination has produced a generation of parents in developed countries who have not experienced major childhood epidemics and thus see the risk of vaccination as greater than that of infection. While most infections occur in developing countries where there is little access to health care (Racaniello, 2011), outbreaks are again occurring in countries in which measles had been declared eradicated (Poland and Jacobson, 2012). It has also been shown that children of mothers whose immunity to measles was due to vaccination may be at higher risk of measles infection and death at younger ages (Moss and Griffin, 2012; Poland and Jacobson, 2012). The continued occurrence of measles in developing nations, in addition to the resurgence of measles in developed countries, highlights the need to understand the impact of measles, and the potential for excess mortality, in both the distant and recent past. Results of this study may also show that these small, historical communities can serve as appropriate models for small communities that experience regular measles epidemics or 
even the affluent communities in developed countries like the United States that are currently experiencing increases in the incidence of measles.

Many modern populations share characteristics with historical populations such as isolation, reduced access to health care, or similarities in social organization. Regions of Africa, where measles is still a frequent childhood disease, share similarities with the communities of Åland, such as isolated villages and lack of resources or infrastructure (e.g. limited access to health care or vaccination). In developed countries where measles is resurfacing, outbreaks occur in communities with high rates of vaccine non-compliance. Still, even large cities are composed of smaller communities with varying levels of isolation, health care access, and social interaction. Understanding how measles can impact mortality in small, historical communities provides better insight into effective mitigation strategies during widespread epidemics in modern communities.

The research presented here is a first step in examining excess non-epidemic mortality during a measles epidemic and the potential of measles to have hidden demographic impacts. The natural progression of this research will include the confirmation of these patterns of excess mortality through comparative studies of epidemics across populations throughout history. A major limitation of this study was the fact that the many diseases in the early $19^{\text {th }}$ century were listed as unknown or described as a list of symptoms. Even when the cause of death translated to an identifiable disease, the ability of the people to clearly identify one disease accurately and separately from another is in question. The inability to reliably identify causes of death creates difficulty in generating analyses that more conclusively identify the interaction between co-occurring diseases. Further studies should consider epidemics in which more accurate diagnoses are available to better understand which diseases are creating excess mortality during immunosuppression. 
This study was also deliberately designed to look at epidemics prior to the mortality and fertility changes observed during the epidemiological and demographic transitions (with the exception of reduced smallpox mortality due to vaccination, which could not be avoided). This research would benefit from studies that focus on changes in mortality surrounding measles epidemics as the demographic and epidemiological transitions shift overall patterns of fertility and mortality in communities. Further expansion of these studies should focus on the roles of cultural factors, social structures, and environmental components, as well as other causes of death, to better understand how these factors impact measles associated mortality over time and the effects this may have on communities past and present. 


\section{REFERENCES}

Aaby P. 1988. Malnutrition and overcrowding/intensive exposure in severe measles infection: Review of community studies. Review of Infectious Diseases 10(2):478491.

Aaby P, Andersen M, and Knudsen K. 1993a. Excess mortality after early exposure to measles. International Journal of Epidemiology 22(1):156-162.

Aaby P, Bhuiya A, Nahar L, Knudsen K, de Francisco A, and Strong M. 2003a. The survival benefit of measles immunization may not be explained entirely by the prevention of measles disease: a community study from rural Bangladesh. International Journal of Epidemiology 32(1):106-115.

Aaby P, Bukh J, Lisse IM, and da Silva MC. 1988. Further community studies on the role of overcrowding and intensive exposure on measles mortality. Reviews of Infectious Diseases 10(2):474-477.

Aaby P, Bukh J, Lisse IM, and Smits AJ. 1981. Measles vaccination and child mortality. Lancet 8237(July):93.

Aaby P, Bukh J, Lisse IM, and Smits AJ. 1983. Measles mortality, state of nutrition, and family structure: A community study from Guinea-Bissau. The Journal of Infectious Diseases 147(4):693-701.

Aaby P, Bukh J, Lisse IM, and Smits AJ. 1984a. Measles vaccination and reduction in child mortality: A community study from Guinea-Bissau. Journal of Infection 8:13-21.

Aaby P, Bukh J, Lisse IM, and Smits AJ. 1984b. Overcrowding and intensive exposure as determinants of measles mortality American Journal of Epidemiology 120(1):49-63.

Aaby P, Bukh J, Lisse IM, Smits AJ, Gomes J, Fernandes MA, Indi F, and Soares M. 1984c. Determinants of measles mortality in a rural area of Guinea-Bissau: Crowding, age, and malnutrition. Journal of Tropical Pediatrics 30(3):164-168.

Aaby P, Coovadia H, Bukh J, Lisse IM, Smits AJ, Wesley A, and Kiepiela P. 1985. Severe measles: A reappraisal fo the role of nutrition, overcrowding and virus dose. Medical Hypotheses 18:93-112.

Aaby P, Garly M-L, Bale C, Martins C, Jensen H, Lisse IM, and Whittle H. 2003b. Survival of previously measles-vaccinated and measles-unvaccinated children in an emergency situation: an unplanned study. The Pediatric infectious disease journal 22(9):798805.

Aaby P, Knudsen K, Whittle H, Lisse IM, Thaqrup J, Poulsen A, Sodemann M, Jakobsen M, Brink L, Gansted U et al. . 1993b. Long-term survival after Edmonston-Zagreb measles vaccination in Guinea-Bissau: Increased female mortality rate. The Journal of Pediatrics 122(6):904-908. 
Aaby P, Martins CL, Garly ML, Bale C, Andersen A, Rodrigues A, Ravn H, Lisse IM, Benn CS, and Whittle HC. 2010. Non-specific effects of standard measles vaccine at 4.5 and 9 months of age on childhood mortality: randomised controlled trial. BMJ 341(c6495).

Aaby P, Samb B, Andersen M, and Simondon F. 1996. No long-term excess mortality after measles infection: A community study from Senegal. American Journal of Epidemiology 143(10):1035-1041.

AAby P, Samb B, Simondon F, Seck AMC, Knudsen K, and Whittle H. 1995. Non-specific beneficial effect of measles immunisation: analysis of mortality studies from developing countries. BMJ: British Medical Journal 311(7003):481-485.

Armelagos G, Barnes KC, and Lin J. 1996. Disease in human evolution: The re-emergence of infectious disease in the Third Epidemiological Transition. AnthroNotes 18(3):1-7.

Armelagos GJ. 2013. Reading the bones. Science 342(6164):1291.

Armelagos GJ, Brown PJ, and Turner B. 2005. Evolutionary, historical and political economic perspectives on health and disease. Social Science \& Medicine 61:755-765.

Arriaza BT, Salo W, Aufderheide AC, and Holcomb TA. 1995. Pre-Columbian tuberculosis in Northern Chile: Molecular and skeletal evidence. American Journal of Physical Anthropology 98:37-45.

Bambra C, Gibson M, Sowden A, Wright K, Whitehead M, and Petticrew M. 2010. Tackling the wider social determinants of health and health inequalities: evidence from systematic reviews. Journal of Epidemiology and Community Health (1979-) 64(4):284-291.

Barrett R. 2017. The specter of Ebola: epidemiologic transitions versus the zombie apocalypse. In: Zuckerman MK, and Martin DL, editors. New directions in biocultural anthropology. New Jersey: John Wiley \& Sons. p 7-26.

Barrett R, Kuzawa CW, McDade T, and Armelagos GJ. 1998. Emerging and re-emerging infectious diseases: The third epidemiological transition. Annual Review of Anthropology 27(247-271):247.

Bartlett MS. 1957. Measles periodicity and community size. Journal of the Royal Statistical Society Series A 120(1):48-70.

Bartlett MS. 1960. The critical community size for measles in the United States. Journal of the Royal Statistical Society Series A 123(1):37-44.

Bengtsson T, and Broström G. 2009. Do conditions in early life affect old-age mortality directly and indirectly? Evidence from 19th-century rural Sweden. Social Science \& Medicine 68(9):1583-1590.

Benjamin B, and Gore AT. 1952. Incidence of common infections of childhood. British Journal of Social Medicine 6(3):197-204. 
Bharti N, Tatem AJ, Ferrari MJ, Grais RF, Djibo A, and Grenfell BT. 2011. Explaining seasonal fluctuations of measles in Niger using nighttime lights imagery. Science 334(6061):1424-1427.

Bjørnstad ON, Finkenstädt BF, and Grenfell BT. 2002. Dynamics of measles epidemics: Estimating scaling of transmission rates using a time series SIR model. Ecological Monographs 72(2):169-184.

Black FL. 1966. Measles endemicity in insular populations: Critical community size and its evolutionary implication. Journal of Theoretical Biology 11:207-211.

Blane D. 1995. Editorial: Social determinants of health--Socioeconomic status, social class, and ethnicity. American Journal of Public Health 85(7):903-905.

Bocquet-Appel J-P. 2002. Paleoanthropological traces of a Neolithic demographic transition. Current Anthropology 43(4):637-650.

Bocquet-Appel J-P. 2011a. The agricultural demographic transition during and after the agriculture inventions. Current Anthropology 52(S4):S497-S510.

Bocquet-Appel J-P. 2011b. When the world's population took off: The springboard of the Neolithic demographic transition. Science 333(6042):560-561.

Bolker BM, and Grenfell BT. 1993. Chaos and biological complexity in measles dynamics. Proceedings: Biological Sciences 251(1330):75-81.

Braveman P, and Tarimo E. 2002. Social inequalities in health within countries: not only an issue for affluent nations. Social Science \& Medicine 54(11):1621-1635.

Briggs CL. 2010. Pressing plagues: On the mediated communicability of virtual epidemics. In: Herring DA, and Swedlund AC, editors. Plagues and epidemics: Infected spaces past and present. Oxford: Berg. p 39-59.

Burström B, Diderichsen F, and Smedman L. 1999. Child Mortality in Stockholm during 1885-1910: The Impact of Household Size and Number of Children in the Family on the Risk of Death from Measles. American Journal of Epidemiology 149(12):11341141.

Caldwell JC. 1976. Toward a restatement of Demographic Transition Theory. Population and Development Review 2(3/4):321-366.

Cauchemez S, and Ferguson NM. 2008. Likelihood-based estimation of continuous-time epidemic models from time-series data: application to measles transmission in London. Journal of The Royal Society Interface 5(25):885-897.

Centers for Disease Control and Prevention. 2011. Measles --- United States, January -May 20, 2011. Morbidity and Mortality Weekly Report 60(20):666-668. 
Centers for Disease Control and Prevention [CDC]. 2017. Smallpox Fact Sheet. https://emergency.cdc.gov/agent/smallpox/overview/disease-facts.asp. Content source: CDC Emergency Risk Communication Branch (ERCB), Division of Emergency Operations (DEO), National Center for Emerging and Zoonotic Infectious Diseases (NCEZID).

Chowell G, Viboud C, Simonsen L, Miller MA, and Acuna-Soto R. 2010. Mortality patterns associated with the 1918 influenza pandemic in Mexico: Evidence for a spring herald wave and lack of preexisting immunity in older populations. Journal of Infectious Diseases 202(4):567-575.

Cisse B, Aaby P, Simondon F, Samb B, Soumaré M, and Whittle H. 1999. Role of schools in the transmission of measles in rural Senegal. American Journal of Epidemiology 149(4):295-301.

Clarke AL, and Low BS. 2001. Testing evolutionary hypotheses with demographic data. Population and Development Review 27(4):633-660.

Clemens JD, Stanton BF, Chakraborty J, Chowdhury S, Rao MR, Mohammed A, Zimicki S, and Wojtyniak B. 1988. Measles vaccination and childhood mortality in rural Bangladesh. American Journal of Epidemiology 128(6):1330-1339.

Cliff AD, and Haggett P. 1980. Changes in the seasonal incidence of measles in Iceland, 18961974. The Journal of Hygiene 85(3):451-457.

Cliff AD, and Haggett P. 1984. Island epidemics. Scientific American 250(5):138-147.

Cliff AD, and Haggett P. 1985. The spread of measles in Fiji and the Pacific: Spatial components in the transmission of epidemic waves through island communities. Canberra: Research School of Pacific Studies, Australian National University: Distributed by Bibliotech, Anutech.

Cliff AD, and Haggett P. 1993. Statistical modelling of measles and influenza outbreaks. Statistical Methods in Medical Research 2:43-73.

Cliff AD, Haggett P, and Graham R. 1983a. Reconstruction of diffusion processes at local scales: the 1846, 1882 and 1904 measles epidemics in northwest Iceland. Journal of Historical Geography 9(4):347-368.

Cliff AD, Haggett P, and Ord JK. 1983b. Forecasting epidemic pathways for measles in Iceland: The use of simultaneous equation and logit models. Ecology of Disease 2(4):377-396.

Cliff AD, Haggett P, and Smallman-Raynor M. 1993. Measles : An historical geography of a major human viral disease from global expansion to local retreat, 1840-1990. Oxford [England]; Cambridge, Mass., USA: Blackwell.

Cliff AD, Haggett P, and Smallman-Raynor M. 2009. The changing shape of island epidemics: Historical trends in Icelandic infectious disease waves, 1902-1988. Journal of Historical Geography 35(3):545-567. 
Cliff AD, Haggett P, and Smallman-Raynor MR. 2000. Island epidemics. New York: Oxford University Press.

Cockburn TA. 1971. Infectious diseases in ancient populations. Current Anthropology 12(1):45-62.

Commission on Social Determinants of Health. 2008. CSDH final report: clsoing the gap in a generation: health equity through action on the social determinants of health. Geneva: World health Organization.

Creighton C (with additional material by DEC Eversley EU, L Ovenall). 1965. Measles. A history of epidemics in Britain, vol 2. Cambridge: Cambridge University Press. $p$ 632-665.

Crosby AW. 1969. The early history of syphilis: A reappraisal. American Anthropologist $71(2): 218-227$.

Crosby AW. 1976. Virgin soil epidemics as a factor in the aboriginal depopulation in America. The William and Mary Quarterly 33(2):289-299.

Cunha BA. 2004. Smallpox and measles: historical aspects and clinical differentiation. Infectious Disease Clinics of North America 18:79-100.

Cutler D, and Miller G. 2005. The role of public health improvements in health advances: The twentieth-century United States. Demography 42(1):1-22.

Dalton PR, and Pole D. 1978. Water-contact patterns in relation to Schistosoma haematobium infection. Bulletin of the World Health Organization 56(3):417-426.

de Vries RD, McQuaid S, van Amerongen G, Yüksel S, Verburgh RJ, Osterhaus ADME, Duprex WP, and de Swart RL. 2012. Measles immune suppression: Lessons from the macaque model. PLoS Pathog 8(8):e1002885.

Demographical Database for Southern Sweden (DDSS). 2012. Hjälpmedel - Dödsorsaker och sjukdomsnamn - förr och nu (Aids - Causes of death and disease names - then and now). http://www.ddss.nu/means/swCauseOfDeath.

Denton M, and Walters V. 1999. Gender differences in structural and behavioral determinants of health: an analysis of the social production of health. Social Science \& Medicine 48(9):1221-1235.

Devor EJ. 1979. Historical demography in the Åland Islands, Finland: The size and composition of households and families in teh parishes of Finström and Kökar from 1760 to 1880. : University of New Mexico.

Doblhammer G, van den Berg GJ, and Lumey LH. 2013. A re-analysis of the long-term effects on life expectancy of the Great Finnish Famine of 1866-68. Population Studies 67(3):309-322. 
Donoghue HD, Spigelman M, Greenblatt CL, Lev-Maor G, Kahila Bar-Gal G, Matheson C, Vernon K, G Nerlich A, and R Zink A. 2004. Tuberculosis: from prehistory to Robert Koch, as revealed by ancient DNA. The Lancet Infectious Diseases 4(9):584-592.

Dreijer M. 1968. Glimpses of Åland history. Mariehamn, Åland Islands: Ålands Museum.

Ellner SP, Bailey BA, Bobashev GV, Gallant AR, Grenfell BT, and Nychka DW. 1998. Noise and nonlinearity in measles epidemics: Combining mechanistic and statistical approaches to population modeling. The American Naturalist 151(5):425-440.

Erickson PI. 2008. What causes disease? Theories of disease causation. Ethnomedicine. Long Grove, IL: Waveland. p 35-58.

Eriksson AW. 1980a. Åland: A case study: An introduction. In: Eriksson AW, editor. Population structure and genetic disorders: Seventh Sigrid Jusélius Foundation Symposium, Mariehamn, Åland Islands, Finland August 1978. London: Academic Press. p 455-457.

Eriksson AW. 1980b. Genetic studies on Åland: Geographical, historical and archival data and some other potentialities. In: Eriksson AW, editor. Population structure and genetic disorders: Seventh Sigrid Jusélius Foundation Symposium, Mariehamn, Åland Islands, Finland August 1978. London: Academic Press. p 459-470.

Eriksson AW, editor. 1980c. Population structure and genetic disorders : Seventh Sigrid Jusélius Foundation Symposium, Mariehamn, Åland Islands, Finland, August 1978: London; New York : Academic Press.

Eriksson AW, Fellman JO, and Forsius HR. 1980. Some genetic and clinical aspects of the Åland Islanders. In: Eriksson AW, editor. Population structure and genetic disorders: Seventh Sigrid Jusélius Foundation Symposium, Mariehamn, Åland Islands, Finland August 1978. London: Academic Press. p 509-536.

Everett M, and Wieland JN. 2012. Diabetes among Oaxaca's transnational population: An emerging syndemic. Annals of Anthropological Practice 36(2):295-311.

Fabrega H. 1971. Medical Anthropology. Biennial Review of Anthropology 7:167-229.

Family Search. 2012. Swedish Genealogical Word List. https://familysearch.org/wiki/en/Swedish_Genealogical_Word_List.

Farmer P. 1996. Social inequalities and emerging infectious diseases. Emerging Infectious Diseases 2(4):259.

Farooq M, and Mallah MB. 1966. The behavioural pattern of social and religious watercontact activities in the Egypt-49 bilharziasis project area. Bulletin of the World Health Organization 35(3):377-387.

Fellman J, and Eriksson AW. 2009. Temporal and regional variations in the seasonality of births in Åland (Finland), 1653-1950. Biodemography and Social Biology 55(1):103-112. 
Ferguson NM, Nokes JD, and Anderson RM. 1996. Dynamical complexity in age-structured models of the transmission of the measles virus: Epidemiological implications at high levels of vaccine uptake. Mathematical Biosciences 138:101-130.

Fine PE, and Clarkson JA. 1982. Measles in England and Wales--I: An analysis of factors underlying seasonal patterns. Int J Epidemiol 11(1):5-14.

Finkenstadt BF, and Grenfell BT. 2000. Time series modelling of childhood diseases: A dynamical systems approach. Journal of the Royal Statistical Society Series C (Applied Statistics) 49(2):187-205.

Fisker AB, Rodrigues A, Martins C, Ravn H, Byberg S, Thysen S, Storgaard L, Pedersen M, Fernandes M, Benn CS et al. . 2015. Reduced all-cause child mortality after general measles vaccination campaign in rural Guinea-Bissau. The Pediatric infectious disease journal 34(12):1369-1376.

Gage TB. 2005. Are modern environments really bad for us?: Revisiting the demographic and epidemiological transitions. Yearbook of Physical Anthropology 48:96-117.

Garenne M, and Aaby P. 1990. Pattern of exposure and measles mortality in Senegal. Journal of Infectious Diseases 161(6):1088-1094.

Grenfell BT. 1992. Chance and chaos in measles dynamics. Journal of the Royal Statistical Society Series B (Methodological) 54(2):383-398.

Grenfell BT, Bjornstad ON, and Finkenstadt BF. 2002. Dynamics of measles epidemics: Scaling noise, determinism, and predictability with the TSIR. Ecological Monographs 72(2):185-202.

Griffin DE. 2010. Measles virus-induced suppression of immune responses. Immunological reviews 236:176-189.

Griffin DE, and Ward BJ. 1993. Differential CD4 T Cell Activation in Measles. The Journal of Infectious Diseases 168(2):275-281.

Griffin DE, Ward BJ, and Esolen LM. 1994. Pathogenesis of measles virus infection: An hypothesis for altered immune responses. The Journal of Infectious Diseases 170:s24-s31.

Halkitis PN, Kupprat SA, Hampton MB, Perez-Figueroa R, Kingdon M, Eddy JA, and Ompad DC. 2012. Evidence for a syndemic in aging HIV-positive gay, bisexual, and other MSM: Implications for a holistic approach to prevention and health care. Annals of Anthropological Practice 36(2):365-386.

Hamer W. 1906. Epidemic disease in Enlgand - The evidence of variability and of persistecy of type. Lancet 1:733-739. 
Harper K, and Armelagos G. 2010. The changing disease-scape in the third epidemiological transition. International Journal of Environmental Research and Public Health 7:675-697.

Harper KN, Zuckerman MK, Harper ML, Kingston JD, and Armelagos GJ. 2011. The origin and antiquity of syphilis revisited: An Appraisal of Old World pre-Columbian evidence for treponemal infection. American Journal of Physical Anthropology 146(S53):99133.

Herring DA, and Sattenspiel L. 2007. Social context, syndemics, and infectious diseases in northern Aboriginal populations. American Journal of Human Biology 19(2):190202.

Herring DA, and Swedlund AC, editors. 2010. Plagues and epidemics: Infected spaces past and present. Oxford: Berg.

Heymann DL, editor. 2008. Control of communicable diseases manual. 19th edition ed. Washington, D.C.: American Public Health Association.

Hibbs AC, Secor WE, Van Gerven D, and Armelagos G. 2011. Irrigation and infection: the immunoepidemiology of schistosomiasis in ancient Nubia. Am J Phys Anthropol 145(2):290-298.

Howell M, and Prevenier W. 2001. From reliable sources: an introduction to historical methods. New York: Cornell University Press. 207 p.

Huldén L, Huldén L, and Heliövaara K. 2005. Endemic malaria: an 'indoor' disease in northern Europe. Historical data analysed. Malaria Journal 4(1):19.

Illangasekare S, Burke J, Chander G, and Gielen A. 2013. The syndemic effects of intimate partner violence, HIV/AIDS, and substance abuse on depression among low-income urban women. Journal of Urban Health 90(5):934-947.

Inhorn MC. 2010. Medical Anthropology at the intersections: Celebrating 50 years of interdisciplinarity. Medical Anthropology Quarterly 24(2):263-269.

Inhorn MC, and Brown PJ. 1990. The anthropology of infectious disease. Annual Review of Anthropology 19:89-117.

Janes CR, Stall R, and Gifford SM, editors. 1986. Anthropology and epidemiology: Interdisciplinary approaches to the study of health and disease. Dordrecht, Holland: D. Reidel Publishing Company.

Jones DS. 2003. Virgin soils revisited. The William and Mary Quarterly 60(4):703-742.

Joralemon D. 2010. Exploring Medical Anthropology. Boston: Allyn and Bacon.

Kannisto V, Nieminen M, and Turpeinen O. 1999. Finnish life tables since 1751. Demographic Research 1(1). 
Keeling MJ, and Grenfell BT. 1997. Disease extinction and community size: Modeling the persistence of measles. Science 275(5296):65-67.

Keeling MJ, and Grenfell BT. 1998. Effect of variability in infection period on the persistence and spatial spread of infectious diseases. Mathematical Biosciences 147(2):207-226.

Kirk D. 1996. Demographic Transition Theory. Population Studies 50(3):361-387.

Klaus HD, Wilbur AK, Temple DH, Buikstra JE, Stone AC, Fernandez M, Wester C, and Tam ME. 2010. Tuberculosis on the north coast of Peru: skeletal and molecular paleopathology of late pre-Hispanic and postcontact mycobacterial disease. Journal of Archaeological Science 37(10):2587-2597.

Knodel J. 1968. Infant mortality and fertility in three Bavarian Villages: An analysis of family histories from the 19th century. Population Studies 23(3):297-318.

Koenig MA, Khan MA, Wojtyniak B, Clemens JD, Chakraborty J, Fauveau V, Phillips JF, Akbar J, and Barua US. 1990. Impact of measles vaccination on childhood mortality in rural Bangladesh. Bulletin of the World Health Organization 68(4):441-447.

Koster FT. 1988. Mortality among primary and secondary cases of measles in Bangladesh. Reviews of Infectious Diseases 10(2):471-473.

Koster FT, Curlin GC, Aziz KM, and Haque A. 1981. Synergistic impact of measles and diarrhoea on nutrition and mortality in Bangladesh. Bulletin of the World Health Organization 59(6):901-908.

Kristensen I, Fine P, Aaby P, and Jensen H. 2000. Routine vaccinations and child survival: follow up study in Guinea-Bissau, West Africa. BMJ 321(7274):1435.

Littleton J, Park J, and Nelesone T. 2012. Helminths and TB in Polynesia: The implications for health practice. Annals of Anthropological Practice 36(2):274-294.

Livingstone FB. 1958. Anthropological implications of sickle cell gene distribution in West Africa. American Anthropologist 60(3):533-562.

Livingstone FB. 1991. On the origin of syphilis: An alternative hypothesis. Current Anthropology 32(5):587-590.

Lloyd AL, and Sattenspiel L. 2009. Spatiotemporal dynamics of measles: Synchrony and persistence in a disease metapopulation. In: Cantrell S, Cosner C, and Ruan S, editors. Spatial Ecology. Boca Raton, FL: CRC Press. p 251-272.

Macfarlane A. 1977. Reconstructing historical communities. New York: Cambridge University Press. 222 p.

Mackenbach JP. 1994. The Epidemiologic Transition Theory. Journal of Epidemiology and Community Health (1979-) 48(4):329-331. 
Manderson L. 1998. Applying medical anthropology in the control of infectious disease. Tropical Medicine \& International Health 3(12):1020-1027.

Marmot M. 2005. Social determinants of health inequalities. The Lancet 365(9464):10991104.

Marmot M, and Allen JJ. 2014. Social determinants of health equity. American Journal of Public Health 104(S4):S517-S519.

Marmot M, and Bell R. 2016. Social inequalities in health: a proper concern of epidemiology. Annals of Epidemiology 26(4):238-240.

Marmot M, Friel S, Bell R, Houweling TAJ, and Taylor S. 2008. Closing the gap in a generation: health equity through action on the social determinants of health. The Lancet 372(9650):1661-1669.

Marmot MG. 2003. Understanding social inequalities in health. Perspectives in Biology and Medicine 46(3):S9-S23.

McElroy A, and Townsend PK. 2015. Medical Anthropology in ecological perspective. 6th ed. Boulder, CO: Westview Press.

Mead WR, and Jaatinen SH. 1975. The Åland Islands. Newton Abbot: David \& Charles. 179 p.

Mercer AJ. 1985. Smallpox and epidemiological-demographic change in Europe: The role of vaccination. Population Studies 39(2):287-307.

Merrill RM, and Timmreck TC. 2006. Introduction to Epidemiology. Sudbury, Massachusetts: Jones \& Bartlett Publishers. 352 p.

Meyer JP, Springer SA, and Altice FL. 2011. Substance abuse, violence and HIV in women: a literature review of the syndemic. Journal of Women's Health 20(7):991-1006.

Mielke JH. 1980. Demographic aspects of population structure in Åland. In: Eriksson AW, editor. Population structure and genetic disorders: Seventh Sigrid Jusélius Foundation Symposium, Mariehamn, Åland Islands, Finland August 1978. London: Academic Press. p 471-486.

Mielke JH. 1982. Population movements and genetic microdifferentiation in Åland, Finland. Collegium Antropologicum 6(1):19-38.

Mielke JH, editor. 2003. War and population composition in Åland, Finland. Cambridge: Cambridge University Press. 216-233 p.

Mielke JH. 2016. Population and disease transition in the Åland Islands, Finland. In: Zuckerman MK, and Martin DL, editors. New Directions in Biocultural Anthropology. First Edition ed. New Jersey: John Wiley \& Sons, Inc. p 339-361.

Mielke JH, Devor EJ, Kramer PL, Workman PL, and Eriksson AW. 1982. Historical population structure of the Åland Islands, Finland. In: Mielke JH, and Crawford MH, editors. 
Current Developments in Anthropological Genetics. New York: Plenum Press. p 255332.

Mielke JH, Jorde LB, Trapp PG, Anderton DL, Pitkänen KJ, and Eriksson AW. 1984. Historical epidemiology of smallpox in Åland, Finland: 1751-1890. Demography 21(3):271295.

Mielke JH, and Pitkänen KJ. 1989. War demography: The impact of the 1808-09 War on the civilian population of Åland, Finland. European Journal of Population 5:373-398.

Mielke JH, Pitkänen KJ, Jorde LB, Fellman JO, and Eriksson AW. 1987. Demographic patterns in the Åland Islands, Finland, 1750-1900. Yearbook of Population Research in Finland XXV:57-74.

Mielke JH, Relethford JH, and Eriksson AW. 1994. Temporal trends in migration in the Åland Islands: Effects of population size and geographic distance. Human Biology 66(3):399-410.

Mielke JH, Workman PL, Fellman JO, and Eriksson AW. 1976. Population structure of the Åland Islands, Finland. Advances in Human Genetics 6:241-321.

Mina MJ, Metcalf CJE, de Swart RL, Osterhaus ADME, and Grenfell BT. 2015. Long-term measles-induced immunomodulation increases overall childhood infectious disease mortality. Science 348(6235):694-699.

Montecino-Rodriguez E, Berent-Maoz B, and Dorshkind K. 2013. Causes, consequences, and reversal of immune system aging. The Journal of Clinical Investigation 123(3):958965.

Morens DM, and Fauci AS. 2007. The 1918 influenza pandemic: Insights for the 21st Century. The Journal of Infectious Diseases 195(7):1018-1028.

Moring B. 1998. Motherhood, milk, and money. Infant mortality in pre-industrial Finland. Social History of Medicine 11(2):177-196.

Moss WJ, and Griffin DE. 2012. Measles. The Lancet 379(9811):153-164.

Muenchhoff M, and Goulder PJR. 2014. Sex differences in pediatric infectious diseases. The Journal of Infectious Diseases 209(suppl_3):S120-S126.

Murray GD, and Cliff AD. 1977. A stochastic model for measles epidemics in a multi-region setting. Transactions of the Institute of British Geographers 2(2):158-174.

Mustanski B, Garofalo R, Herrick A, and Donenberg G. 2007. Psychosocial health problems increase risk for HIV among urban young men who have sex with men: preliminary evidence of a syndemic in need of attention. Annals of behavioral medicine : a publication of the Society of Behavioral Medicine 34(1):37-45.

Netea Mihai G, Quintin J, and van der Meer Jos WM. 2011. Trained immunity: A memory for innate host defense. Cell Host \& Microbe 9(5):355-361. 
Núñez M, and Garcia-Guixé E. 2011. Vida, enfermedad y muerte en dos pueblos finlandeses durante 1751-1850. In: González MA, Cambra-Moo 0, Rascón PJ, Campo MM, Robledo AM, Labajo GE, and Sánchez J, editors. Paleopatología: ciencia multidisciplinar. Madrid: Sociedad Española de Paleopatología. p 225-239.

Oldstone MBA. 2010. Viruses, plagues, \& history: Past, present, and future. New York: Oxford University Press, Inc.

Olsen B, Munster VJ, Wallensten A, Waldenstrom J, Osterhaus ADME, and Fouchier RAM. 2006. Global patterns of Influenza A virus in wild birds. Science 312(5772):384-388.

Olsen LF, and Schaffer WM. 1990. Chaos versus noisy periodicity: Alternative hypotheses for childhood epidemics. Science 249(4968):499-504.

Omran AR. 1971. The epidemiologic transition: A theory of the epidemiology of population change. The Milbank Memorial Fund Quarterly 49(4):509-538.

Palloni A. 1987. Assessing the levels and impact of mortality in crisis situations. Center for Demography and Ecology Working Paper 87-38. Madison, WI: University of Wisconsisn.

Panum PL. 1939. Observations made during the epidemic of measles in the Faeroe Islands in the year 1846. Medical Classics 3:803-886.

Parsons JT, Grov C, and Golub SA. 2012. Sexual compulsivity, co-occurring psychosocial health problems, and HIV risk among gay and bisexual men: Further evidence of a syndemic. American Journal of Public Health 102(1):156-162.

Perry Robert T, and Halsey Neal A. 2004. The clinical significance of measles: A review. The Journal of Infectious Diseases 189(S1):S4-S16.

Peter A. 1995. Assumptions and contradictions in measles and measles immunization research: Is measles good for something? Social Science \&amp; Medicine 41(5):673686.

Pitkänen K. 1977. The reliability of the registration of births and deaths in Finland in the eighteenth and nineteenth centuries: some examples. . Scandinavian Economic History Review XXV:138-159.

Pitkänen K. 1983. Infant mortality decline in a changing society. Yearbook of Population Research in Finland 21:46-74.

Pitkänen K. 1993. Deprivation and disease: Mortality during the Great Finnish Famine of the 1860s. Helsinki: Publications of the Finnish Demographic Society.

Pitkänen KJ, and Mielke JH. 1993. Age and sex differentials in mortality during two nineteenth century population crises. European Journal of Population / Revue Européenne de Démographie 9(1):1-32. 
Pitkänen KJ, Mielke JH, and Jorde LB. 1989. Smallpox and its eradication in Finland: Implications for disease control. Population Studies 43(1):95-111.

Poland GA, and Jacobson RM. 2012. The re-emergence of measles in developed countries: Time to develop the next-generation measles vaccines? Vaccine 30(2):103-104.

Powell ML, and Cook DC, editors. 2005. The myth of syphilis: The natural history of treponematosis in North America. Gainesville: University Press of Florida.

Preston SH, and Haines MR. 1991. Fatal years - child mortality in late nineteenth-century America. New Jersey: Princeton University Press.

Preston SH, Heuveline P, and Guillot M. 2001. Demography: measuring and modelling population processes. Oxford: Blackwell Publishing. 291 p.

Racaniello V. 2011. An exit strategy for measles virus. Science 334(6063):1650-1651.

Raphael D. 2006. Social determinants of health: Present status, unanswered questions, and future directions. International Journal of Health Services 36(4):651-677.

Rowland DT. 2003. Demographic methods and concepts. Oxford: Oxford University Press. $546 \mathrm{p}$.

Rudy's List of Archaic Medical Terms (Rudy's List). 2013. Swedish/English glossary of causes of death and other archaic medical terms. http://www.antiquusmorbus.com/international/Swedish.htm.

Salo WL, Aufderheide AC, Buikstra J, and Holcomb TA. 1994. Identification of Mycobacterium tuberculosis DNA in a pre-Columbian Peruvian mummy. Proceedings of the National Academy of Sciences 91(6):2091-2094.

Sattenspiel L. 2015. Coevolution of humans and pathogens. In: M M, editor. Basics in human evolution. Oxford: Elsevier.

Sattenspiel L, and Harpending H. 1983. Stable populations and skeletal age. American Antiquity 48(3):489-498.

Sattenspiel L, and Herring DA. 1998. Structured epidemic models and the spread of influenza in the central Canadian subarctic. Human Biology 70(1):91-115.

Sattenspiel L, and Powell C. 1993. Geographic spread of measles on the island of Dominica, West Indies. Hum Biol 65(1):107-129.

Schenzle D. 1984. An age-structured model of pre- and post-vaccination measles transmission. IMA Journal of Applied Mathematical Medical and Biology 1(2):169191.

Scotch NA. 1963. Medical Anthropology. Biennial Review of Anthropology 3:30-68. 
Scrimshaw NS, Salomon JB, Bruch HA, and Gordon JE. 1966. Studies of diarrheal disease in Central America. The American Journal of Tropical Medicine and Hygiene 15(4):625-631.

Shanks GD, Hu Z, Waller M, Lee S-e, Terfa D, Howard A, van Heyningen E, and Brundage JF. 2014. Measles epidemics of variable lethality in the early 20th century. American Journal of Epidemiology 179(4):413-422.

Shenk MK. 2009. Testing three evolutionary models of the demographic transition: Patterns of fertility and age at marriage in urban South India. American Journal of Human Biology 21(4):501-511.

Simonsen L, Viboud C, Chowell G, Andreasen V, Olson DR, Parekh V, Mølbak K, and Miller MA. 2011. The need for interdisciplinary studies of historic pandemics. Vaccine 29(Supplement 2):B1-B5.

Singer M. 2009. Introduction to syndemics: A critical systems approach to public and community health. San Francisco, CA: Jossey-Bass.

Singer M, and Clair S. 2003. Syndemics and public health: Reconceptualizing disease in biosocial context. Medical Anthropology Quarterly 17(4):423-441.

Sinha DP. 1977. Measles and malnutrition in a West Bengal village. Tropical and geographical medicine 29(2):125-134.

Sonck J. 1979. Social and economic transformation in an Ålandian peasant community.: University of Helsinki.

Soper HE. 1929. The interpretation of periodicity in disease prevalence. Journal of the Royal Statistical Society 92(1):34-73.

Sparks CS. 2007. Households, land and labor: Population dynamics in the Northern Orkney Islands, Scotland, 1851 to 2003: The Pennsylvania State University. 142 p.

Strömmer A. 1969. Väestöllinen muuntuminen Suomessa [The demographic transition in Finland]. Tornio: Population Research Institute.

Swedish-Finn Historical Society (SFHS). 2013. Medical dictionary. http://finlander.genealogia.fi/sfhswiki/index.php/Medical_dictionary.

SweGGate StarGuide (SweGGate). 2013. Swedish dictionary: Medical section. http://www.rootsweb.ancestry.com/ swewgw/Fact/Med/facdic_med.htm.

Teitelbaum MS. 1975. Relevance of demographic transition theory for developing countries. Science 188(4187):420-425.

The Lancet. 2017. Syndemics: health in context. The Lancet 389(10072):881. 
Torres X, and Núñez M. 2005. Morbidity and mortality in Finland based on parish deathcause registers from 1750-1850. International Conference Life Courses in Context Section of the Commission for Historical Demography. Sydney.

Trapp PG, Mielke JH, Jorde LB, and Eriksson AW. 1983. Infant mortality patterns in Åland, Finland. 55(1):131-149.

Trostle JA, and Sommerfeld J. 1996. Medical anthropology and epidemiology. Annual Review of Anthropology 25(1):253-274.

Turpeinen 0. 1973. Regional differentials in Finnish mortality rates 1816-1865. Scandinavian Economic History Review 21(2):145-163.

Turpeinen 0.1978. Infectious diseases and regional differences in Finnish death rates, 1749-1773. Population Studies 32(3):523-533.

Turpeinen 0. 1979a. Fertility and mortality in Finland since 1750. Population Studies 33(1):101-114.

Turpeinen 0. 1979b. Infant mortality in Finland 1749-1865. Scandinavian Economic History Review 27(1):1-21.

Turpeinen 0. 2000. The population transition and seasonal fluctuations in infant mortality in Finland, Estonia, and Russia. Yearbook of Population Research in Finland 36:5-28.

Turpeinen O, and Kannisto V. 1997. Abridged life tables for Finland 1751-1880. . In: Finland S, editor. Population. Helsinki. p 37.

Turpeinen 0, and Pitkänen K. 1979. Infant mortality in Finland 1749-1865. The Scandinavian economic history review / [the Scandanavian Society for Economic and Social History and Historical Geography] 27(1):1-21,67.

Valkonen T, Blomgren J, Kauppinen TM, Martikainen P, and Mäenpää E. 2008. The effects of socioeconomic and cultural characteristics of regions on the spatial patterns of the Second Demographic Transition in Finland. Demographic Research 19(61):20432056.

Van Blerkom LM. 2003. Role of viruses in human evolution. Am J Phys Anthropol Suppl 37:14-46.

van Wijhe M, McDonald SA, de Melker HE, Postma MJ, and Wallinga J. 2016. Effect of vaccination programmes on mortality burden among children and young adults in the Netherlands during the 20th century: a historical analysis. The Lancet Infectious Diseases 16(5):592-598.

Vuorinen HS. 1991. Social variation in infant mortality in a core city of Finland during the 19th and early 20th centuries: Positive effect of industrialization? Scandinavian Journal of Public Health 19(4):248-255. 
Watkins SC. 1987. The fertility transition: Europe and the Third World compared. Sociological Forum 2(4):645-673.

Watkins SC, and Menken J. 1988. On the role of crises in historical perspective: reply. Population and Development Review 14(1):165-170.

Wiesenfeld SL. 1967. Sickle-cell trait in human biological and cultural evolution. Development of agriculture causing increased malaria is bound to gene-pool changes causing malaria reduction 157(3793):1134-1140.

Wiley AS, and Allen JS. 2009. Medical Anthropology: A Biocultural Approach. New York: Oxford University Press.

Wilson EB, and Worcester J. 1945. Damping of epidemic waves. Proceedings of the National Academy of Sciences of the United States of America 31(9):294-298.

Wolfe ND, Daszak P, Kilpatrick AM, and Burke DS. 2005. Bushmeat hunting, deforestation, and prediction of zoonotic disease. Emerging Infectious Diseases 11(12):1822-1827.

Wolfson LJ, Grais RF, Luquero FJ, Birmingham ME, and Strebel PM. 2009. Estimates of measles case fatality ratios: a comprehensive review of community-based studies. Int J Epidemiol 38(1):192-205.

Woods R. 1997. Infant mortality in Britain: A survey of current knowledge on historical trends and variations. In: Bideau A DB, and Brignoli HP, editor. Infant and childhood mortality in the past. Oxford: Clarendon Press. p 74-90.

Woods R WN, Galley C. 1997. Differential mortality patterns among infants and other young children: The experience of England and Wales in the nineteenth century. In: Corsini CA VP, editor. The decline of infant and childhood mortality The European experience: 1750-1990. Dordrecht: Martinus Nijhoff Publishers. p 57-72.

World Health Organization WHO. 2011. Measles. Fact Sheets. http://www.who.int/mediacentre/factsheets/fs286/en/index.html.

World Health Organization WHO. 2018. Measles. Fact Sheets. http://www.who.int/mediacentre/factsheets/fs286/en/.

Yi-Xin H, and Manderson L. 2005. The social and economic context and determinants of schistosomiasis japonica. Acta Tropica 96(2):223-231.

Young A. 1982. The anthropologies of illness and sickness. Annual Review of Anthropology 11(1):257-285.

Zuckerman MK, Harper KN, Barrett R, and Armelagos GJ. 2014. The evolution of disease: anthropological perspectives on epidemiologic transitions. Global Health Action 7:10.3402/gha.v3407.23303. 
Zuckerman MK, and Martin DL. 2017. Introduction: The development of biocultural perspectives in anthropology. In: Zuckerman MK, and Martin DL, editors. New directions in biocultural anthropology. New Jersey: John Wiley \& Sons. p 7-26. 


\section{Appendix A: Cause of Death (COD) Translations: Some Examples}

\begin{tabular}{|c|c|c|}
\hline Category & Causes of death & Approximate translations \\
\hline Measles & Mässling & measles \\
\hline Smallpox & Smittkoppor & Smallpox \\
\hline \multirow[t]{8}{*}{ Respiratory } & Andtäppa & Asthma (chest constriction) \\
\hline & Bröstfeber & Fever of the chest (possibly pneumonia) \\
\hline & Bröstlidande & Difficulty breathing \\
\hline & Bröstsiuka & Sickness of the chest (possibly tuberculosis) \\
\hline & Bröstvattensot & Swelling in the chest \\
\hline & Flussfeber & $\begin{array}{l}\text { Respiratory disease of fluid and fever (possibly } \\
\text { bronchitis, flu/pneumonia) }\end{array}$ \\
\hline & Förkylning & Cold or respiratory infection \\
\hline & Lungsot & Consumption, tuberculosis \\
\hline \multirow[t]{6}{*}{ Gastrointestinal } & Bukref & Gastrointestinal disease \\
\hline & Diarrhe & Diarrhea \\
\hline & Förstoppning & Constipation \\
\hline & Rödsot & Dysentery \\
\hline & Magplåga & Stomach pain \\
\hline & Magref & Colic \\
\hline \multirow[t]{3}{*}{ Old age } & Ålderdom & Old age \\
\hline & Ålderdom bräcklighet & Infirmities of old age (frailty) \\
\hline & Ålderdom svaghet & Malnutrition/wasting associated with old age \\
\hline \multirow[t]{3}{*}{ Accidental } & Drunknad & Drowning \\
\hline & Ihjälfrusen & Frozen to death \\
\hline & Olycka & Accident \\
\hline \multirow[t]{8}{*}{ Other/unknown } & Barnsbörd & Child Birth \\
\hline & $\begin{array}{l}\text { Augustfeber, fråssa, } \\
\text { Frossa }\end{array}$ & Malaria \\
\hline & Dödfödt & Stillborn \\
\hline & Hetsig feber & Fever and inflammation \\
\hline & Kikhosta & Pertussis \\
\hline & Slag & Stroke or sudden impact \\
\hline & Tvinsot & Atrophy/weight loss \\
\hline & Vattnsot & Swelling/edema \\
\hline
\end{tabular}




\section{APPENDIX B: Age-Specific Death Rates by Study Period Only}

Age-specific death rates for each study period were calculated over a 2-year period by dividing the linear average of deaths for both years by the linear average of the population. This was done for each age-group. The resulting mortality rate was multiplied by 1,000 and graphed in Figure 7.3 to illustrate differences in mortality by age group for each study period.

Åland 1816-1817

\begin{tabular}{lrrrc}
\hline $\begin{array}{l}\text { Age } \\
\text { group }\end{array}$ & $\begin{array}{c}\text { Estimated } \\
\text { population }\end{array}$ & $\begin{array}{c}\text { Deaths } \\
\text { during year }\end{array}$ & Death rate & $\begin{array}{c}\text { Proportion } \\
\text { in age } \\
\text { category }\end{array}$ \\
\hline \multicolumn{1}{c}{$\mathrm{i}$} & $\mathrm{N}_{\mathrm{i}}$ & $\mathrm{D}_{\mathrm{i}}$ & $\mathrm{M}_{\mathrm{i}}$ & $\mathrm{C}_{\mathrm{i}}$ \\
\hline$<1$ & 338 & 129 & 0.38222 & 0.02724 \\
$1-4$ & 1,208 & 25 & 0.02070 & 0.09748 \\
$5-9$ & 1,179 & 5 & 0.00382 & 0.09514 \\
$10-14$ & 1,277 & 6 & 0.00431 & 0.10305 \\
$15-19$ & 1,261 & 4 & 0.00278 & 0.10176 \\
$20-24$ & 1,119 & 4 & 0.00313 & 0.09030 \\
$25-29$ & 948 & 3 & 0.00264 & 0.07646 \\
$30-34$ & 866 & 6 & 0.00693 & 0.06988 \\
$35-39$ & 831 & 7 & 0.00783 & 0.06702 \\
$40-44$ & 776 & 8 & 0.00967 & 0.06258 \\
$45-49$ & 682 & 10 & 0.01393 & 0.05504 \\
$50-54$ & 594 & 11 & 0.01853 & 0.04789 \\
$55-59$ & 467 & 8 & 0.01608 & 0.03765 \\
$60-64$ & 371 & 13 & 0.03374 & 0.02990 \\
$65-59$ & 267 & 13 & 0.04690 & 0.02151 \\
$70-74$ & 155 & 13 & 0.08091 & 0.01247 \\
$75-79$ & 99 & 11 & 0.11168 & 0.00795 \\
$80+$ & 52 & 13 & 0.24038 & 0.00420 \\
& & & & \\
All & 12,485 & 282.5 & 0.02263 & 1.00750 \\
\hline \hline & & $\mathrm{CDR} 22.63$ per 1,000 & \\
\hline \hline
\end{tabular}


Åland 1820-1821

\begin{tabular}{ccccc}
\hline $\begin{array}{c}\text { Age } \\
\text { group }\end{array}$ & $\begin{array}{c}\text { Estimated } \\
\text { population }\end{array}$ & $\begin{array}{c}\text { Deaths } \\
\text { during year }\end{array}$ & Death rate & $\begin{array}{c}\text { Proportion } \\
\text { in age } \\
\text { category }\end{array}$ \\
\hline \multicolumn{1}{c}{$\mathrm{i}$} & \multicolumn{1}{c}{$\mathrm{N}_{\mathrm{i}}$} & $\mathrm{D}_{\mathrm{i}}$ & $\mathrm{M}_{\mathrm{i}}$ & $\mathrm{C}_{\mathrm{i}}$ \\
\hline$<1$ & 315 & 111 & 0.35079 & 0.02542 \\
$1-4$ & 1,204 & 79 & 0.06561 & 0.09716 \\
$5-9$ & 1,218 & 35 & 0.02834 & 0.09825 \\
$10-14$ & 1,236 & 10 & 0.00809 & 0.09974 \\
$15-19$ & 1,284 & 10 & 0.00740 & 0.10357 \\
$20-24$ & 1,134 & 13 & 0.01147 & 0.09147 \\
$25-29$ & 971 & 8 & 0.00824 & 0.07836 \\
$30-34$ & 868 & 10 & 0.01094 & 0.07005 \\
$35-39$ & 824 & 12 & 0.01396 & 0.06645 \\
$40-44$ & 791 & 12 & 0.01518 & 0.06379 \\
$45-49$ & 674 & 16 & 0.02374 & 0.05439 \\
$50-54$ & 603 & 17 & 0.02822 & 0.04862 \\
$55-59$ & 466 & 22 & 0.04619 & 0.03756 \\
$60-64$ & 378 & 19 & 0.04901 & 0.03046 \\
$65-59$ & 266 & 24 & 0.08851 & 0.02143 \\
$70-74$ & 160 & 24 & 0.15047 & 0.01287 \\
$75-79$ & 100 & 13 & 0.12563 & 0.00803 \\
$80+$ & 52 & 23 & 0.43269 & 0.00420 \\
& \multicolumn{5}{c}{ CDR 36.13 per 1,000 } \\
All & 12,539 & 453 & 0.03613 & 1.01182 \\
\hline \hline \multicolumn{5}{c}{} \\
\hline \hline
\end{tabular}


Åland 1823-1824

\begin{tabular}{ccrcc}
\hline $\begin{array}{c}\text { Age } \\
\text { group }\end{array}$ & $\begin{array}{c}\text { Estimated } \\
\text { population }\end{array}$ & $\begin{array}{c}\text { Deaths } \\
\text { during year }\end{array}$ & Death rate & $\begin{array}{c}\text { Proportion } \\
\text { in age } \\
\text { category }\end{array}$ \\
\hline \multicolumn{1}{c}{$\mathrm{i}$} & \multicolumn{1}{c}{$\mathrm{N}_{\mathrm{i}}$} & $\mathrm{D}_{\mathrm{i}}$ & $\mathrm{M}_{\mathrm{i}}$ & $\mathrm{C}_{\mathrm{i}}$ \\
\hline$<1$ & 368 & 129 & 0.34966 & 0.02966 \\
$1-4$ & 1,249 & 44 & 0.03484 & 0.10075 \\
$5-9$ & 1,269 & 12 & 0.00906 & 0.10240 \\
$10-14$ & 1,222 & 7 & 0.00573 & 0.09861 \\
$15-19$ & 1,131 & 12 & 0.01017 & 0.09123 \\
$20-24$ & 1,210 & 18 & 0.01447 & 0.09760 \\
$25-29$ & 1,107 & 17 & 0.01536 & 0.08933 \\
$30-34$ & 930 & 10 & 0.01076 & 0.07501 \\
$35-39$ & 825 & 11 & 0.01334 & 0.06653 \\
$40-44$ & 794 & 11 & 0.01322 & 0.06407 \\
$45-49$ & 705 & 11 & 0.01490 & 0.05685 \\
$50-54$ & 599 & 15 & 0.02421 & 0.04834 \\
$55-59$ & 557 & 9 & 0.01527 & 0.04491 \\
$60-64$ & 417 & 11 & 0.02521 & 0.03361 \\
$65-59$ & 305 & 10 & 0.03115 & 0.02461 \\
$70-74$ & 199 & 9 & 0.04271 & 0.01606 \\
$75-79$ & 117 & 11 & 0.09442 & 0.00940 \\
$80+$ & 58 & 11 & 0.18103 & 0.00468 \\
& \multicolumn{5}{c}{ CDR 26.92 per 1,000 } \\
All & 13,057 & 351.5 & 0.02692 & 1.05366 \\
\hline \multicolumn{5}{c}{} \\
\hline \hline
\end{tabular}




\section{APPENDIX C: Infant Mortality Rate Confidence Intervals}

Upper and lower confidence intervals were calculated using the binomial formula to evaluate whether the infant mortality rate in Sweden was significantly different from the infant mortality rate of the Åland Islands communities. Confidence intervals of 99\% indicate that $99 \%$ of variates in the distribution should fall between the lower and upper limits. Confidence intervals could not be calculated for Finland as the raw data required was unavailable and the infant mortality rates were obtained from a published table (Turpeinen, 1979a).

Åland Islands, Finland

\begin{tabular}{cccc}
\hline Year & $\begin{array}{c}\text { Infant } \\
\text { mortality rate }\end{array}$ & $\begin{array}{c}\text { 99\% Lower } \\
\text { confidence interval }\end{array}$ & $\begin{array}{c}\text { 99\% Upper } \\
\text { confidence interval }\end{array}$ \\
\hline 1815 & 309.63 & 303.92 & 315.35 \\
1816 & 277.42 & 272.06 & 282.78 \\
1817 & 282.89 & 277.45 & 288.34 \\
1818 & 243.30 & 238.07 & 248.53 \\
1819 & 276.74 & 271.18 & 282.31 \\
1820 & 258.99 & 253.46 & 264.53 \\
1821 & 253.93 & 248.61 & 259.26 \\
1822 & 233.85 & 228.70 & 239.01 \\
1823 & 230.13 & 225.16 & 235.09 \\
1824 & 316.81 & 311.24 & 322.38 \\
1825 & 227.74 & 222.82 & 232.67 \\
1826 & 211.18 & 206.39 & 215.97 \\
1827 & 241.45 & 236.50 & 246.40 \\
1828 & 221.12 & 216.34 & 225.89 \\
1829 & 248.38 & 243.20 & 253.56 \\
1830 & 270.97 & 265.65 & 276.29 \\
\hline \hline
\end{tabular}


Sweden

\begin{tabular}{cccc}
\hline Year & $\begin{array}{c}\text { Infant } \\
\text { mortality rate }\end{array}$ & $\begin{array}{c}99 \% \text { Lower } \\
\text { confidence interval }\end{array}$ & $\begin{array}{c}99 \% \text { Upper } \\
\text { confidence interval }\end{array}$ \\
\hline 1815 & 169.85 & 169.52 & 170.18 \\
1816 & 183.48 & 183.14 & 183.82 \\
1817 & 178.76 & 178.42 & 179.10 \\
1818 & 168.68 & 168.35 & 169.01 \\
1819 & 183.06 & 182.72 & 183.41 \\
1820 & 163.45 & 163.12 & 163.77 \\
1821 & 175.65 & 175.32 & 175.97 \\
1822 & 162.43 & 162.12 & 162.74 \\
1823 & 147.51 & 147.22 & 147.80 \\
1824 & 155.83 & 155.52 & 156.13 \\
1825 & 153.99 & 153.70 & 154.29 \\
1826 & 171.57 & 171.26 & 171.88 \\
1827 & 160.62 & 160.30 & 160.94 \\
1828 & 170.32 & 170.01 & 170.64 \\
1829 & 193.96 & 193.64 & 194.29 \\
1830 & 180.49 & 180.17 & 180.81 \\
\hline \hline
\end{tabular}




\section{APPENDIX D: Life Tables}

Single year, abridged life tables were calculated using intercensal population

estimates for non-census years. Calculations were completed using the methods discussed in Chapter 6 from Rowland (2003) and Preston (2001). Tables are provided for each year of each study period: 1816, 1817, 1820, 1821, 1823, and 1824.

Åland 1816 life table based on population estimates

\begin{tabular}{cccccccccc}
\hline $\begin{array}{c}\text { Age } \\
\text { group }\end{array}$ & $\begin{array}{c}\text { Åland } \\
\text { population }\end{array}$ & Deaths & $\mathrm{m}_{\mathrm{x}}$ & $\mathrm{q}_{\mathrm{x}}$ & $\mathrm{l}_{\mathrm{x}}$ & $\mathrm{d}_{\mathrm{x}}$ & $\mathrm{L}_{\mathrm{x}}$ & $\mathrm{T}_{\mathrm{x}}$ & $\mathrm{e}_{\mathrm{x}}$ \\
\hline$<1$ & 342 & 129 & 0.377 & 0.317 & 100000 & 31734 & 84133 & 3989315 & 39.89 \\
$1-4$ & 1210 & 21 & 0.017 & 0.067 & 68266 & 4580 & 263904 & 3905182 & 57.21 \\
$5-9$ & 1160 & 6 & 0.005 & 0.026 & 63686 & 1626 & 314365 & 3641278 & 57.18 \\
$10-14$ & 1298 & 4 & 0.003 & 0.015 & 62060 & 949 & 307928 & 3326913 & 53.61 \\
$15-19$ & 1250 & 3 & 0.002 & 0.012 & 61111 & 729 & 303733 & 3018985 & 49.40 \\
$20-24$ & 1112 & 2 & 0.002 & 0.009 & 60382 & 541 & 300558 & 2715252 & 44.97 \\
$25-29$ & 936 & 1 & 0.001 & 0.005 & 59841 & 319 & 298408 & 2414694 & 40.35 \\
$30-34$ & 865 & 6 & 0.007 & 0.034 & 59522 & 2029 & 292538 & 2116286 & 35.55 \\
$35-39$ & 834 & 7 & 0.008 & 0.041 & 57493 & 2363 & 281558 & 1823748 & 31.72 \\
$40-44$ & 768 & 8 & 0.010 & 0.051 & 55130 & 2798 & 268655 & 1542190 & 27.97 \\
$45-49$ & 686 & 6 & 0.009 & 0.043 & 52332 & 2240 & 256060 & 1273535 & 24.34 \\
$50-54$ & 589 & 13 & 0.022 & 0.105 & 50092 & 5239 & 237363 & 1017475 & 20.31 \\
$55-59$ & 467 & 7 & 0.015 & 0.072 & 44853 & 3240 & 216165 & 780112 & 17.39 \\
$60-64$ & 367 & 12 & 0.033 & 0.151 & 41613 & 6289 & 192343 & 563947 & 13.55 \\
$65-69$ & 267 & 14 & 0.052 & 0.232 & 35324 & 8188 & 156150 & 371604 & 10.52 \\
$70-74$ & 152 & 16 & 0.105 & 0.417 & 27136 & 11307 & 107413 & 215454 & 7.94 \\
$75-79$ & 98 & 11 & 0.112 & 0.438 & 15829 & 6937 & 61803 & 108041 & 6.83 \\
$80+$ & 52 & 10 & 0.192 & 1.000 & 8892 & 8892 & 46238 & 46238 & 5.20 \\
& & & & & & & & & \\
Total & 12,453 & 276 & 0.022 & & & & & & \\
\hline \hline
\end{tabular}


Åland 1817 life table based on population estimates

\begin{tabular}{|c|c|c|c|c|c|c|c|c|c|}
\hline $\begin{array}{l}\text { Age } \\
\text { group }\end{array}$ & $\begin{array}{c}\text { Åland } \\
\text { population }\end{array}$ & Deaths & $\mathrm{m}_{\mathrm{x}}$ & $\mathrm{q}_{\mathrm{x}}$ & $l_{x}$ & $d_{x}$ & $\mathrm{~L}_{\mathrm{x}}$ & $\mathrm{T}_{\mathrm{x}}$ & $e_{x}$ \\
\hline$<1$ & 333 & 129 & 0.387 & 0.325 & 100000 & 32453 & 83774 & 3798399 & 37.98 \\
\hline $1-4$ & 1206 & 29 & 0.024 & 0.092 & 67547 & 6199 & 257790 & 3714626 & 54.99 \\
\hline $5-9$ & 1198 & 3 & 0.003 & 0.012 & 61348 & 763 & 304833 & 3456836 & 56.35 \\
\hline $10-14$ & 1256 & 7 & 0.006 & 0.027 & 60585 & 1665 & 298763 & 3152003 & 52.03 \\
\hline $15-19$ & 1272 & 4 & 0.003 & 0.016 & 58920 & 919 & 292303 & 2853240 & 48.43 \\
\hline $20-24$ & 1126 & 5 & 0.004 & 0.022 & 58001 & 1274 & 286820 & 2560937 & 44.15 \\
\hline $25-29$ & 959 & 4 & 0.004 & 0.021 & 56727 & 1171 & 280708 & 2274117 & 40.09 \\
\hline $30-34$ & 867 & 6 & 0.007 & 0.034 & 55556 & 1890 & 273055 & 1993409 & 35.88 \\
\hline $35-39$ & 827 & 6 & 0.007 & 0.036 & 53666 & 1912 & 263550 & 1720354 & 32.06 \\
\hline $40-44$ & 783 & 7 & 0.009 & 0.044 & 51754 & 2263 & 253113 & 1456804 & 28.15 \\
\hline $45-49$ & 678 & 13 & 0.019 & 0.091 & 49491 & 4528 & 236135 & 1203691 & 24.32 \\
\hline $50-54$ & 598 & 9 & 0.015 & 0.073 & 44963 & 3261 & 216663 & 967556 & 21.52 \\
\hline $55-59$ & 466 & 8 & 0.017 & 0.082 & 41702 & 3432 & 199930 & 750893 & 18.01 \\
\hline $60-64$ & 374 & 13 & 0.035 & 0.160 & 38270 & 6119 & 176053 & 550963 & 14.40 \\
\hline $65-69$ & 266 & 11 & 0.041 & 0.187 & 32151 & 6025 & 145693 & 374910 & 11.66 \\
\hline $70-74$ & 157 & 9 & 0.057 & 0.251 & 26126 & 6550 & 114255 & 229217 & 8.77 \\
\hline $75-79$ & 99 & 11 & 0.111 & 0.435 & 19576 & 8511 & 76603 & 114962 & 5.87 \\
\hline $80+$ & 52 & 15 & 0.288 & 1.000 & 11065 & 11065 & 38359 & 38359 & 3.47 \\
\hline Total & 12,517 & 289 & 0.023 & & & & & & \\
\hline \multicolumn{10}{|c|}{$\mathrm{CDR}=23$ per 1,000} \\
\hline
\end{tabular}


Åland life table based on population estimates

\begin{tabular}{|c|c|c|c|c|c|c|c|c|c|}
\hline $\begin{array}{l}\text { Age } \\
\text { group }\end{array}$ & $\begin{array}{c}\text { Åland } \\
\text { population }\end{array}$ & Deaths & $\mathrm{m}_{\mathrm{x}}$ & $\mathrm{q}_{\mathrm{x}}$ & $l_{\mathrm{x}}$ & $d_{x}$ & $\mathrm{~L}_{\mathrm{x}}$ & $\mathrm{T}_{\mathrm{x}}$ & $e_{x}$ \\
\hline$<1$ & 307 & 108 & 0.352 & 0.299 & 100000 & 29917 & 85042 & 2614609 & 26.15 \\
\hline $1-4$ & 1192 & 77 & 0.065 & 0.229 & 70083 & 16037 & 248258 & 2529567 & 36.09 \\
\hline $5-9$ & 1318 & 30 & 0.023 & 0.108 & 54046 & 5820 & 255680 & 2281309 & 42.21 \\
\hline $10-14$ & 1139 & 9 & 0.008 & 0.039 & 48226 & 1868 & 236460 & 2025629 & 42.00 \\
\hline $15-19$ & 1341 & 11 & 0.008 & 0.040 & 46358 & 1863 & 227133 & 1789169 & 38.59 \\
\hline $20-24$ & 1171 & 11 & 0.009 & 0.046 & 44495 & 2042 & 217370 & 1562036 & 35.11 \\
\hline $25-29$ & 1033 & 9 & 0.009 & 0.043 & 42453 & 1810 & 207740 & 1344666 & 31.67 \\
\hline $30-34$ & 873 & 9 & 0.010 & 0.050 & 40643 & 2042 & 198110 & 1136926 & 27.97 \\
\hline $35-39$ & 807 & 9 & 0.011 & 0.054 & 38601 & 2094 & 187770 & 938816 & 24.32 \\
\hline $40-44$ & 829 & 15 & 0.018 & 0.087 & 36507 & 3160 & 174635 & 751046 & 20.57 \\
\hline $45-49$ & 654 & 21 & 0.032 & 0.149 & 33347 & 4956 & 154345 & 576411 & 17.29 \\
\hline $50-54$ & 627 & 18 & 0.029 & 0.134 & 28391 & 3802 & 132450 & 422066 & 14.87 \\
\hline $55-59$ & 463 & 23 & 0.050 & 0.221 & 24589 & 5433 & 109363 & 289616 & 11.78 \\
\hline $60-64$ & 394 & 26 & 0.066 & 0.283 & 19156 & 5425 & 82218 & 180253 & 9.41 \\
\hline $65-69$ & 261 & 26 & 0.100 & 0.399 & 13731 & 5476 & 54965 & 98035 & 7.14 \\
\hline $70-74$ & 173 & 33 & 0.191 & 0.646 & 8255 & 5331 & 27948 & 43070 & 5.22 \\
\hline $75-79$ & 101 & 12 & 0.119 & 0.458 & 2924 & 1339 & 11273 & 15122 & 5.17 \\
\hline $80+$ & 51 & 21 & 0.412 & 1.000 & 1585 & 1585 & 3849 & 3849 & 2.43 \\
\hline Total & 12,734 & 468 & 0.037 & & & & & & \\
\hline \multicolumn{10}{|c|}{$\mathrm{CDR}=37$ per 1,000} \\
\hline
\end{tabular}


Åland 1820 life table based on population estimates

\begin{tabular}{|c|c|c|c|c|c|c|c|c|c|}
\hline $\begin{array}{l}\text { Age } \\
\text { group }\end{array}$ & $\begin{array}{c}\text { Åland } \\
\text { population }\end{array}$ & Deaths & $\mathrm{m}_{\mathrm{x}}$ & $\mathrm{q}_{\mathrm{x}}$ & $l_{x}$ & $d_{x}$ & $\mathrm{~L}_{\mathrm{x}}$ & $\mathrm{T}_{\mathrm{x}}$ & $e_{x}$ \\
\hline$<1$ & 307 & 108 & 0.352 & 0.299 & 100000 & 29917 & 85042 & 2614609 & 26.15 \\
\hline $1-4$ & 1192 & 77 & 0.065 & 0.229 & 70083 & 16037 & 248258 & 2529567 & 36.09 \\
\hline $5-9$ & 1318 & 30 & 0.023 & 0.108 & 54046 & 5820 & 255680 & 2281309 & 42.21 \\
\hline $10-14$ & 1139 & 9 & 0.008 & 0.039 & 48226 & 1868 & 236460 & 2025629 & 42.00 \\
\hline $15-19$ & 1341 & 11 & 0.008 & 0.040 & 46358 & 1863 & 227133 & 1789169 & 38.59 \\
\hline $20-24$ & 1171 & 11 & 0.009 & 0.046 & 44495 & 2042 & 217370 & 1562036 & 35.11 \\
\hline $25-29$ & 1033 & 9 & 0.009 & 0.043 & 42453 & 1810 & 207740 & 1344666 & 31.67 \\
\hline $30-34$ & 873 & 9 & 0.010 & 0.050 & 40643 & 2042 & 198110 & 1136926 & 27.97 \\
\hline $35-39$ & 807 & 9 & 0.011 & 0.054 & 38601 & 2094 & 187770 & 938816 & 24.32 \\
\hline $40-44$ & 829 & 15 & 0.018 & 0.087 & 36507 & 3160 & 174635 & 751046 & 20.57 \\
\hline $45-49$ & 654 & 21 & 0.032 & 0.149 & 33347 & 4956 & 154345 & 576411 & 17.29 \\
\hline $50-54$ & 627 & 18 & 0.029 & 0.134 & 28391 & 3802 & 132450 & 422066 & 14.87 \\
\hline $55-59$ & 463 & 23 & 0.050 & 0.221 & 24589 & 5433 & 109363 & 289616 & 11.78 \\
\hline $60-64$ & 394 & 26 & 0.066 & 0.283 & 19156 & 5425 & 82218 & 180253 & 9.41 \\
\hline $65-69$ & 261 & 26 & 0.100 & 0.399 & 13731 & 5476 & 54965 & 98035 & 7.14 \\
\hline $70-74$ & 173 & 33 & 0.191 & 0.646 & 8255 & 5331 & 27948 & 43070 & 5.22 \\
\hline $75-79$ & 101 & 12 & 0.119 & 0.458 & 2924 & 1339 & 11273 & 15122 & 5.17 \\
\hline $80+$ & 51 & 21 & 0.412 & 1.000 & 1585 & 1585 & 3849 & 3849 & 2.43 \\
\hline Total & 12,734 & 468 & 0.037 & & & & & & \\
\hline \multicolumn{10}{|c|}{$\mathrm{CDR}=37$ per 1,000} \\
\hline
\end{tabular}


Åland 1823 life table based on population estimates

\begin{tabular}{|c|c|c|c|c|c|c|c|c|c|}
\hline $\begin{array}{l}\text { Age } \\
\text { group }\end{array}$ & $\begin{array}{c}\text { Åland } \\
\text { population }\end{array}$ & Deaths & $\mathrm{m}_{\mathrm{x}}$ & $\mathrm{q}_{\mathrm{x}}$ & $l_{x}$ & $d_{x}$ & $\mathrm{~L}_{\mathrm{x}}$ & $\mathrm{T}_{\mathrm{x}}$ & $e_{x}$ \\
\hline$<1$ & 358 & 110 & 0.307 & 0.266 & 100000 & 26634 & 86683 & 3822754 & 38.23 \\
\hline $1-4$ & 1240 & 26 & 0.021 & 0.080 & 73366 & 5906 & 281652 & 3736071 & 50.92 \\
\hline $5-9$ & 1276 & 5 & 0.004 & 0.019 & 67460 & 1309 & 334028 & 3454419 & 51.21 \\
\hline $10-14$ & 1210 & 1 & 0.001 & 0.004 & 66151 & 273 & 330073 & 3120391 & 47.17 \\
\hline $15-19$ & 1158 & 7 & 0.006 & 0.030 & 65878 & 1961 & 324488 & 2790318 & 42.36 \\
\hline $20-24$ & 1204 & 9 & 0.007 & 0.037 & 63917 & 2345 & 313723 & 2465830 & 38.58 \\
\hline $25-29$ & 1096 & 13 & 0.012 & 0.058 & 61572 & 3546 & 298995 & 2152107 & 34.95 \\
\hline $30-34$ & 921 & 13 & 0.014 & 0.068 & 58026 & 3956 & 280240 & 1853112 & 31.94 \\
\hline $35-39$ & 822 & 15 & 0.018 & 0.087 & 54070 & 4718 & 258555 & 1572872 & 29.09 \\
\hline $40-44$ & 799 & 12 & 0.015 & 0.072 & 49352 & 3572 & 237830 & 1314317 & 26.63 \\
\hline $45-49$ & 697 & 14 & 0.020 & 0.096 & 45780 & 4378 & 217955 & 1076487 & 23.51 \\
\hline $50-54$ & 603 & 19 & 0.032 & 0.146 & 41402 & 6046 & 191895 & 858532 & 20.74 \\
\hline $55-59$ & 542 & 7 & 0.013 & 0.063 & 35356 & 2212 & 171250 & 666637 & 18.86 \\
\hline $60-64$ & 413 & 13 & 0.031 & 0.146 & 33144 & 4836 & 153630 & 495387 & 14.95 \\
\hline $65-69$ & 298 & 12 & 0.040 & 0.183 & 28308 & 5178 & 128595 & 341757 & 12.07 \\
\hline $70-74$ & 195 & 10 & 0.051 & 0.227 & 23130 & 5257 & 102508 & 213162 & 9.22 \\
\hline $75-79$ & 114 & 16 & 0.140 & 0.519 & 17873 & 9285 & 66153 & 110654 & 6.19 \\
\hline $80+$ & 57 & 11 & 0.193 & 1.000 & 8588 & 8588 & 44501 & 44501 & 5.18 \\
\hline Total & 13,003 & 313 & 0.024 & & & & & & \\
\hline \multicolumn{10}{|c|}{$\mathrm{CDR}=24$ per 1,000} \\
\hline
\end{tabular}


Åland 1824 life table based on population estimates

\begin{tabular}{|c|c|c|c|c|c|c|c|c|c|}
\hline $\begin{array}{l}\text { Age } \\
\text { group }\end{array}$ & $\begin{array}{c}\text { Åland } \\
\text { population }\end{array}$ & Deaths & $\mathrm{m}_{\mathrm{x}}$ & $\mathrm{q}_{\mathrm{x}}$ & $l_{\mathrm{x}}$ & $\mathrm{d}_{\mathrm{x}}$ & $\mathrm{L}_{\mathrm{x}}$ & $\mathrm{T}_{\mathrm{x}}$ & $e_{x}$ \\
\hline$<1$ & 377 & 147 & 0.390 & 0.326 & 100000 & 32630 & 83685 & 2960297 & 29.60 \\
\hline $1-4$ & 1257 & 61 & 0.049 & 0.177 & 67370 & 11920 & 245640 & 2876612 & 42.70 \\
\hline $5-9$ & 1262 & 18 & 0.014 & 0.069 & 55450 & 3818 & 267705 & 2630972 & 47.45 \\
\hline $10-14$ & 1234 & 13 & 0.011 & 0.051 & 51632 & 2650 & 251535 & 2363267 & 45.77 \\
\hline $15-19$ & 1103 & 16 & 0.015 & 0.070 & 48982 & 3428 & 236340 & 2111732 & 43.11 \\
\hline $20-24$ & 1215 & 26 & 0.021 & 0.102 & 45554 & 4627 & 216203 & 1875392 & 41.17 \\
\hline $25-29$ & 1118 & 21 & 0.019 & 0.090 & 40927 & 3671 & 195458 & 1659189 & 40.54 \\
\hline $30-34$ & 938 & 7 & 0.007 & 0.037 & 37256 & 1365 & 182868 & 1463731 & 39.29 \\
\hline $35-39$ & 827 & 7 & 0.008 & 0.041 & 35891 & 1487 & 175738 & 1280863 & 35.69 \\
\hline $40-44$ & 789 & 9 & 0.011 & 0.055 & 34404 & 1908 & 167250 & 1105125 & 32.12 \\
\hline $45-49$ & 712 & 7 & 0.010 & 0.048 & 32496 & 1559 & 158583 & 937875 & 28.86 \\
\hline $50-54$ & 595 & 10 & 0.017 & 0.081 & 30937 & 2495 & 148448 & 779292 & 25.19 \\
\hline $55-59$ & 571 & 10 & 0.018 & 0.084 & 28442 & 2386 & 136245 & 630844 & 22.18 \\
\hline $60-64$ & 420 & 8 & 0.019 & 0.091 & 26056 & 2369 & 124358 & 494599 & 18.98 \\
\hline $65-69$ & 312 & 7 & 0.022 & 0.106 & 23687 & 2516 & 112145 & 370241 & 15.63 \\
\hline $70-74$ & 203 & 7 & 0.034 & 0.159 & 21171 & 3360 & 97455 & 258096 & 12.19 \\
\hline $75-79$ & 119 & 6 & 0.050 & 0.224 & 17811 & 3988 & 79085 & 160641 & 9.02 \\
\hline $80+$ & 59 & 10 & 0.169 & 1.000 & 13823 & 13823 & 81556 & 81556 & 5.90 \\
\hline Total & 13,111 & 390 & 0.030 & & & & & & \\
\hline \multicolumn{10}{|c|}{$\mathrm{CDR}=30$ per 1,000} \\
\hline
\end{tabular}


Erin Miller was born in Lawrenceburg, Indiana to Scott and Loretta Miller. After graduating from Rising Sun High School in Rising Sun, she attended Indiana University in Bloomington, Indiana. During this time, she completed an honor's thesis relating to faunal analysis from the Clark's Point archaeological site in Indiana. She earned a Bachelor of Arts in Anthropology, with a minor in Biology, and graduated with Departmental Honors in 2005.

She started graduate work in Anthropology at Ball State University in Muncie, Indiana in 2006 and graduated with a Master of Arts in 2008. Her thesis research consisted of human skeletal analysis from the Elrod archeological site excavated in the 1930s. She served as a graduate assistant and instructor and assisted in the management of the department's biological anthropology laboratory collection.

Erin started work on a doctoral degree in Anthropology at the University of Missouri in August of 2008. As a graduate student, she worked to develop epidemiological models for projects of colleagues in the department in addition to presenting research at local, regional, and national conferences. During her tenure she served as an undergraduate instructor in both Anthropology and Biology. She also served as a graduate researcher for Dr. Gregory Alexander in the Sinclair School of Nursing. She currently holds a position with the State of Missouri Office of Epidemiology as a Senior Epidemiology Specialist tasked with managing the implementation and expansion of the new Missouri Violent Death Reporting System. 